\title{
Contributions of Polyelectrolyte Complexes and Ionic Bonding to Performance of Barrier Films for Packaging: A Review
}

\begin{abstract}
Martin A. Hubbe
Barrier films that are used on packages play an important role, especially in the protection of food products. Research is being carried out at an accelerating pace to replace petroleum-based plastic films, which do not biodegrade and are difficult to recycle. This review article considers publications related to the use of polyelectrolyte complexes (PECs) in barrier films as a strategy to decrease the permeation of oxygen and other substances into and out from packages. Research progress has been achieved in using combinations of positively and negatively charged polymers, sometimes together with platy mineral particles, as a way to restrict diffusion through packaging materials. In principle, the ionic bonds within PECs contribute to a relatively high cohesive energy density within such a barrier film, which can resist diffusion of various gases and greasy substances. Resistance to water vapor, as well as aqueous substances, represent important challenges for barrier concepts that depend on ionic bond contributions. Factors affecting barrier performance of PEC-based films are discussed in light of research findings.
\end{abstract}

Keywords: Polyelectrolyte complexes; Layer-by-layer (LbL); Water vapor; Oxygen; Self-assembly; Healing

Contact information: North Carolina State University, Dept. of Forest Biomaterials, Campus Box 8005, Raleigh, NC27695-8005, USA, email: hubbe@ncsu.edu

\section{Contents}

Introduction ........... 4545

Hypotheses ......... 4545

Background ........... 4547

Historical background ..... 4547

Materials for PEC films .... 4550

Permeability of PEC films . . 4551

Strength of PEC films ..... 4553

Mechanisms of PEC films ... 4554

Thermodynamics ....... 4554

Self-assembly . . . . . . . 4555

Non-equilibrium states . . . 4558

Healing . . . . . . . . . 4559

Preparation methods . . . . 4561

Layer-by-layer . . . . . . 4561

Langmuir-Blodgett. . . . . . . 4563

Mixing and casting. ....... 4564

Charge-stabilized PECs. . . 4565

Post-treatments ....... 4567

Healing for preparation . . . 4568

Factors affecting barrier .... 4569

Overview ........... 4569
Polyelectrolyte charge . . . . 4570

Stoichiometry in the PEC . . . 4571

Types of ionic groups . . . . . 4571

Structural fitting . . . . . . . 4572

Cross-links . . . . . . . . . 4573

Plasticizers . . . . . . . . . 4574

Salinity ............... 4575

Hydrogen bonding ...... 4576

Hydrophobic effect . . . . . . . 4576

Layer attributes . . . . . . . . 4577

Fillers .............. 4578

Defects . . . . . . . . . . 4582

Other layers. . . . . . . . . . 4582

Paths forward for PEC barriers 4583

Likely key contributions. . . . . 4583

Applied directly to items. .... 4583

Paired with other layers. ... . 4584

Assessment of hypotheses . . 4584

Acknowledgements ....... 4586

Literature Cited .......... 4586

Appendix: Table A........ 4603 


\section{INTRODUCTION}

Research is under way throughout the world to find eco-friendly ways to ship and store food and other products with less spoilage. Packaging systems for food products currently rely heavily upon the usage of petroleum-based plastics, as well as metal films and glass (Lange and Wyser 2003; Fang and Vitrac 2017). Plastic films such as lowdensity polyethylene (LDPE) persist for a long time in the environment (da Costa et al. 2016; Blasing and Amelung 2018). Plastic-containing litter and other waste that reach the ocean are creating serious harm to aquatic life and food chains (Derraik 2002).

Important progress has been achieved in the usage of bio-based, biodegradable materials in the preparation of barrier layers for packages. For example, nanocellulose can be formed into dense films having superior ability to block the diffusion of oxygen (Hubbe et al. 2017). Such films can be effective, especially under low humidity conditions, due to the high cohesive energy density provided by the hydrogen bonds (Lagarón et al. 2004). The present article reviews progress related to a parallel track of research in which ionic bonds provide strong bonding, thus limiting the ability of permeants to pass through a barrier layer. In particular, polyelectrolyte complexes (PECs) have been shown to be effective under favorable circumstances in reducing the passage of gases, vapors, and liquids (De Oliveira et al. 2008; Priolo et al. 2010a; Ibn Yaich et al. 2015; Haile et al. 2017; Smith et al. 2018).

\section{Hypotheses}

To provide focus in the course of reviewing literature related to ionic bonding contributions and PECs as barrier films, a series of hypotheses, as follows, will be considered in this article.

Hypothesis 1: Contribution to cohesive energy density

As a first hypothesis, it is proposed that ionic bonding can contribute substantially to the barrier performance of thin films prepared from ionically charged polymers, i.e. polyelectrolytes and related systems. The idea is that strong bonding between the polymer segments within the plastic material can prevent the random opening up of spaces within the polymeric material that are large enough for the passage of molecules (Lagarón et al. 2004). It is further proposed that ionic bonds linking surfaces of mineral particles or nanocellulose to oppositely charged polyelectrolytes within a PEC system also can contribute to barrier properties.

\section{Hypothesis 2: Can be prepared as contiguous nanostructures}

It is proposed that, by the use of suitable procedures, it is possible to achieve a sufficiently contiguous nanostructure within PECs and related film structures, as would be required for very high efficiency of barrier effects. To place this hypothesis in context, it is well known that interactions among oppositely charged polyelectrolytes often lead to strongly flocculated mixtures (Durandpiana et al. 1987; Hubbe 2007). In fact, even PECs themselves can used as effective flocculants (Korhonen et al. 2013; Petzold and Schwarz 2014). Accordingly, it is important to look for evidence in the published literature about ways to avoid such unintended nonuniformity in the structure of ionically bonded films. 
Hypothesis 3: Nanofillers can enhance barrier performance of PEC films

It is proposed that the barrier performance of PEC films can be improved by incorporation of various solid fillers or reinforcing particles during their preparation. According to the principle of tortuosity, diffusion of molecules through a film will be slowed down by the presence of completely impermeable particles, such as minerals (Ghanbarian et al. 2013). In addition, one might propose that reinforcing particles, especially those that have a fibrillar shape, might in some cases help hold a film material more securely as a contiguous structure, thus contributing to barrier properties.

\section{Hypothesis 4: Healing of PEC barrier films can be achieved}

It is proposed that reliance upon ionic bonds is compatible with the preparation of self-healable barrier films. Self-healing means that, by manipulation of conditions such as temperature, moisture, or saline solution, a crack in a film will be able to close itself up. This hypothesis is important to consider in the context of evidence that PEC films can be brittle, especially when dry (Feng et al. 2006; Meka et al. 2017; Fares et al. 2019).

\section{Hypothesis 5: Vulnerable to permeants}

The first four hypothesis statements, as described above, all pertain to proposed favorable aspects of barrier films that rely upon ionic bonds. The final four consider negative aspects, i.e., proposals that PECs and related films are likely to provide poor barrier capabilities, at least in some circumstances.

As the fifth hypothesis, it is proposed that PECs and related barrier films will tend to be permeable to various permeants. Such a hypothesis is important in light of the hydrophilic nature of polyelectrolytes, which can serve as a reason to doubt their ability to resist the permeation of water and water vapor. For example, PECs including the cationic polyelectrolyte chitosan are good barriers to oxygen, but that capability degrades when they are exposed to high humidity (Lazar et al. 2019). Also, PECs are known to swell in the presence of water (Ahmadiannamini et al. 2012).

\section{Hypothesis 6: Susceptibility to mechanical failure}

It is proposed that barrier layers based on PECs and similar systems tend to be prone to mechanical failure and that this is a significant issue. This susceptibility to failure can include a brittle nature, vulnerability to damage by scratching, and a typically low modulus of elasticity. A tendency toward brittle failure has been noted (Feng et al. 2006; Fares et al. 2019). Such studies indicate that even wet PEC films generally have little ability to stretch without failure, and dried PECs often can be described as brittle. Concerns about scratch resistance follows from the extremely thin nature of many PEC-based films.

\section{Hypothesis 7: Susceptibility to non-equilibrium trapped states}

It is proposed that PECs, during their formation, essentially become frozen into structures that are governed by kinetics, as well as by the flow conditions during initial mixing and preparation. Such structures, because of their inability later to rearrange themselves into an equilibrium structure, are proposed to trap nonuniformities, which may include pores. It is proposed that there is an inherent conflict between the desire for a high cohesive energy density and the desire for a high degree of uniformity within the nanostructure. 
Hypothesis 8: Their fussy nature makes their implementation challenging

Finally, it is proposed that PEC-based films can be described as "fussy". In other words, it is proposed that various deviations from ideal conditions of preparation and composition will result in unfavorable barrier performance. Evidence of the fussy nature may consist of wide ranges in reported barrier performance, a propensity for the formation of porous structures rather than dense, continuous structures (Hariri and Schlenoff 2010), and stickiness of PECs, resulting in deposits on processing equipment that are hard to clean up (Heermann et al. 2006).

\section{BACKGROUND}

The purpose of this section is to lay groundwork for subsequent discussions of mechanistic aspects as well as factors affecting the barrier performance of PECs and related films. Topics in this section include historical notes related to PECs, materials that have been used to make PEC barrier films, permeability properties of typical PEC-based films, and physical properties of typical PEC-based films.

\section{Historical Background}

Evidence for ionic bonding contributions

Max Born, who published in the period of 1918 to 1920, appears to have been the first to give a modern account of the energies associated with contact between oppositely charged ions (Sherman 1932). Born's work focused on the crystal structure of sodium chloride, making use of emerging methods in X-ray diffraction. Clear evidence and quantitation of ionic bonds within organic materials did not become established until later. For instance, the presence of ionic bonds was proposed to account for the development of wet strength when the highly cationic polymer polyethyleneimine (PEI) was added to paper (Trout 1951). It was observed that, rather than fall apart upon complete wetting, the paper retained a modest faction of the strength that it had when it was dry. By contrast, ordinary paper, which relies on hydrogen bonding to establish strong inter-fiber bonding, loses almost all of its strength when it becomes completely soaked in water. Allan and Reif (1971) demonstrated the development of especially strong wet strength when PEI was sprayed onto paper prepared from cellulosic fibers that had been rendered more anionic by derivatization with an anionic dye. The likely mechanism is illustrated schematically in Fig. 1. Note that the cellulose itself, due to its content of surface carboxylate groups, can be regarded as a polyelectrolyte in terms of its interactions with the PEI. Delgado et al. (1997) achieved a more elegant demonstration of ionic bond participation by attaching zwitterionic groups to papermaking fibers; the subsequent development of wet strength was consistent with double ion-pair formation between such groups bound to adjacent fibers within the paper. Moeller (1966) showed that cationic starch was able to increase the strength of paper even when the water was removed from the sheet by freeze-drying. If one assumes that hydrogen bonds are effectively prevented from forming under such drying conditions, then one is left to conclude that the strength development must have been due to ionic bonds. 


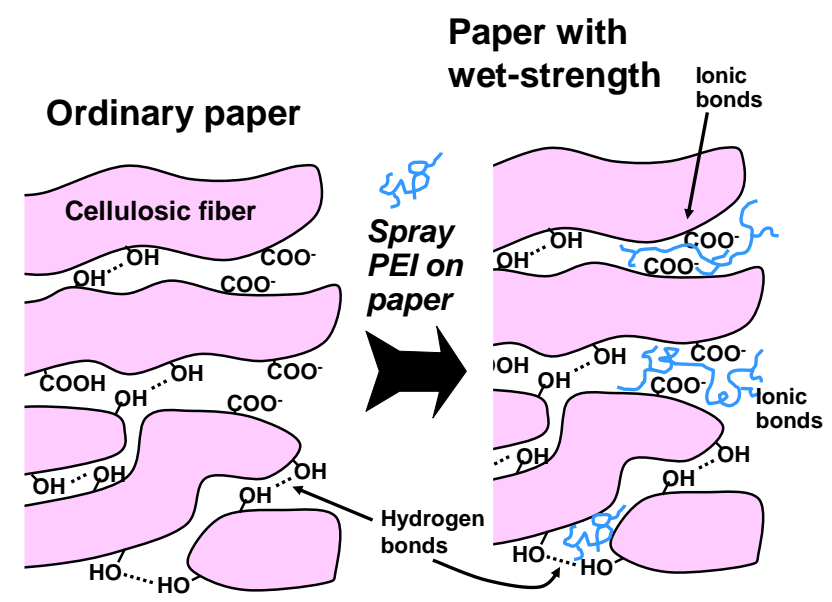

Fig. 1. Wet-strengthening effect of a high-charge cationic polyelectrolyte sprayed onto ordinary paper, providing early evidence of practical contributions of ionic bonding to material properties

The first reported observations of polyelectrolyte complex formation came even earlier. Kossel (1896) showed evidence of PEC formation in studies of the nuclei of biological cells. Willstätter and Rhodewald (1934) showed related effects when studying glycogens. Bungenberg de Jong and Kruyt (1929) carried out some of the first extensive research involving mixtures of oppositely charged polyelectrolytes. For instance, they showed that such mixtures could separate into two phases, each phase having a fixed polymer concentration and a distinct ratio of polyelectrolytes to water. The science of PEC formation and properties became well grounded by the 1960s (Michaels 1965). A key milestone, from the perspective of forming barrier films, was the discovery of layer-bylayer (LbL) multilayer formation of PECs (Decher and Hong 1991; Decher 1997). Though the preparation of such multilayers is time-consuming, the precision of layering has led to impressive results and a great increase in understanding.

\section{Usage of PECs in charge titrations}

PECs are formed in the course of titration methods that are widely used to determine the charge-equivalent concentrations of polyelectrolytes in solution. Terayama (1952) used a charge-sensitive dye, toluidine blue-O, to determine the titration endpoint. A key step in such a titration is illustrated in Fig. 2. As shown, the dye initially has a blue coloration when it is placed into pure water. Complexation between the dye and a highcharge-density anionic polymer such as the potassium salt of polyvinylsulfate (PVSK) causes the hue of the dye to shift from blue to pink. The color change can serve for detecting the endpoint of charge titrations due to the fact that the complexes formed with the dye are not as strong as the complexes formed between the two polyelectrolytes. The technique became widely used in the papermaking industry for monitoring and control of process conditions (Halabisky 1977; Hubbe 1979). Such titrations subsequently became quicker and more reliable with the advent of streaming current detectors, which can be used either in the laboratory or within the manufacturing process for online measurements (Hubbe and Waetzig 2018). Such measurements depend on the accuracy of forming 1:1 matching of charged groups between the titrant and the aqueous mixture. Increasing systematic deviations from 1:1 pairing, depending on which standard titrant is being added to which, have been found with increasing salt concentration (Chen et al. 2003). 


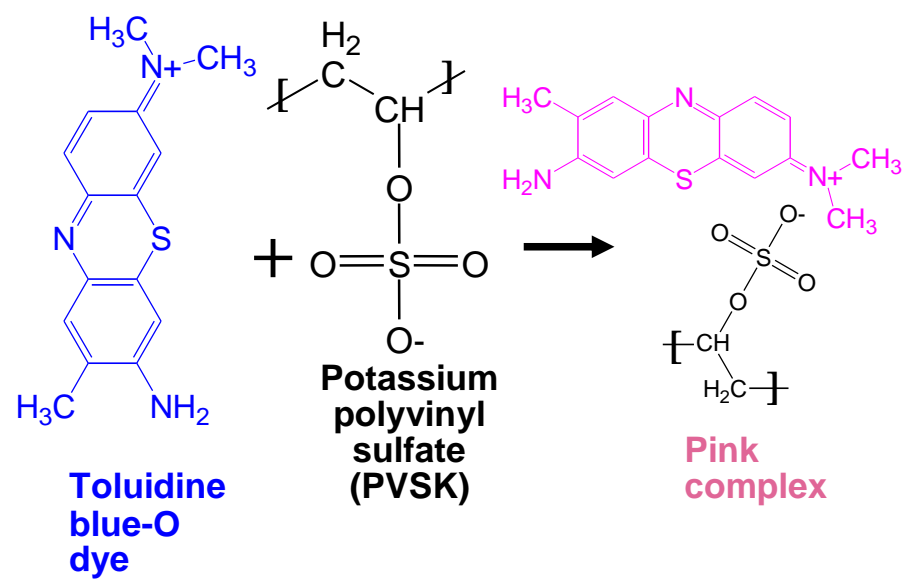

Fig. 2. Charge complexation giving rise to the characteristic color change when toluidine blue is used as an indicator of the endpoint for polyelectrolyte titrations

Usage of PECs as bonding agents

PECs can function as bonding agents to increase the strength properties of paper (Carr et al. 1974; Nagata 1991; Gärdlund et al. 2003, 2005; Lofton et al. 2005; Maximova et al. 2005; Torgnysdøtter and Wågberg 2006; Fatehi et al. 2009; Sang et al. 2010; Mocchiutti et al. 2016; Strand et al. 2017; Schnell et al. 2018). Superior performance has been found when forming the PECs in-situ within a briskly stirred suspension of fibers (Hubbe 2005; Heermann et al. 2006). By such treatment it is possible to adsorb much greater amounts of polyelectrolyte onto cellulosic fiber surfaces, compared to conventional treatments that involve single treatment with a polyelectrolyte solution. Paper-like sheets could be prepared even when using non-bonding glass microfibers (Hubbe 2005). Compared to treatment with PECs, higher paper strength sometimes has been achieved by the painstaking procedure of LbL assembly of multilayers (Eriksson et al. 2005; Ankerfors et al. 2009; Feng et al. 2009). However, direct addition of PECs, usually with a minor excess of positively charged polyelectrolyte, is very much faster than the LbL method and is almost as effective relative to the amounts of polyelectrolytes used. Key impediments to wider industrial use of PECs as a strategy for increasing paper strength include the high cost of chemicals and a propensity for the formation of tacky deposits on forming screens (Heermann et al. 2006).

\section{Usage of PECs for barrier films}

More recently, various researchers have been studying the preparation of PECbased films, with evaluation of their barrier properties. Such studies are extensively listed in Table A, which due to its size is placed in the Appendix to this article. Review articles have appeared discussing various aspects of such research (Priolo et al. 2015; Lindström and Österberg 2020; Machado et al. 2020). In general it has been found that PEC-based films resist the permeation of oxygen, especially under dry conditions. However, PECs often contain about 20\% water (Mende et al. 2002). Generally, PEC-based films become more permeable to oxygen, water vapor, and various liquids with increasing moisture content or relative humidity. 


\section{Materials Suitable for PEC Barrier Films Polyelectrolytes}

An attractive feature of PEC technology is the facility with which a broad range of substances can be included in a PEC-based barrier film. In principle, PECs are formed from a positively charged (cationic) polyelectrolyte and a negatively charged one (anionic). Each polyelectrolyte needs to be soluble in water. The charge density of each needs to be high enough to promote strong association. Petroleum-based polyelectrolytes that are often used in studies of PECs include acrylamide copolymers, polydiallyldimethylammonium chloride (poly-DADMAC), and polyvinylsulfate, potassium salt (PVSK). Bio-based polyelectrolytes often used in studies of PECs include cationic starch, chitosan, alginates, and carboxymethyl cellulose (CMC). In addition, various hemicellulose fractions and their derivatives are being studied as components of PECs (Ibn Yaich et al. 2015). The chemical structures of some of the mentioned polyelectrolytes are shown in Fig. 3.

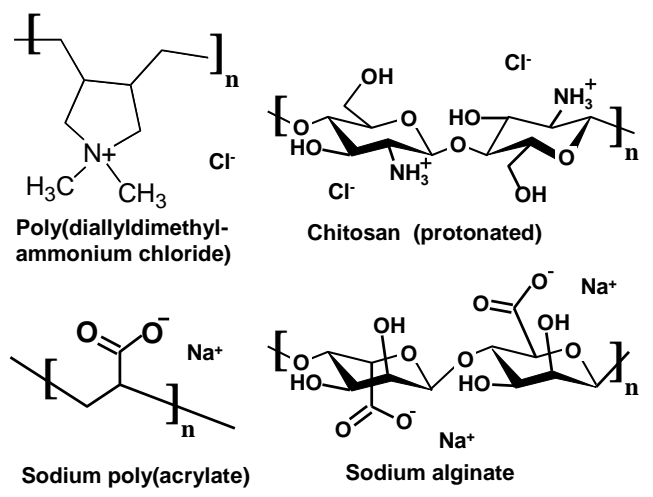

Fig. 3. Chemical structures of some polyelectrolytes that have been commonly used in forming polyelectrolyte complexes (PECs). Cationic polymers on top; anionic below. Synthetic polyelectrolytes on left; bio-based on right

\section{Colloidal particles as components of PECs}

Because a PEC is formed by combining positively and negatively charged colloidal-sized entities, it makes logical sense that one can substitute solid particles, having a suitable surface charge, in place of one of the polyelectrolytes. The recent review by Lindström and Österberg (2020) describes the increasing research attention being devoted to sodium montmorillonite (sometimes called bentonite or nanoclay) as a component in PECs prepared as barrier film. Such nanoclay has a highly platy shape and a negative surface charge, so the particles can be used in combination with cationic polyelectrolytes. Another option is to employ hydrotalcite, which is sometimes referred to as $\mathrm{Mg}$ Al doublehydroxide nanoplatelets (Dou et al. 2014; Lee et al. 2016). These have a positive surface charge. Figure 4, in its top section, presents drawings of two mineral products that have been employed in PEC barrier films.

Another widely researched solid component for PEC barrier films is nanocellulose. As shown in the bottom section of Fig. 4, two of the major classes of nanocellulose are cellulose nanocrystals (CNC) and nanofibrillated cellulose (NFC), which is sometimes called cellulose nanofibril. Though the fibrillar shape of the nanocellulose particles does not lend itself well to the physical blocking of substances from diffusing in a film, the material generally has a high content of crystalline regions, which are impermeable. Also, nanocellulose, if it is well bonded to the surrounding material in a film, has the potential to 
help maintain a defect-free film structure in ideal cases. Abdul Khalil et al. (2016) reviewed the usage of NFC in combination with chitosan to form composite films. The properties of different kinds of nanocellulose have been reviewed (Salas et al. 2014; Klemm et al. 2018).
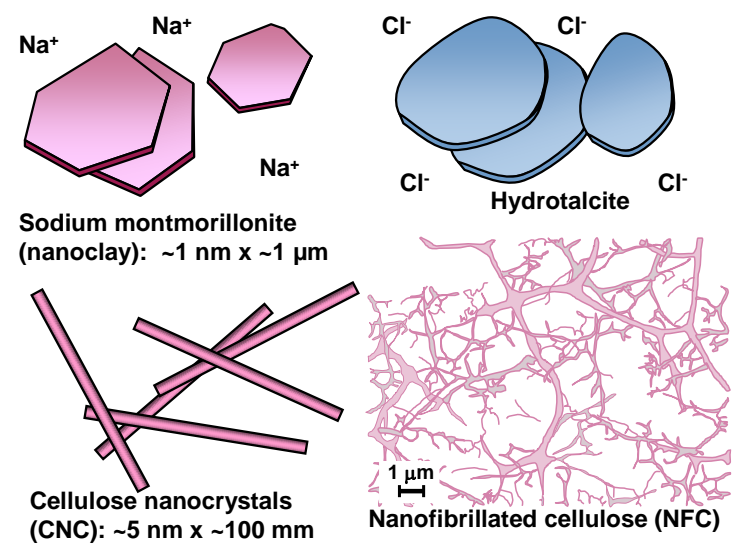

Fig. 4. Sketches of some particles that have been considered for the preparation of PEC barrier films. Platy minerals on top; fibrillar cellulosic particles on bottom

\section{Permeability of Typical PEC Barrier Films}

The ability of typical PEC materials to impede the diffusion of oxygen, water vapor, liquid water, and greasy substances, etc., is of great interest to researchers who are considering PECs for barrier films. As stated in the first of the hypotheses at the start of this article, it is proposed that ionic bonding within thin films can contribute substantially to the barrier performance of thin films prepared from ionically charged polymers, i.e. polyelectrolytes and related systems. On the other hand, as illustrated in Fig. 5, the strong tendency of oppositely charged polymers to flocculate can be expected to be a cause of nonuniform structures in some cases.

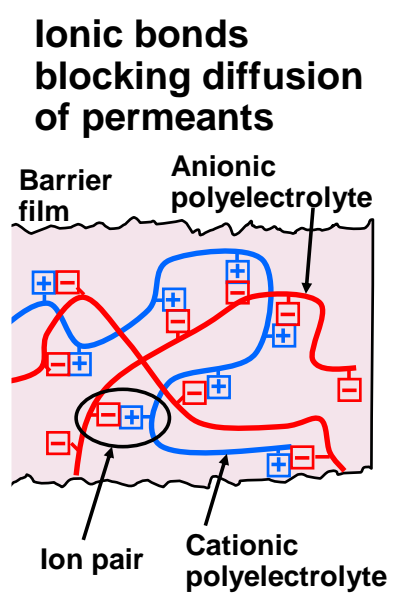

\section{Nonuniformity due to flocculation, leading to defects}

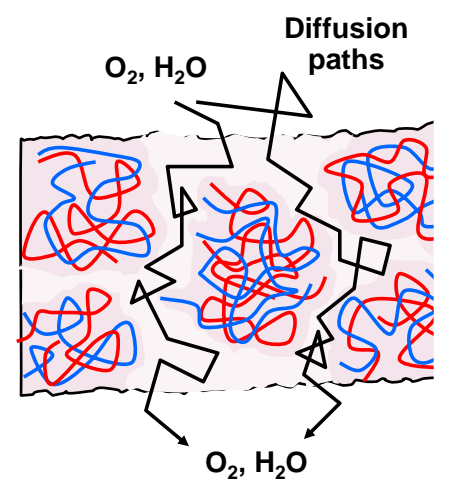

Fig. 5. Sketch illustrating two competing tendencies of the ionic bonds formed between oppositely charged polyelectrolytes. Left: lonic bonds, by increasing the cohesive energy density, have potential to impede diffusion of permeants through the film. Right: Flocculation during preparation of some PECs can be expected to leave pores and defects, which may make the film more permeable. 
Table A (see Appendix) includes a large number of studies in which PEC films were used in an effort to decrease permeation of various substances through films. Because Table A contains data that can be useful at several times in the discussion that follows, some key aspects will be noted. The first two columns list the positively charged (cationic) and negatively charged (anionic) components, which are usually polyelectrolytes but sometimes nanoparticles, where indicated. All abbreviations are defined in the first set of notes below the table. The third column indicates the nanoparticles, if used; items in parentheses indicate cases where the nanoparticles explicitly played the central role of complex formation with an oppositely charged ingredient, usually a polyelectrolyte. The fourth column indicates the preparation method, and it should be noted that the preparation methods will each be described in a later section. In preparing the list of the reported permeability values, some of the data have been converted to match the most commonly reported sets of units. Note that oxygen permeability is commonly reported using the units $\mathrm{cm}^{3} /\left(\mathrm{m}^{2} \cdot\right.$ day $\cdot$ atm $)$, whereas water vapor permeability is often reported as $\mathrm{g} /\left(\mathrm{m}^{2} \cdot \mathrm{day} \cdot \mathrm{atm}\right)$. In a few cases, the cited authors did not report their results in a way that allowed such conversions to be made. In particular, some authors expressed rates of permeation based on a unit thickness of the barrier film but without disclosing the determined value of film thickness.

To briefly summarize the results in Table A, the term "highly variable" is maybe the best description. Various studies included in the table have shown decreases in permeation of gases when a PEC-based film was compared to either a layer of a single polyelectrolyte (De Oliveira et al. 2008) or a bare default plastic film without the PEC layer on it (Haile et al. 2017). By contrast, other studies not included in the table have reported the intentional preparation of permeable or porous membranes by use of PEC formulations (Lukas et al. 2002; Li et al. 2013; Molgaard et al. 2014; Zhao et al. 2014; Zhu et al. 2014; Ong et al. 2016). As mentioned earlier, some of the more promising barrier systems are those that include nanoclay or hydrotalcite within the PEC film structure (Jang et al. 2008; Priolo et al. 2010a,b, 2013; Tzeng et al. 2014). Permeability values below the detection limit of the instruments employed are listed in Table A with the "less than" sign $(<)$.

Several studies, including the following, have documented effective resistance against the permeation of oxygen through PEC films (Jang et al. 2008; Priolo et al. 2010a,b; Li et al. 2013; Molgaard et al. 2014; Ibn Yaich et al. 2015; Shimizu et al. 2016; Haile et al. 2017; Schnell et al. 2017; Soltani et al. 2017; Satam et al. 2018; Smith et al. 2018). These favorable results possibly have a similar explanation as has been discussed in the case of pure nanocellulose films, which have a high hydrogen bond density. It has been proposed that the high resistance to oxygen in such nanocellulose films is due to a combination of defect-free structure and the fact that the hydrogen bonds hold the adjacent macromolecular chains tightly together. By arresting motions of the segments of the macromolecules, the hydrogen bonds effectively prevent permeant molecules from squeezing between the adjacent macromolecular chains within a film (Aulin et al. 2013; Hubbe et al. 2017; Lindström and Österberg 2020). It is reasonable to suppose that ionic bonds could play a similar role.

Significant resistance to grease and oil permeation has been reported for some typical PEC systems (Sirviö et al. 2014; Basu et al. 2017; Chi and Catchmark 2018a,b). Ahmadiannamini et al. (2012) noted that certain PECs did not swell in organic solvents, which is consistent with the presence of frequent hydrogen bond connections holding the molecules tightly together. The favorable barrier results achieved against the penetration of grease and oils probably has explanations that are parallel to those used to explain 
resistance to oxygen. Both types of permeant are non-polar and uncharged. Thus, the permeants do not have a tendency to become solubilized in the inherently polar PEC materials. Rather, the enhanced energy density contributed by the ionic bonding can be viewed as a means by which the polymer chains are held close together and relatively immobile. In addition, the organic solvents have a very different dielectric constant from that of water. The higher dielectric constant of water is an additional factor leading to higher swelling of PECs in aqueous systems. A simulation study has predicted a strong influence of local dielectric constant in the swelling of PECs (Qiao et al. 2010).

The presence of water appears to pose some of the greatest challenges to the PEC systems as potential barrier layers. The polyelectrolytes that are employed to make the PECs must be readily soluble in water in order to allow the needed processing, and that hydrophilic nature appears to be a point of inherent vulnerability of PEC barrier layers. Various articles have documented the tendency of PECs to swell in water (Fajardo et al. 2011; Ahmadiannamini et al. 2012; Zhu et al. 2014; Bajpai et al. 2016; Lv et al. 2018). In general, PECs can be expected to be less hydrophilic than either of their components. However, De Oliveira et al. (2008) reported an instance where the PEC was more hydrophilic than chitosan, which was one of its components. The hydrophobic nature of chitosan films, when used alone, is likely due to specific factors related to molecular conformation and orientation (Hubbe 2019). Farhat et al. (1999) found that polyelectrolyte multilayers contained about 10 to $20 \%$ of water. Even when dry, the ability of typical PECs to resist water vapor permeation can be described as intermediate, i.e. better than a polyelectrolyte layer alone, but not a superior barrier (Bajpai et al. 2016; Chi and Catchmark 2018b). Some PEC layers even can be described as "permselective," i.e. having a much higher water vapor permeability in comparison to their permeability toward other substances (Meier-Haack and Muller 2002).

Even when dry, PEC films have variable ability to resist the permeation of water vapor (Li et al. 2011; Sirviö et al. 2014; Ibn Yaich et al. 2015; Soni et al. 2016; Basu et al. 2017; Schnell et al. 2017). The most promising PEC systems for restricting the passage of water appear to be those that incorporate highly platy mineral particles (Findenig et al. 2012; Chi and Catchmark 2018a; Wang et al. 2018).

\section{Physical Properties of Typical PEC Barrier Films}

Physical properties such as stretchability and modulus of elasticity can be important in determining whether or not a barrier film will be able to resist breakage during use. In general, PECs tend to be more rigid and less stretchable than films prepared from the corresponding separate polyelectrolytes (De Oliveira et al. 2008). Figure 6 provides a schematic plot to emphasize the generally weak nature of PECs and also the strong dependency of their properties on humidity and moisture content.

The drying of PECs tends to make them more brittle (Rhim and Lee 2004; Feng et al. 2006; Meka et al. 2017; Fares et al. 2019). Non-conventional strategies such as usage of non-ionic soluble polymers in PEC-like structures may be needed if high levels of stretching without breakage are required (Qin et al. 2017). The non-ionic polymers appear to function as plasticizers. On the other hand, evidence suggests that PECs are sufficiently flexible to greatly increase the toughness of paper, when they are used as a bonding agent (Vainio et al. 2006).

High scratch resistance is not expected for PECs in general, though it can be achieved in certain formulations that include highly platy minerals (Humood et al. 2016). Likewise, PECs are not generally expected to have high resistance to electrical 
conductance. Increasing electrical conductance of PECs can be expected with increasing moisture content and with increasingly non-stoichiometric charge composition (Zheng et al. 2006; Ghostine et al. 2013). As shown by De et al. (2011) and Cramer and Schonhoff (2014), sometimes the ionic conduction within a PEC is dominated by migration of ions having one charge rather than the other.

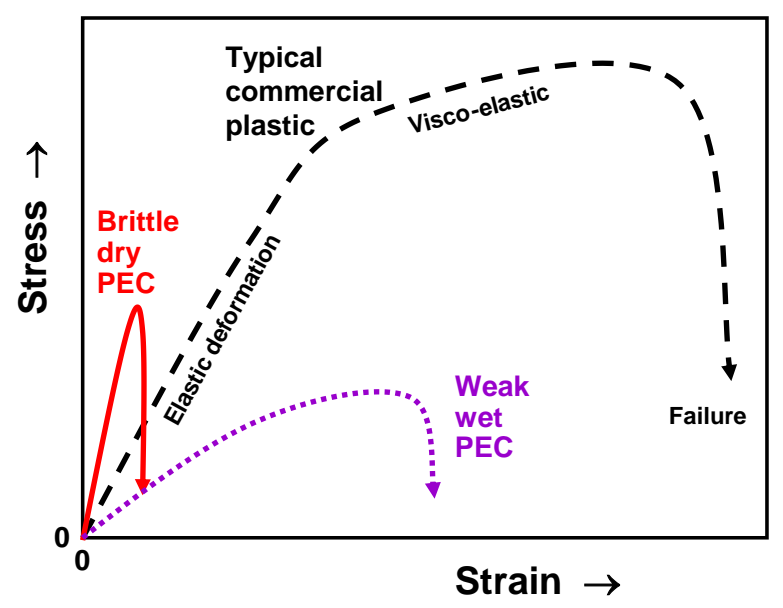

Fig. 6. Schematic plot contrasting the stress strain curves of typical dry and wet PEC material compared to a commercial plastic such as polyethylene

\section{MECHANISMS OF PEC FORMATION AND BEHAVIOR}

This section reviews the basics of what has been published about the mechanisms by which PECs form and stay together. Topics include thermodynamic considerations, self-assembly, trapped non-equilibrium states, and healing.

\section{Thermodynamic Considerations}

\section{Free energy content}

Thermodynamic principles ordinarily are based on starting assumptions that the processes being considered are reversible and that they are continually trending towards a state of equilibrium. Those assumptions are not necessarily true for many of the PEC systems considered in this article. Nevertheless, the main conclusions from thermodynamics continue to be quite useful for understanding the mechanisms relating to PEC formation and some of their properties. Key thermodynamic issues related to PECs have been described in various publications (Michaels 1965; Decher 1997; Park et al. 2002; Schneider 2012; Das and Tsianou 2017; Ji et al. 2017; Rathee et al. 2018).

The driving force for oppositely charged polyelectrolytes to associate with each other in aqueous systems is known to depend on the energy of formation of ionic bonds. Various authors have estimated the free energy involved in ionic bond formation to be in the range of about 1.2 or more kcal/mole (Allan et al. 1993; De Stefano et al. 1998; De Robertis et al. 2001; Schneider 2012; Spruijt et al. 2012; Askeland and Wright 2015). Higher values of $\Delta G$ for ionic bonding have been reported in some cases, which is consistent with the multivalent ionic species considered in some of these cited works. Notably, Spruijt et al. (2012) used an advanced atomic force microscopy method in which 
single chains of polyelectrolytes were pulled away from a surface coated with a brush copolymer having a sparse, but opposite charge. By that means it was possible to quantify the force and energy needed to break an individual ion-pair attachment. In the absence of salt, each ion pair accounted for about $3.6 \mathrm{kcal} / \mathrm{mole}$ of energy, but that quantity was reduced to about $0.6 \mathrm{kcal} / \mathrm{mole}$ when salt was added to the solution.

The amount of energy embodied within a single pair of oppositely charged ions is clearly not enough to cause oppositely charged entities to remain together in an aqueous mixture. Rather, just like a grain of sodium chloride tossed into a glass of water, the ions will immediately enter the bulk solution, spending only a very small fraction of their time as ion pairs. Glinel et al. (2002) estimated that a charge density of at least 0.36 elementary charges per nanometer is needed to induce effective complexation between polyelectrolytes of opposite charge in the absence of salt. When a critical concentration of neutral salt is present in an aqueous solution, the polyelectrolytes require between $53 \%$ and $75 \%$ of the units to be charged in order to maintain a stable PEC that does not dissolve back into the bulk solution (Schoeler et al. 2002). To place these values into context, the well-known high-charge cationic titrant poly-diallyldimethylammonium chloride (polyDADMAC) has 19.5 charges per nm of chain length, and $53 \%$ of that amount would give 10.3 charges per nm of chain length.

\section{Self-assembly}

Due to the inherent electrical attraction between positive and negative ionic groups, the term "self-assembly" is often employed when describing the preparation of PEC systems. When using such a term, it is important to keep in mind that many factors in addition to the electrical charges on the polyelectrolytes can contribute to the results. A high-performing PEC barrier layer is unlikely to be formed just by combining the materials under arbitrary conditions. To draw an analogy, even though plants are very capable of growing in the wild, they are not likely to form an organized garden that meets with the approval of a gardener without a lot of detailed effort by the gardener.

Michaels (1965), in an early review of PEC technology, laid out two limiting-case models to describe the conformation of PECs formed in aqueous solution. As illustrated in Fig. 7, the "scrambled egg" model envisions PECs as similar to random intertwined strands of cooked spaghetti. The "ladder" model envisions PECs as forming in zipper-like fashion between pairs of oppositely charged macromolecular chains.

A.

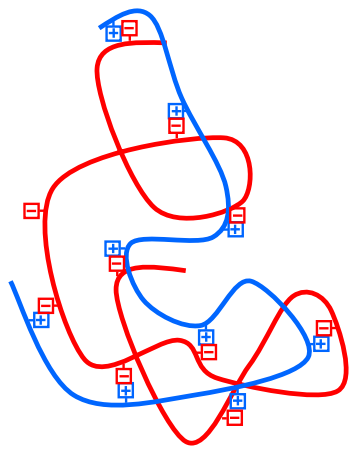

B.

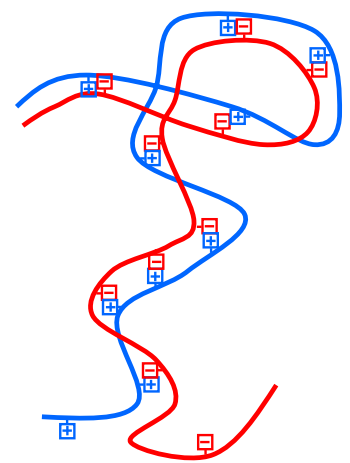

Fig. 7. Illustration of the (A) "scrambled egg" and (B) "ladder" models of polyelectrolyte complex nanostructure, as described by Michaels (1965) 
The ladder model would be consistent with an orderly pairing between each set of oppositely charged ions along the two chains. In either model, the process is driven toward completion not only by the ionic attractions, but also by the fact that the pairing of ionic groups on the macromolecular chains allows the counter-ions to diffuse away from the polyelectrolytes into the bulk of solution. The greater degrees of freedom experienced by the released counter-ions makes a large contribution of entropy, which is part of the free energy discussed in the previous subsection. Michaels et al. (1965) concluded, based on changes in conductivity due to the release of ions, that the process happens quickly and that the ladder model was dominant under the dilute conditions used in their research. Lazutin et al. (2012), based on molecular dynamics simulations, predicted that a scrambled egg form of PECs will be predominant in systems comprised of highly flexible polyelectrolyte chains.

The reason for the entropy increase, upon formation of a PEC by combining solutions of oppositely charged polyelectrolytes (Michaels 1965; Veis 2011; Das and Tsianou 2017; Rathee et al. 2018), is illustrated in Fig. 9. At the left of the figure one can envision two beakers that contain polyelectrolyte solutions having opposite signs of charge. In addition to the charges bound to the chains, there also are counter-ions. Though the counter-ions are not fixed to the polyelectrolyte chains, their average positions are constrained based on double-layer theory (Debye and Hückel 1923; Tadmor et al. 2002; Muthukumar 2004; Landy et al. 2012; Chremos and Douglas 2016). The polyelectrolyte chains themselves have relatively few degrees of freedom, due to the fact that each monomeric group is constrained by covalent bonds. The situation is analogous to a chaingang of prisoners, who still regard themselves as being locked up, even though collectively they are not attached to anything. When the two oppositely charged polyelectrolyte solutions are combined, as shown in the right side of the figure, the polyelectrolyte chains give up much of what little freedom they had when in separate solutions. Ion pairs form within the precipitated PEC material. Meanwhile, the monomeric ions such as sodium and chloride gain complete freedom as they diffuse away from the PEC and enter the bulk of solution, making a major contribution to the free energy of the system.

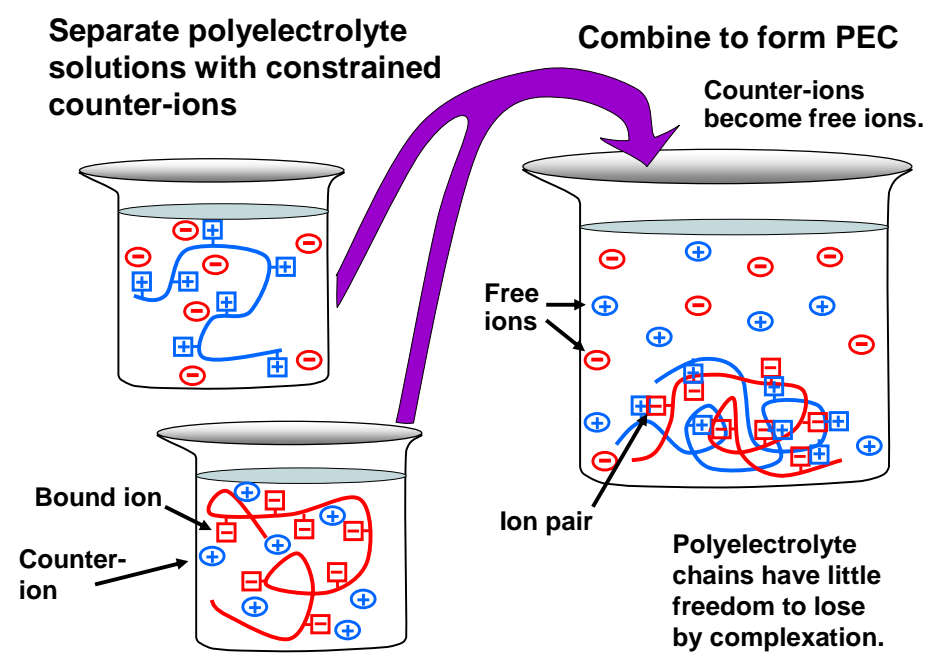

Fig. 8. Illustration of the changing situation and relative freedom of monomeric ions when two polyelectrolyte solutions are combined to form a polyelectrolyte complex 
An approximately 1:1 stoichiometry of interactions between ionic groups on polyelectrolytes chains, as mentioned earlier in the context of polyelectrolyte titrations, has been widely reported as a predominant tendency of PECs (Michaels 1965; Philipp et al. 1982; Argüelles-Monal et al. 1990; Schneider 2012; Meka et al. 2017). Deviations from 1:1 stoichiometry generally have been observed to involve minor proportions the total charges (Michaels 1965). Sometimes deviations from stoichiometry are required by conformational requirements of the two respective polyelectrolytes (Tse et al. 1979; Advincula et al. 1996); in other words, an attempt to form a ladder-type of PEC results in the skipping of some ionic groups. Tse (1979) found that equal spacing of charged groups within different ionenes in comparison to polyvinylsulfate led to non-equilibrium interactions in which some charged groups were not included in the complexation. Haronska et al. (1989) predicted deviations from 1:1 stoichiometry due to differences in the tendencies of different counter-ions to dissociate from the polyelectrolyte-bound groups. Michaels et al. (1965) attributed deviations from 1:1 stoichiometry to the tight coiling of polyelectrolytes, which becomes increasingly important with increasing concentrations of salt in the solution. Han et al. (2016) proposed that un-paired bound ionic groups within PECs may be responsible for unusually high swelling and flexibility.

A special class of unpaired ionic groups associated with PECs are those at the ends of chains or on protruding loops, wherein the segments extend outwards into the bulk solution. Those charges have been called "extrinsic" (Schlenoff and Dubas 2001; Riegler and Essler 2002; Fares and Schlenoff 2017b). Such structures were proposed by Chen et al. (2003) to account for deviations from 1:1 stoichiometry when polyelectrolyte titrations were carried out with standard titrants at increasing levels of salinity. Nearly equal and opposite trends of deviation from 1:1 stoichiometry were observed depending on which of the two polyelectrolytes was used to titrate the other one. These results were in agreement with the findings of Pergushov et al. (1999) and Naderi et al. (2005). The findings are consistent with a model in which a core of PEC, having approximately 1:1 stoichiometry, is surrounded by tails of the one of the polyelectrolytes extending into the solution phase. When a titration is carried out to a neutral endpoint, based on streaming current output, there will be an excess of the second gradually added polyelectrolyte (i.e. the titrant) at the surfaces of the PEC entities, allowing them to be charge-stabilized in the resulting suspension that is present at the titration endpoint.

Results reported by Basu et al. (2017) suggest that an unbalanced ratio of polyelectrolytes sometimes can give more favorable results in PEC film preparation. The researchers selected a ratio that would provide cationically stabilized PECs in suspension. These were allowed to adsorb onto paperboard surfaces by a dipping method. Oil-resistant properties were achieved after drying of the paper.

There has been some debate about what happens when an existing layer of polyelectrolyte (which might consist of the outer-most polyelectrolyte layer on a multilayer film structure) comes into contact with a solution of an oppositely charged polyelectrolyte. It has been proposed, for instance, that the latest adsorbing polymers interact in a three-dimensional manner with those already at the surface, leading to a fuzzy layered structure (Decher 1997; Arys et al. 2001). Other authors have emphasized a high degree of recognizability of the layered structure after multilayer formation (Kotov et al. 1995; Radeva et al. 2001; Cho et al. 2008; Kiel et al. 2010). 


\section{Trapped Non-equilibrium States}

Binding by multiple charge interactions

When oppositely charged polyelectrolytes interact with each other in an aqueous solution, their patterns of attachments are governed primarily by kinetics. Once contact has been established in which a local grouping of several ion pairs connects the two polyelectrolytes, the pattern can become essentially frozen. The term trapped nonequilibrium states has been used to describe such situations (Claesson et al. 2005; Naderi et al. 2005; Wu et al. 2018; Potaufeux et al. 2020). Michaels (1965) mentioned the "entrapment" of polyelectrolyte segments that had failed to form ion pairs within a PEC during its formation. Spruijt et al. (2012) estimated that a group of about five ionic bonds, working together, would be enough to trap oppositely charged polyelectrolytes into an essentially irreversible association. This rule is illustrated schematically in Fig. 9. Even though each of the individual ionic bonds is in a continual process of equilibration, it is extremely unlikely that all of them will disengage at the same time. Wang (2009) demonstrated the development of trapped non-equilibrium states in the course of numerical simulations. Trapped non-equilibrium states within PECs are of particular concern with respect to PEC-based barrier films due to an expectation that they will lead to nonuniformities, and maybe even to the presence of open channels, within the films. Also, such considerations help to explain why the details of mixing and orders of addition can make a large difference in PEC film properties (Naderi et al. 2005).

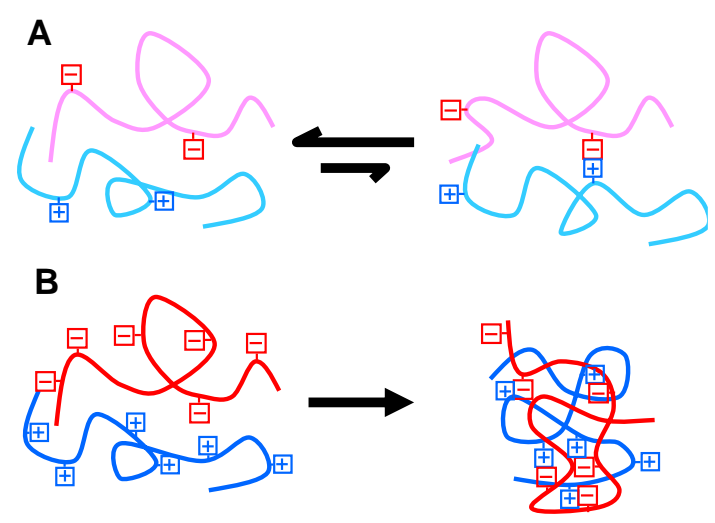

Fig. 9. Illustration of the principle that groups of five or more simultaneous ion pairs can be sufficient to establish an essentially irreversible attachment between oppositely charged polyelectrolytes

The concept of trapped non-equilibrium states helps to explain the performance advantage that was achieved when forming PECs in the presence of a stirred fiber suspension, for the purpose of increasing the strength of a resulting sheet of paper (Hubbe 2005; Heermann et al. 2006). When the polyelectrolytes were instead mixed with each other prior to their addition to the fiber suspension, the strength contributions were much lower, and the PECs showed a much greater tendency to contaminate the forming screen that was used to prepare sheets of paper. The results suggest that PEC formation in-situ within a stirred fiber suspension involves concurrent adsorption and complexation, thus taking advantage of some extra degrees of freedom before the PECs become fully entrapped together (Hubbe 2006). Another potential advantage of forming the PECs in situ within a cellulosic fiber suspension just before forming a paper sheet is that such PECs are likely to be more highly swollen with water. Strand et al. (2017) found that PECs 
coupled with relatively large amounts of water tended to contribute greater strength to paper after the drying process.

\section{Entanglements of polyelectrolyte chains}

The preceding discussion has been based on an assumption that ionic charge interactions serve as the main or only factor holding PECs together as durable structures. Polymer chain entanglements also can be considered, in light of their wide importance in the behavior of polymers in general (Seguela 2005). Such contributions have been considered in the case of PECs (Yeo et al. 2012; Akkaoui et al. 2020). Yeo et al. (2012) reported that the degree of entanglement during layer-by-layer preparation could be manipulated by adjusting the $\mathrm{pH}$. The polybase employed in the research was poly(allylamine hydrochloride) (PAH), which has weak base groups. The degree of chain entanglement was found to increase with increasing charge density of the PAH with decreasing pH. Akkaoui et al. (2020) noted a strong dependency of PEC suspension viscosity on molecular weight. On the basis of the cited work, chain entanglement can be regarded as a significant contribution to the quasi-irreversible (i.e. "sticky") interactions involved in the formation of PECs. Future studies might be conducted to reveal implications of entanglement with respect to the barrier properties of PEC films.

\section{Healing}

Self-assembly tendency

The term healing has been used to describe a process by which cuts or cracks within a film structure can come together in such a way that the cut or crack essentially disappears. Such a process has been shown dramatically in the case of relatively large hydrogel blocks that had been prepared with bright coloration (Yuan et al. 2019). The cited authors were able to cut the hydrogel specimens with a razor and then reassemble differently colored blocks. The initial properties were restored as the material remained together. South and Lyon (2010) reported the rapid healing of LbL PEC hydrogel films formed with poly(diallyldimethylammonium chloride), $\mathrm{N}$-isopropyl polyacrylamide, acrylic acid, and a poly(ethylene glycol) diacrylate crosslinker. Ren et al. (2016) proposed that an endothermic process of reversible ionic bonding was responsible for an observed healing of PEC hydrogels prepared from a chitosan derivative and alginate.

Strength is another important criterion of self-healing. Thus, Luo et al. (2106) observed a return to the starting strength and toughness levels after disruption and healing of certain PECs. Notably, the favorable healing and other properties were achieved even in some cases where there were deviations from 1:1 stoichiometry of the mixture. Nie et al. (2019) reported favorable self-healing results for PECs prepared from polymerized ionic liquids. In all of these cases, the mechanism appears to involve an ability of various bonds or associations to self-assemble after their breakage. Reif (1972), in aiming to understand the wet-strength capability of polyethyleneimine (PEI), proposed the selfassembly of ionic bonds by their "realignment" after disruption.

It has been proposed that the movements of macromolecular segments, rather than diffusion of complete macromolecular chains, is a likely explanation of self-healing tendencies of various PECs (Fares and Schlenoff 2017b). Those authors focused on the diffusion of "sites" rather than the diffusion of whole polyelectrolytes. By locally detaching and then reconnecting with an adjacent pairing between oppositely charged groups, net changes can take place at a speed that is about two orders of magnitude faster than that of diffusion of whole macromolecular chains. Figure 10 presents a pictorial 
concept of how the continual and random opening up of ion pairs, in concert with Brownian motions of the polymer segments, may permit reassembly of a PEC in ways that might repair mechanical damage or rupture.

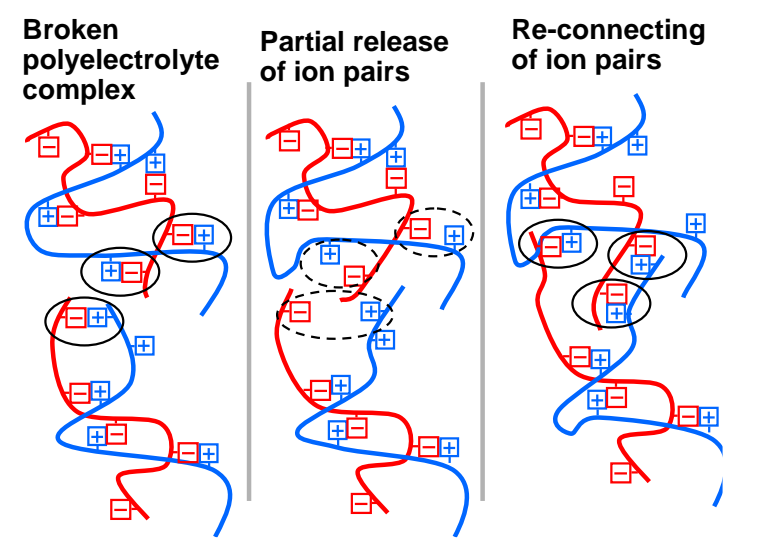

Fig. 10. Illustration of a mechanism by which a PEC film, when in a suitable environment, might be subject to processes of random release and reconnection, which may result in repair of ruptures

\section{Weakening of the interaction}

The mechanism by which PECs sometimes are able to heal themselves may be related to the reversibility of individual ionic cross-links (Han et al. 2016). Accordingly, a promising approach to bring about self-healing involves the intentional weakening of ionic associations. This can be done, for instance, by adding salt (Fares and Schlenoff $2017 \mathrm{~b}$ ). Another approach is to change the $\mathrm{pH}$ to favor less expression of ionic charge on one of the polyelectrolytes (Smith et al. 2018). Sometimes all that may be needed to sufficiently weaken ion pairs within a PEC is to apply moisture so that the PEC can heal itself while in a swollen condition (Yan et al. 2000).

Ren et al. (2016) intentionally weakened ionic attachments within a PEC by replacing ordinary chitosan with a derivatized version of chitosan having quaternary ammonium groups. Because of the bulky nature of such groups, the positive and negative ions within the resulting PEC cannot come as close together, and the energy of interaction is lower. The healing capability of the specialized PEC was attributed to this difference.

An inherent drawback of various healing-promotion strategies involving a weakening of ionic interactions is that they tend to reduce the cohesive energy density within the resulting PEC. As was discussed earlier, a high cohesive energy density is generally regarded as a required attribute of non-crystalline films that need to inhibit the passage of oxygen, oils, or greases (Lagarón et al. 2004; Aulin et al. 2013). It follows that some self-healing strategies may require a two-step process, such as increasing the salt concentration, followed by rinsing. Alternatively, the $\mathrm{pH}$ could be reduced enough to allow the PEC linkages to disengage, and this could be followed by a return to neutral $\mathrm{pH}$ (maybe with buffer solution) to allow the PEC's ionic connections to form again, hopefully with a more uniform nanostructure structure within the film. Another challenge that faces processing strategies based on the use of salts to promote healing is a general observation that PEC structures, once formed, may remained trapped with respect to their molecular arrangements. In other words, even though the number of remaining ionic interactions is reduced by the salt addition, the decrease in connectedness is still not sufficient to permit 
timely rearrangements of long-chain polyelectrolytes comprising the PEC film. Future research is recommended in this topic area.

\section{Hydrophobic association of alkyl tails}

The importance of hydrophobic associations between the alkyl groups of fatty acids and triglyceride esters was highlighted in a recent review article in this journal related to pitch deposition and hydrophobic sizing in paper manufacturing systems (Hubbe et al. 2020). As explained further in that work, the effect can be attributed to the change in free energy when hydrophobic groups self-associate, thereby allowing a greater amount of hydrogen bonding within the system as a whole. A net negative change in free energy leads to spontaneous association. For such associations to be influential, the hydrophobic entities need to be large enough, e.g. alkyl chains having at least ten and ideally 16 or more carbons in the chain.

In the work of Nie et al. (2019), a reported self-healing ability within structures formed from polymerized ionic liquids appeared to be related to a partial reliance on hydrophobic associations between groups attached to polymer chains. The allowable "slippage" between such groups and the ability of such associations to form again were given as explanations for the self-healing tendencies. Kotov (1999) proposed that such interactions can operate in concert with ionic bonding when the macromolecules contain a suitable combination of ionic groups and hydrophobic groups. Stevens et al. (2014) employed a hydrophobically modified polyelectrolyte in an effort to improve the selfhealing ability of a PEC system that incorporated nanoclay particles with the highly cationic polyelectrolyte PEI. Wickramasinhage et al. (2020) prepared PEC hydrogels that could be stretched by relative amounts as high as $4000 \%$ without breakage. This was done by formulating PEC systems with extensive associations among hydrophobic groups.

\section{PREPARATION METHODS FOR PEC FILMS}

Various approaches have been employed in published research related to the preparation of PEC-based films. In this article, emphasis is placed on approaches aiming to achieve both a relatively uniform, dense film, and a high density of ionic interactions, as needed to effectively inhibit diffusion of gases and oils or greases through the film. Topics within this section include layer-by-layer (LbL) assembly of PECs, LangmuirBlodgett options, mixing and casting options, procedures based on the preparation of charge-stabilized PEC colloids, and various post-treatments to improve the barrier properties of PEC films.

\section{Layer-by-Layer}

Exposing, rinsing, and drying

In studies where the emphasis is placed on exact control and on maximization of performance, above other considerations, the layer-by-layer (LbL) method offers advantages. As long as the successive layers to be added to the film have sufficiently high and opposite ionic charge, along with some other suitable properties, that approach can encompass a huge range of options, including the incorporation of minerals in place of one of the polyelectrolytes in the pair. Studies have emphasized the fact that the layered nature of LbL-applied PEC films can be clearly distinguished by means of such methods as X-ray diffraction (Decher et al. 1992, 1994; Tarabia et al. 1998; Arys et al. 2001). Such layered 
structures are a consequence of the LbL application method, since they are not found when, for instance, the bulk solution contains a mixture of positively and negatively charged polyelectrolytes (Wang 2009).

The most successful early studies of the LbL method tended to use a specific sequence of steps, as follows: (A) dipping an ionically charged substrate into a solution of oppositely charged polyelectrolyte, (B) rinsing away excess polyelectrolyte, usually using pure water, and (C) drying the film. As indicated in Fig. 11, the cycle then repeats, starting with a solution of the oppositely charged polyelectrolyte. Thereafter, the whole process of steps A through F can be continued, often allowing the accumulation of multiple layers.
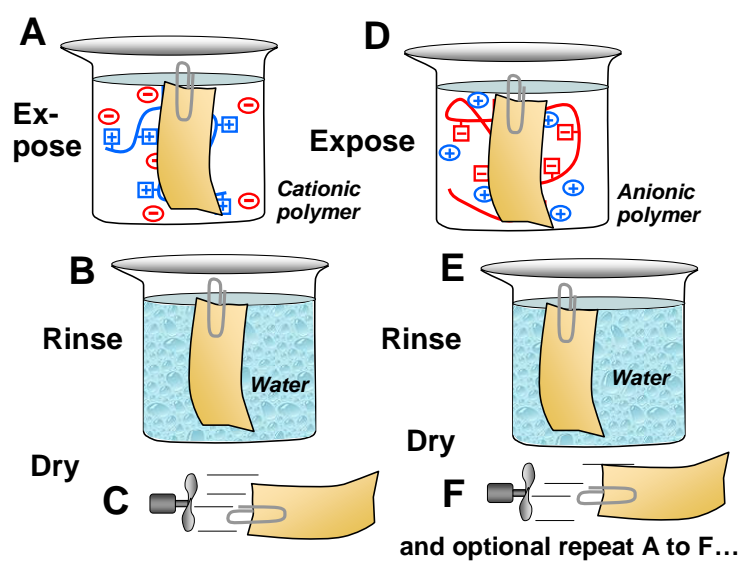

Fig. 11. Depiction of the sequence of steps for the most careful and traditional preparation of layer-by-layer PEC films. Note that parts A and D show polyelectrolytes with their charged groups (attached in squares) and counter-ions (in circles).

In addition to removing excess polyelectrolyte, beyond what is needed to interact with the preceding layer (or a bare surface at the start of the process), the rinsing step also seems to play an important role in removal of salt ions (Das and Tsianou 2017). The counter-ions, such as sodium and chloride ions, which are initially associated with a pair of polyelectrolytes, become released when the PEC is formed. By rinsing those ions away, one tends to lock the PEC together in an irreversible manner. Recent findings by Fares $e t$ al. (2019) suggest that better results can be achieved when an optimized relatively low concentration of salts is present in the rinse solution. It appears that such an approach allows for a more gentle assembly of the PEC structures, leading to greater uniformity and better barrier performance. By contrast, usage of ion-free rinse water was said to result in defects and pores. Machado et al. (2020) similarly found that they could achieve superior resistance to oxygen permeation when skipping the rinsing step, i.e. forming "unwashed" PEC films.

Gamboa et al. (2010) found that the sequencing of rinsing and drying steps could make a very large difference in the barrier performance of PEC films. They used a "high speed" robotic method in which the rinsing was carried out with a gentle spray. The fact that each cycle of this "high speed" procedure took six minutes helps to dramatize the fact that the LbL method is generally much too slow to be considered for manufacture of most commodity items, including packaging films.

Even in a very early article by the inventors of the LbL method (Decher et al. 1994), the drying step was regarded as optional. Since drying is likely to be a time-consuming step in the process, there is motivation to skip it. On the other hand, the drying step can 
play a role in dehydrating the PEC, allowing it to become dense, nonporous, and insoluble (Basu et al. 2017).

\section{Overcompensation}

With each subsequent exposure of a surface to the next solution of oppositely charged polyelectrolyte, an excess of polyelectrolyte charge is left on the surface. In other words, the surface charge is overcompensated (Schlenoff and Dubas 2001; Fares and Schlenoff 2017a). This over-charging appears to be an essential feature of the LbL process. One indication of this overcompensation is a switching back and forth between positive and negative zeta potentials during deposition of successive layers of polyelectrolytes (Ladam et al. 2000; Lin et al. 2008; Li et al. 2019a). Further evidence of overcompensation can be provided by studies utilizing charged fluorescent probes (Caruso et al. 1999). Such probes were found to adsorb onto LbL multilayer only when the outermost layer had a charge opposite to that of the probe.

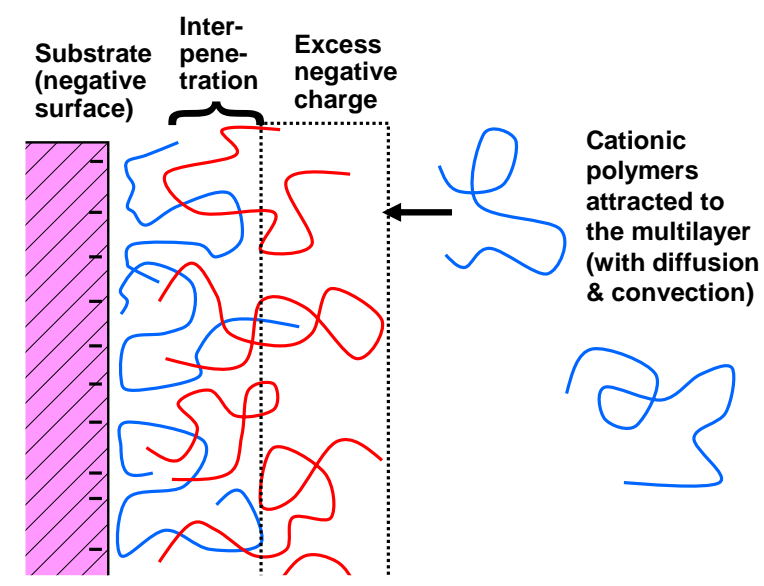

Fig. 12. Illustration of the over-compensation effect, wherein each subsequent layer of polyelectrolyte interpenetrates as complexes mainly with the preceding layer and presents an excess of charge in the outer tails and loops

\section{Langmuir-Blodgett Options}

The Langmuir-Blodgett method is analogous to formation of LbL PEC multilayer films, except that the layers are comprised of surfactants rather than polyelectrolytes (Ariga et al. 2013). To start the deposition process, a monolayer of a selected insoluble surfactant is spread on the surface of an aqueous solution in a shallow trough. A barrier is moved with precise control to compress the monolayer film. While using the barrier to control the two-dimensional pressure within the film, a solid object, such as a glass slide, is very slowly dipped into and just as slowly withdrawn from the trough. During each downstroke, an oriented molecular layer of surfactant is transferred to the substrate. During each upstroke, another molecular layer is deposited, such that all of the molecules are in a headto-head and tail-to-tail arrangement in different layers. Lvov et al. (1993) showed that the LbL method and the Langmuir-Blodgett method can be combined. Though the cited work did not consider either healing capabilities or barrier properties, the approach appears to merit research attention to explore these aspects. 


\section{Mixing and Casting}

Given the inherently very slow nature of the LbL process just discussed, it is worth considering whether a high-performing PEC barrier layer can be formed by just mixing solutions of two oppositely charged polyelectrolytes together. Such an approach is bolstered by the highly favorable results achieved when forming PECs in situ during the agitation of a fiber suspension that is subsequently formed into a sheet or paper (Hubbe 2005). Superior inter-fiber bonding strength was achieved. In the papermaking process, the use of PECs, whether prepared in-situ or prepared ahead of time, makes it possible to incorporate the treatment into a current-generation commercial manufacturing process with no sacrifice in production speed. However, the goal of achieving increased paper strength is very different from serving as an effective barrier layer. The strong flocculation that occurs when oppositely charged polyelectrolytes are directly mixed together raises concerns regarded an expected non-uniformity of the resulting material and whether or not it can be formed into a coherent layer.

In principle, solutions of two oppositely charged polyelectrolytes can be mixed together, followed by spreading or extruding the mixture as a layer, and then drying. Haile et al. (2017) were able to prepare a PEC film by first allowing the complexed polyelectrolytes to settle after mixing solutions of PEI and polyacrylic acid. The relatively concentrated PECs, along with some water, were spread as a film using a wire-wound steel rod (Mayer rod). Oxygen barrier performance was achieved after thermal treatment (150 ${ }^{\circ} \mathrm{C}$ for 2 hours at high humidity) of the resulting layer.

\section{Blending of a PEC suspension and casting it}

In the interest of achieving a more uniform layer, Basu et al. (2017) agitated the PEC mixtures in a blender before spreading the mixture. The approach is illustrated in Fig. 13.

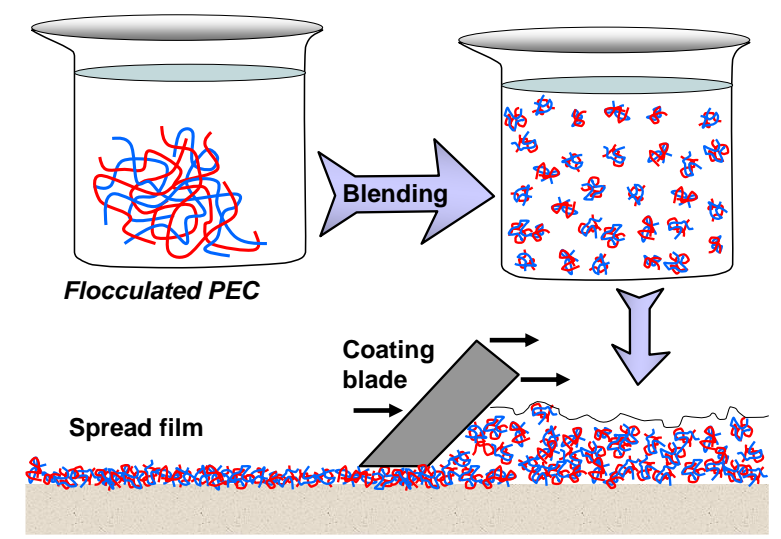

Fig. 13. Schematic description of possible steps in the preparation of a PEC film by combining the polyelectrolytes as a flocculated mixture, applying high hydrodynamic shear to convert the mixture into small PEC particles, and then spreading the mixture on a surface

Basu et al. (2017) speculated that the high shear conditions would cause the PECs to form elongated, fiber-like nanostructures that might be beneficial for the film properties. Dehydration of the PECs that had been formed from carboxymethylcellulose (CMC) and chitosan yielded dense, nonporous, and insoluble films that resisted both water and oil. Similarly promising results were obtained by Chi and Catchmark (2018b) and Chi et al. (2020), who used high-shear homogenization to create nanostructured PEC particles. 
These were said to electrostatically coalesce in the course of dehydration. The films prepared by Chi and Catchmark (2018b) had homogeneous properties, which indicated that any pores and voids had been successfully removed.

\section{Preparing and Using Charge-stabilized PEC Colloids}

Concept of barrier layers from PEC Colloids

In principle, it would be possible to create a barrier layer by exposing an ionically charged surface to a suspension of charge-stabilized PECs. For example, Kekkonen et al. (2002) showed that a colloidal suspension of charge-stabilized PECs could be adsorbed onto silica. Studies related to papermaking technology provide evidence that such an approach has the potential to deposit relatively large amounts of polyelectrolyte in a single exposure step (Hubbe 2005; Lofton et al. 2005; Heermann et al. 2006). The question that needs to be determined is whether such layers could be effective barriers against oxygen and other substances. Evidence presented in the previous subsection suggests that favorable results are possible, especially after drying of the films. It is not known whether the intersections between adjacent charge-stabilized PEC particles, after they have been formed together as a film, will serve as defects that permit greater diffusion of various substances through the film. Figure 14 illustrates how such a process could work, involving the three steps of preparing a polyelectrolyte solution, adding a second polyelectrolyte solution with stirring, and allowing the charge-stabilized PEC colloids to be attracted to a substrate, leading to their deposition as a contiguous layer.

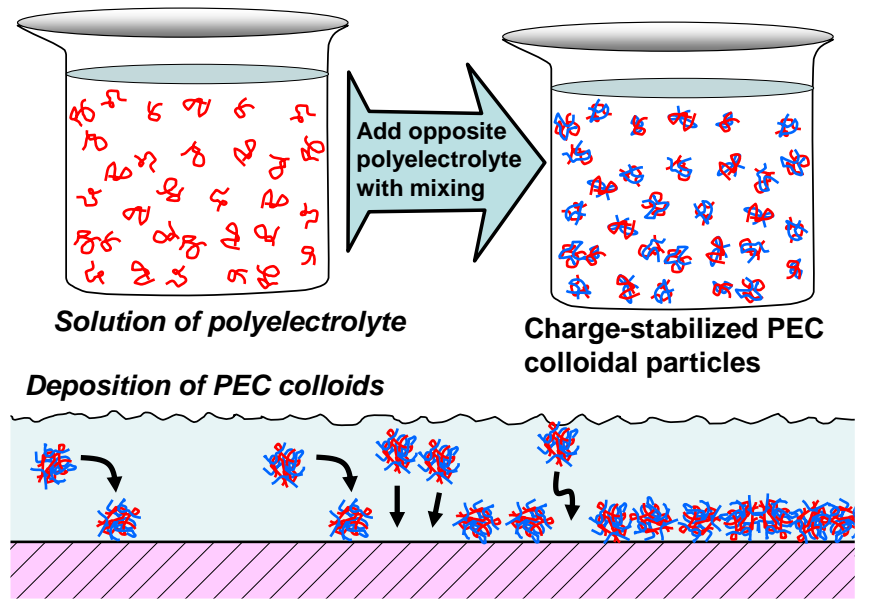

Fig. 14. Steps in the preparation of a PEC film by combining the polyelectrolytes as a flocculated mixture, applying hydrodynamic shear, and then allowing the suspended PEC particles to adsorb onto a substrate having an opposite net charge

\section{Forming Charge-stabilized PECs}

To be able to prepare a PEC layer from PEC colloids, the first step involves forming the charge-stabilized colloidal particles. When a dilute solution of a polyelectrolyte is being gradually added to a stirred solution of an oppositely charged polyelectrolyte, most of the time one of the two polyelectrolytes will be in excess. At those points in the titration, the mixture is likely to consist of roughly spherical PEC particles that are each electrostatically stabilized due to an outer layer that is composed of whichever polyelectrolyte is in the excess (Dautzenberg et al. 1996). When that outer charged layer of the PEC particles is opposite to that of a suspended solid, such as cellulosic fibers or a 
packaging material such as paper, strong adsorption can be expected (Hubbe et al. 2005). To achieve such goals, the amount of the second polyelectrolyte may need to be adjusted so that the resulting PEC particles are charge-stabilized to a favorable degree.

\section{Conditions during PEC preparation}

The aqueous conditions of the mixture in which the PEC is being prepared can be expected to affect the polyelectrolyte ratio and other properties. As was noted earlier, increasing concentrations of salt cause increases in the relative amounts of excess polyelectrolyte in the stabilizing layers on the PEC colloids (Chen et al. 2003). Salt also tends to weaken the interaction between the bound positive and negative ionic groups of the polyelectrolytes (Han et al. 2016). A promising strategy involves finding an optimum (relatively low) concentration of salt that gives a good balance between colloidal stability (so that massive precipitation does not occur), while also avoiding overly energetic interaction between the polyelectrolytes. Overly energetic interaction would be expected to result in trapped non-equilibrium states (Lagarón et al. 2004), leading to non-uniformity of films prepared from the PEC material. This explanation is also consistent with the findings of Gamboa et al. (2010) and Machado et al. (2020), who found the best barrier performance of PEC layers when rinsing steps were skipped during LbL deposition, thus moderating the strength of interaction during the formation of the PECs. Smith et al. (2018) likewise found the best resistance to oxygen permeation when PEC films, which were prepared in a single step by mixing, were made in the presence of an optimized salt concentration. Wu et al. (2018) found that an optimum level of salt allowed the formed PEC films to readjust themselves so that they achieved more stable structures rather than kinetically trapped structures.

Higher levels of salt also have been found useful for the preparation for PECs, but for uses other than for barrier films (McAloney et al. 2001; Lindhoud and Stuart 2014; Lalwani et al. 2020). For instance, membranes with well-defined permeability properties can be prepared by mixing polyelectrolytes under "saloplastic" conditions (Porcel and Schlenoff 2009; Harari and Schlenoff 2010; Shamoun et al. 2012). In other words, there was enough salt so that the PEC material could be formed into a porous film even after it was precipitated from solution.

Adjustment of the $\mathrm{pH}$ can be a powerful tool by means to direct polyelectrolyte behavior during PEC formation, especially when either weak acid or weak base groups are present on the polyelectrolytes (Philipp et al. 1982). In such cases, changes in $\mathrm{pH}$ can change the charge density of the respective polyelectrolytes. Accordingly, some researchers have manipulated the $\mathrm{pH}$ back and forth between different levels as a means to increase the amounts of polyelectrolyte deposited during each step in an LbL assembly process (Eriksson et al. 2005; Priolo et al. 2010a; Yang et al. 2011). Likewise, Fajardo et al. (2011) studied changes to PEC structure, as well as the release of polyelectrolyte molecules from PECs following changes in $\mathrm{pH}$. Such strategies need to be considered with caution, however, since the charged nature of some PEC films adjacent to an aqueous solution will tend to shift the value of $\mathrm{pH}$ within the film so that it does not match the $\mathrm{pH}$ of the bulk solution (Rmaile and Schlenoff 2002). 


\section{Post-treatments}

Crosslinking effects

After a PEC film has been formed, some researchers have applied a final procedural step or steps to modify the resulting film properties. Some such treatments can be described as crosslinking. For example, the initial procedure may consist of forming a layer of nanofibrillated cellulose (NFC) that has been oxidized under specialized conditions to achieve a high density of carboxylate groups, and then those films are treated with a solution with calcium ions (Sirviö et al. 2014; Shimizu et al. 2016). The calcium ions can be expected to form complexes with carboxylate groups, thus bonding the material together with ionic crosslinks. This scenario is illustrated in Fig. 15. Shimizu et al. (2016) reported very low oxygen permeabilities when such films had been treated with divalent or trivalent metal cations. Sirviö et al. (2014) reported that the water vapor permeability was decreased following treatment of the NFC film with calcium chloride. If one considers the NFC as functioning as a polyelectrolyte in such interactions, the resulting cross-linked film can be regarded as being analogous to a PEC. A related result was achieved by Rhim and Lee (2004), who used calcium chloride to post-treat barrier films that had been prepared with sodium alginate.

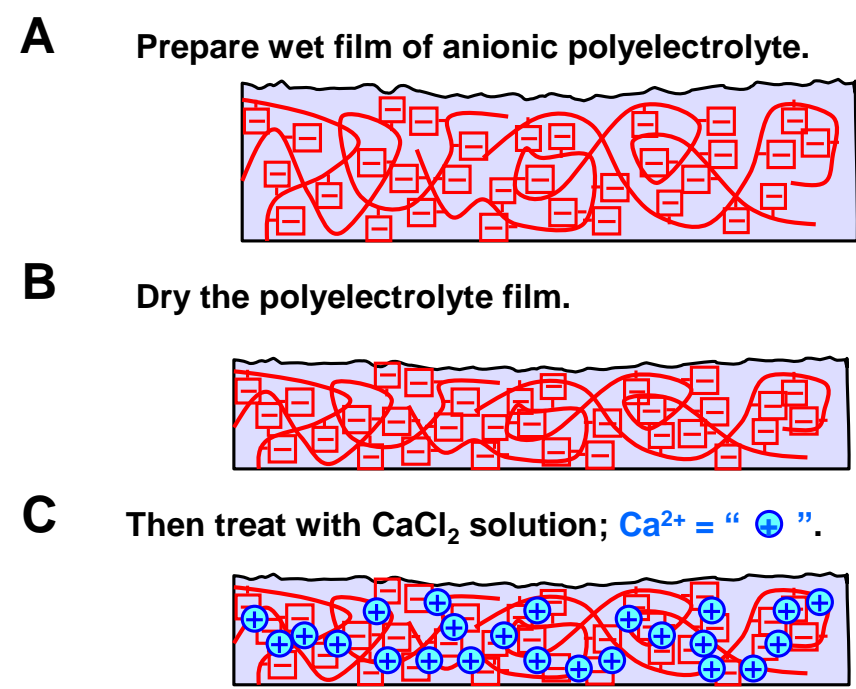

Fig. 15. Procedure for forming a barrier film by preparing a solution of anionic polyelectrolyte (e.g. alginate or polyacrylate), drying the layer to form a film, then crosslinking the film by treated it with calcium chloride solution

Covalent reactions can be used as a more permanent way to accomplish crosslinking within a PEC film. For example, Ben Dhieb et al. (2019) achieved much more effective resistance to diffusion of oxygen through films comprised of polyvinyl alcohol and nanoclay following crosslinking with either glyoxal or glutaraldehyde. Lazar et al. (2019) used a free-radical initiator to induce crosslinking in a PEC film comprised of chitosan and polyacrylic acid. A 36-fold reduction in oxygen transmission was observed due to the crosslinking. Likewise, Yang et al. (2012) achieved large decreases in oxygen permeability through a PEC film comprised of PEI and polyacrylic acid following crosslinking with either glutaraldehyde, 1-[3-(dimethylamino)propyl]-3-ethylcarbodiimide methiodide (EDC), or thermal crosslinking. Peng et al. (2018) achieved crosslinking by 
means of Diels-Alder reactions within a copolymer formulation that included both positively and negatively charged monomers, i.e. a polyampholyte having reversible covalent crosslinking capabilities.

\section{Heating after PEC film formation}

Heat treatments can be regarded as a way to permit the final self-assembly of polyelectrolyte segments, with the aim of achieving a relatively dense, impermeable film. A recent review article mentions such "thermal annealing" as an emerging trend in PEC technology (Lalwani et al. 2020). Based on reviewed literature, the authors concluded that the heat treatment tended to give denser and better-organized PEC films. Lvov et al. (1993) reported an improvement in the ordering of multilayer PEC films after heating to $70{ }^{\circ} \mathrm{C}$ and gradual cooling. Schnell et al. (2017) achieved promising results after heating PEC films comprising xylan and chitosan to $75^{\circ} \mathrm{C}$ for $10 \mathrm{~min}$, followed by gradual evaporation at $40{ }^{\circ} \mathrm{C}$. Yang et al. (2012) noted reduced water vapor transmission after thermal crosslinking of PEI-poly(acrylic acid) PEC films at $180{ }^{\circ} \mathrm{C}$ for $5 \mathrm{~h}$. Small positive effects relative to resisting oxygen permeability were observed. Haile et al. (2017) heated PECtype films for $2 \mathrm{~h}$ at $150{ }^{\circ} \mathrm{C}$. The thermal treatment was found to be much more effective in comparison to exposing the film to a high humidity condition.

\section{Healing}

Self-healing strategies and procedures can be regarded as another category of potential post-treatment of PEC barrier films. Ideally, one might hope such repair to happen automatically due to the inherent nature of the components of the film. Alternatively, the aim might be for the repair to take place when the film is exposed to certain conditions. Although there have been a variety of approaches used to achieve selfhealing characteristics of films, all of them share a central requirement: Some aspect of the bonding needs to be reversible. For example, McKee et al. (2014) designed a system in which a composite was held together, in part by the interdigitation of polymer chains having 2-ureido-4[1H]-pyrimidone (UPy) pendant groups. The association among such groups falls into a range allowing them to (a) come apart at a stress low enough so that breakage can occur before the polymer chains are damaged, and (b) once the stress has been removed, the associations can form again rapidly. As mentioned earlier, certain relatively labile covalent bonds, such as Diels-Alder crosslinks (Peng et al. 2018) also appear to fall in that range.

Potaufeux et al. (2020) make the case that ionic bonds also can fall into the same category. They noted that increased temperature, which makes it easier to locally exceed the activation energy related to ionic bonding, can promote self-healing. However, that view can be challenged. As was noted during the discussion of trapped non-equilibrium states, ionic bonds tend to work in groups. Whereas an individual ionic bond may be envisioned as forming, coming apart, and forming reversibly many times per second, a bunch of five or more such bonds acting together can be expected to act in an irreversible manner (Spruijt et al. 2012), thus conferring a brittle nature to the PEC. It follows that a promising strategy to achieve greater healing tendency may involve an intentional weakening of the ionic pairing forces and energies. 


\section{Moisture-mediated healing}

As a first step towards rendering PECs more self-healable, one can increase the moisture content, either by direct addition of water or by exposure to a very high relative humidity (Zhang et al. 2016). This can be viewed as a reversal of the final drying step that is included in many procedures for preparation of PEC films (Decher 1997). Swelling with water can be expected to increase the mobility of polymer segments (Chen et al. 2018). South and Lyon (2010) found that they could heal damaged PEC structures by exposing them to water. The PECs had been prepared by combining negatively charged hydrogels with poly(diallyldimethylammonium chloride) solution. Likewise, Zhang et al. (2016) were able to repair PEC films made from PEI and poly(acrylic acid) by exposing them to distilled water.

Some researchers have found that it is sufficient just to place a damaged PEC structure in the presence of high humidity to bring about self-healing. Dou et al. (2014) studied the barrier properties of PEC films prepared with the negatively charged polyelectrolyte poly(sodium styrene-4-sulfonate) and positively charged hydrotalcite particles. The oxygen barrier ability was found to deteriorate gradually when the film was flexed (between 200 and 500 times bending). When the PEC films were post-treated with a poly(vinyl alcohol) solution, the resulting film achieved a remarkable self-healing ability that was triggered by exposure to air with $85 \%$ relative humidity. Song et al. (2017) were able to repair cracks in a PEC film comprised for PEI and polyacrylic acid by exposing it for 10 minutes at $97 \%$ relative humidity.

\section{Salt-mediated healing}

As noted by Meka et al. (2017) and O'Neal et al. (2018), increasing ionic strength of the aqueous environment is an effective way to weaken the ionic bond interactions within a PEC. This is evidenced, for instance, by increased swelling in the presence of a salty solution (Dubas and Schlenoff 2001). Under such conditions, the pattern of ionic bonding within the structure is more easily rearranged, and this can contribute to selfhealing. Zhang et al. (2016) found that superior healing results could be achieved by first using a $\mathrm{NaCl}$ solution, and this was followed by rinsing with distilled water. Presumably the saline solution allowed relaxation of the structure, and then a tight, well-bonded structure was restored upon removal of the salt.

O'Neal et al. (2018) and Guo et al. (2018) found that the self-healing capability of poly(ionic liquid) materials could be profoundly affected by the size of the counter-ion. The ability of LbL-formed PEC films to self-anneal and self-heal could be increased by replacing $\mathrm{Cl}^{-}$ions in the film with the larger $\mathrm{Br}^{-}$ions (O'Neal et al. 2018). Replacing the $\mathrm{Br}^{-}$counter ion with bis(trifluoromethanesulfonyl)imide (TFSI-) counter-ion rendered the poly(ionic liquid) yet more self-healable. Because ionic liquids fall into a specialized class of materials, it is not yet known whether the same principles can be applied to more typical PEC materials.

\section{FACTORS AFFECTING PEC BARRIER PROPERTIES}

\section{Overview of Factors Affecting Barrier Properties}

This section will focus on factors that govern the effectiveness of various PEC films in preventing the transmission, through an intact film, of oxygen, greases and oils, water vapor, or aqueous solutions. Topics within this section include polyelectrolyte charge and 
mass, the stoichiometry within the PEC, effects of different kinds of ionic groups, structural fitting between the respective polyelectrolytes, cross-linking within a PEC, plasticizers, salinity, hydrogen bonding contributions, the hydrophobic effect, layer attributes, defects, fillers, and the use of other barrier layers in combination with PECs.

\section{Polyelectrolyte Charge and Mass}

Charge density

The likely importance of charge density, relative to the development of barrier properties, can be considered in the light of the first hypothesis proposed at the start of this article. That is, it was proposed that ionic bonding can contribute to a higher cohesive energy barrier and thereby impede passage of substances through the film. Oxygen is a nonpolar molecule, so it makes sense to expect that PEC films, which contain highly polar bonds, to be effective barriers. By extension, one might expect a higher charge density on the polyelectrolyte to yield a higher density of ionic bonds and thereby higher barrier performance. Such a concept is supported, in part by a lesser swelling in water of PECs formed from polyelectrolytes having a higher charge density (Ahmadiannamini et al. 2012; Das and Tsianou 2017). However, Kurihara and Isogai (2015) found only a weak dependency on charge density when evaluating the moisture content of films formed with oxidized cellulose nanofibers and acrylamide copolymers. The cited authors observed large agglomerates when combining the cationic PAM copolymers with the anionic nanofibers. Such evidence of flocculation is not consistent with forming an effective barrier film. Notably, in none of the cases just cited was there a clear relationship drawn between polyelectrolyte charge density and the resulting barrier performance of PEC films. Accordingly, there is an opportunity for important future research.

\section{Blockiness}

It has been proposed that a blocky structure of polyelectrolytes has the potential to form stronger ionic associations within PECs (Potaufeux et al. 2020). Denser and more salt-resistant structures can be expected (Rumyantsev et al. 2019). Again, however, the present search of the literature did not find any published research demonstrating whether or not blockiness of the polyelectrolytes is correlated with PEC film barrier properties.

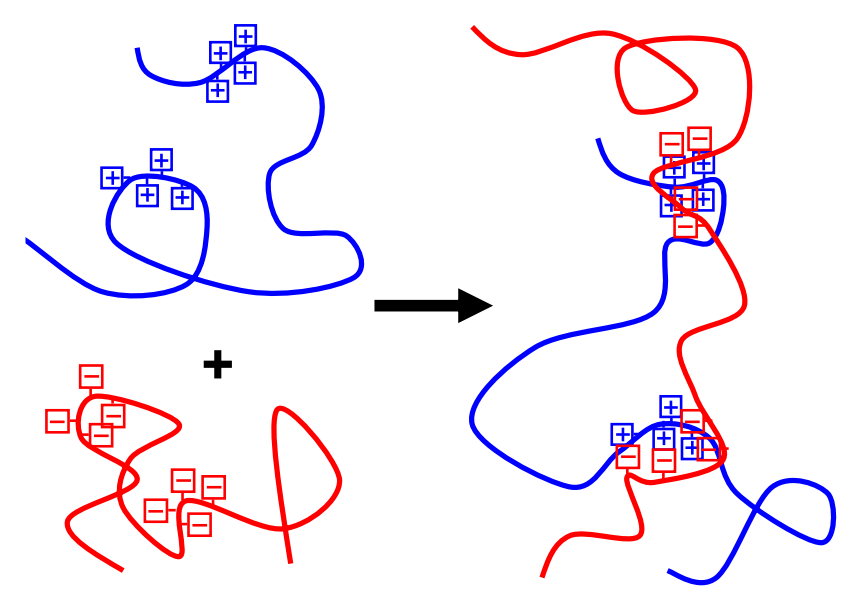

Fig. 16. Illustration of the expected propensity of "blocky" polyelectrolytes to form complexes that are hard to reverse, but loose in structure 
As illustrated in Fig. 16, a blocky distribution of charges on the polyelectrolyte chains can be expected, on the one hand, to give strong and hard-to-reverse connections between the chains. On the other hand, the structure is likely to be relatively loose. The loose structure might be expected to favor transmission of permeants through the film.

\section{Molecular mass}

Though molecular mass of polyelectrolytes can be important with respect to many applications, for instance in flocculation of wastewater, the search of the literature did not reveal a clear trend of effects of molecular mass on PEC barrier properties. One might suspect that higher-mass polyelectrolytes would be more prone to problems with formation of large agglomerate structures, leading to nonuniformity of the resulting films. Surprisingly, Fares and Schlenoff (2017b) found no dependency on molecular weight with respect to the diffusion of polyelectrolytes within PECs. By contrast, Chi et al. (2020) observed that larger molecular mass of starch-based PEC components led to stiff and entangled structures and a densely packed film structure with favorable barrier properties.

\section{Solubility of the permeant in the barrier phase}

It has been proposed that a low solubility between the permeant and the material composing the film layer can be a major contributor to barrier performance (Lagarón et al. 2004). This expectation is borne out in the great effectiveness of polyolefin films, e.g. polyethylene (Doong et al. 1995), in resisting water and water vapor (Dury-Brun et al. 2007). The polyethylene is non-polar and lacking in hydrogen bonding ability, thus offering very low solubility to water. To a large extent, the relative solubilities of various low-mass substances can be predicted based on the polarizabilities of electrons, by the content of polar groups, and by hydrogen bonding capability (Hansen 2004). These concepts appear to have been applied only to a limited extent with respect to the barrier properties of PEC films (Doong et al. 1995; Basu et al. 2017).

\section{Stoichiometry within the PEC}

There is reason to expect that barrier performance of PEC films will be favored by 1:1 stoichiometry of interactions among the polyelectrolyte ionic groups. Un-matched ions that remain in a PEC film can be expected to encourage adsorption of water molecules, which likely would lead to swelling and consequent greater permeability to all low-mass substances. In support of this concept, Lv et al. (2018) were able to "tune" the swelling ratio of hydrogels by adjusting the mass ratio of carboxymethylchitosan and alginate.

An inherent flaw in the proposition being considered is the fact that the selfassembly process tends to favor formation of PEC domains with 1:1 matching or ionic charges on the polymer chains, with any excess of charged groups either acting as a stabilizing layer (Chen et al. 2003) or remaining in the adjacent solution phase (Michaels et al. 1965; Dautzenberg et al. 1996). Depending on the details of procedures, a chargestabilizing layer may be expected to play an essential role in the assembly of a PEC film. In light of such complications, it is perhaps not surprising that the present review of the literature did not find any clear evidence regarding whether or not the charge-stoichiometry within a PEC film is correlated with barrier performance.

\section{Polyelectrolytes with Different Types of lonic Groups}

As was noted earlier, certain pairs of positive and negative ions bound to polyelectrolytes are known to interact with each other more strongly than some others 
(Sukhishvili et al. 2006). Relatively strong ionic bonds are expected when primary amine groups interact with either sulfite or sulfate groups, whereas weaker bonds are formed when quaternary ammonium groups interact with carboxylate groups. There has been no published work in which such differences were rigorously studied in relation to barrier performance. As illustrated in Fig. 17, the protonated primary amine group (left top) is physically much smaller than the trimethylalkyl amine group (right top). Thus, the center of charge of the primary amine group is able to approach much closer to an adjacent negative ion. The strong ability of the sulfate ion to engage in ionic bonds is possibly due to the strong electronegativity of the oxygen atom, which causes the negative charge to be expressed on the external part of the ionic group.
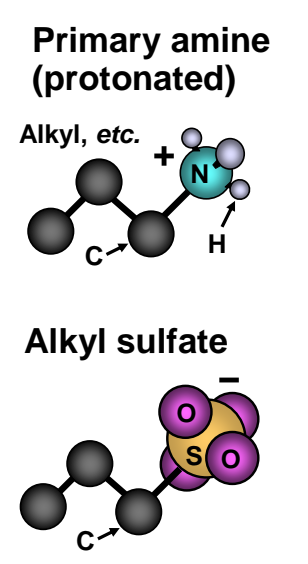

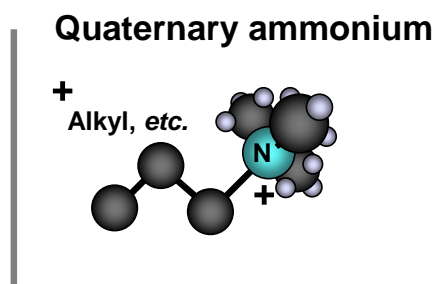

Alkyl carboxylate

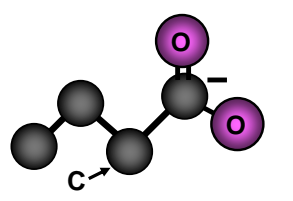

Fig. 17. Ionic groups having differing ability to form high-energy ion pairs. Left: Ionic groups of organic compounds providing stronger ion pairs; Right: lonic groups of organic compounds providing weaker ion pairs

\section{Structural Fitting between the Polyelectrolytes}

Different polyelectrolytes can have widely different structures, some of which would appear to preclude efficient pairing with certain oppositely charged polyelectrolytes, especially if one assumes that a ladder structure must be involved. For example, Fig. 18 considers the case of interaction between a stiff polyelectrolyte chain and another polyelectrolyte of opposite charge having a different spacing of ionic groups.

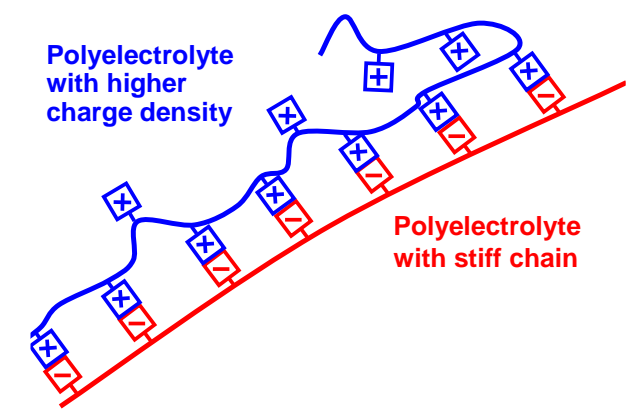

Fig. 18. Illustration explaining how there can be incompatibility in the spacing of ionic groups of two polyelectrolytes, resulting in incomplete pairing, especially if at least one of the chains is stiff 
Such contrasts in the spacing of ionic groups have been predicted to affect the nature of resulting PECs (Lytle et al. 2019). The cited work developed this concept based on a simple model based on placing hypothetical beads - some representing positive or negative sites - along straight strings lying parallel to each other in two dimensions. The model appears to imply that, by careful pre-arrangement of such beads, highly contrasting behavior can be achieved, even in two dimensions. If such a mechanism remains valid for real materials in three-dimensional space, it follows that complex charged polymers, such as proteins, can be pre-programmed with a propensity to form complex structures that allow them to display contrasting characteristics, even including such things as enzymatic abilities. In that context, one can appreciate that there might be potential to design sets of positively and negatively charged polyelectrolytes having an inherent ability to selfassemble themselves into effective barrier layers. However, when one is considering threedimensional space, multiple macromolecular conformations, and many different possible distributions of ionic groups, the results of self-assembly may be very difficult to predict.

When considering strategies that might be more likely to achieve success in the medium term, one can take simple steps such as choosing polyelectrolytes having different stiffness of their chains. Molecular dynamics simulations showed that PECs formed from polyelectrolytes having highly flexible chains tended to form scrambled egg-type PECs, whereas stiffer chains favored ladder-type PECs (Lazutin et al. 2012). Since there does not appear to have been any focused work attempting to connect polyelectrolyte chain stiffness to barrier properties, this can be regarded as a needed area of future research.

\section{Cross-links and Barrier Properties}

The establishment of cross-links within a barrier film can be regarded as a way to restrict the motion of polymer segments, thereby possibly decreasing the diffusion rates of low-mass substances through the films. By analogy to hydrogel preparation, covalent crosslinks can be expected to permanently insolubilize polyelectrolyte material and restrict its ability to swell when wetted (Wang et al. 2009; Hubbe et al. 2013). Ben Dhieb et al. (2019) found that crosslinking of a barrier film comprised of polyvinyl alcohol and nanoclay, using either glyoxal or glutaraldehyde, increased the resistance to oxygen permeation under high humidity conditions. Yang et al. (2012) reported that crosslinking with either glutaraldehyde, 1-[3-(dimethylamino)propyl]-3-ethylcarbodiimide methiodide (EDC), or thermal crosslinking decreased oxygen permeation through a PEC film with PEI and poly(acrylic acid). In addition, the water vapor transmission was reduced following thermal crosslinking. Lazar et al. (2019) reported that free-radical crosslinking of a PEC film including chitosan and poly(acrylic acid) achieved a large reduction of oxygen transmission when evaluated at $90 \%$ relative humidity.

When multivalent ions are added to a solution of anionic polyelectrolyte, two kinds of results can be obtained, depending on the concentration of polyelectrolyte (Ermoshkin and de la Cruz 2003). In a favorable range of concentration, the cited authors proposed that the mixing would result in a gel-like structure, encompassing all of the material in one phase. Under dilute conditions, the mixture is expected to separate, resulting in precipitation of complexed material.

The addition of divalent metal cations to a film that contains carboxylate groups can be regarded as a form of crosslinking. Rhim and Lee (2004) found that treatment of soy protein films with calcium chloride solution decreased water vapor permeability and swelling. Surprisingly, however, only a small decrease in water vapor permeability was found when sodium alginate films were similarly immersed in calcium chloride solution. 
More promising results were obtained by Shimizu et al. (2016), who prepared films by drying suspensions of oxidized nanofibrillated cellulose (NFC). Extremely low values of oxygen permeability were obtained after such films had been exposed to either calcium chloride or aluminum chloride solutions. In the latter examples, one can envision the highly anionic nanocellulose playing the role of an anionic polyelectrolyte. Sirviö et al. (2014) achieved related results by treating NFC with calcium ions. The ionically crosslinked NFC films showed very strong resistance to turpentine. The treatment also decreased the water vapor permeability.

\section{Plasticizers and Barrier Properties}

In light of the role of plasticizers in allowing greater mobility of polymer segments within a film, it is reasonable to expect the presence of plasticizers to have a negative effect on PEC film barrier properties. Plasticizers also tend to decrease the cohesive energy density, thereby favoring permeation (Lagarón et al. 2004). On the other hand, certain films may be so brittle that they have no practical use in the absence of plasticizers (Rhim and Lee 2004). Figure 19 illustrates a concept in which the plasticizer compounds in a PEC film can promote the permeability of the film in two ways. First, the plasticizer may allow for greater mobility of polymer segments, making it more likely that permeant molecules will be able to find an opportunity to squeeze through. Second, the permeant molecules may find a path of least resistance by passing through the plasticizer-rich domains of the film. Diffusion may be favored in such domains due to the absence of ionic bonding and possibly due to a lower molecular mass and/or higher solubility of the diffusing substance.

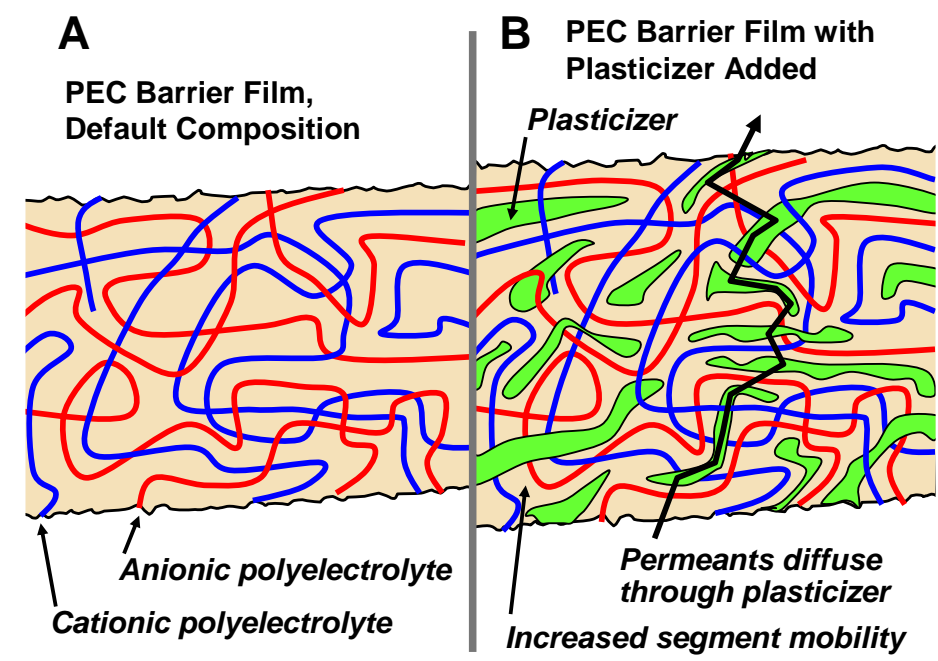

Fig. 19. Pictorial description of a PEC film formed in the $(A)$ absence or $(B)$ presence of a plasticizer

When a PEC film is exposed to aqueous solution or high humidity, the water molecules can function as plasticizing agents (Lysaght 1976). Farhat et al. (1999) and Mende et al. (2002) estimated that typical polyelectrolyte multilayers contain about 10 to $20 \%$ moisture under ambient conditions. 
The plasticizing role of water is evident from a change in the properties of dry PEC films from brittle nature to a rubbery state upon treatment with water (Feng et al. 2006; Meka et al. 2017). Meanwhile, the oxygen barrier performance degrades with increasing moisture content in the case of typical PECs (Holder et al. 2012; Lazar et al. 2019).

Nonionic substances such as polyethylene glycol (PEG or PEO) and glycerol are often considered to control the brittle nature of biopolymer films. Schnell et al. (2017) obtained moderate resistance against oxygen permeation when $10 \%$ of glycerol was present in PEC films comprised of xylan and chitosan. Likewise, Machado et al. (2020) had 40\% glycerol present in PEC films comprised of pectin and chitosan. Good resistance to water vapor and oxygen were obtained. Cho et al. (2015) demonstrated promising barrier performance of multilayer films prepared by successive layering with PEI, PAA, PEO, and PAA. In such "quad-layer" construction, the non-ionic polymer essentially takes the place of one of the cationic polymer layers. Such structures were highly effective barriers to oxygen diffusion. Thus, despite the expectation that plasticizers are likely to hurt barrier properties, they still need to be considered as important potential components in PEC barrier films.

Although brittleness is an important issue with respect to various potential applications of PECs, it needs to be emphasized that brittleness is a common feature of a wide range of polymers. For example, starch films show brittle behavior (Ghanbarzadeh et al. 2011). In comparison, PEC films prepared from starch derivatives have been reported to have a suitable range of properties (Chi et al. 2020). An important topic for future research will be to determine whether the generally non-crystalline nature of PECs can be advantageous with respect to avoiding high levels of brittleness under various conditions of usage.

\section{Salinity and Barrier Properties}

Effects of salt were considered earlier in the context of preparing or bringing about self-healing PEC films. In general, the presence of salts tends to weaken the ionic bonding (Dautzenberg 1997; Fu et al. 2017), which is generally unfavorable for achieving strong resistance to permeation. On the other hand, a small amount of salt has been found to provide a substantial decrease in aggregation within PEC films (Dautzenberg 1997), and that is likely to favorably affect barrier performance. Findenig et al. (2012) found that barrier performance of PECs formed from PEI and 2-hydroxy-3-trimethylammonium propyl chloride starch, together with nanoclay, were improved after treatment with water. Such effects will be considered in more detail in a later subsection dealing with platy minerals. In summary, though there is a general expectation that exposure to salinity is likely to be harmful for PEC barrier properties, the present review of the literature did not find specific evidence to support such an expectation.

Figure 20 presents a sequence of steps that might be considered as a strategy to improve the uniformity of an existing PEC, based on the cited research.

The first frame shows a PEC having areas that are lacking in the amount of polymeric material. The central part suggests a loosening of ion parts in the presence of salt (as indicated by a light purple background). The right-hand part envisions the final situation after a final rinsing of the film with water, to remove the salt ions and re-establish the ion pairs within the PEC film. 


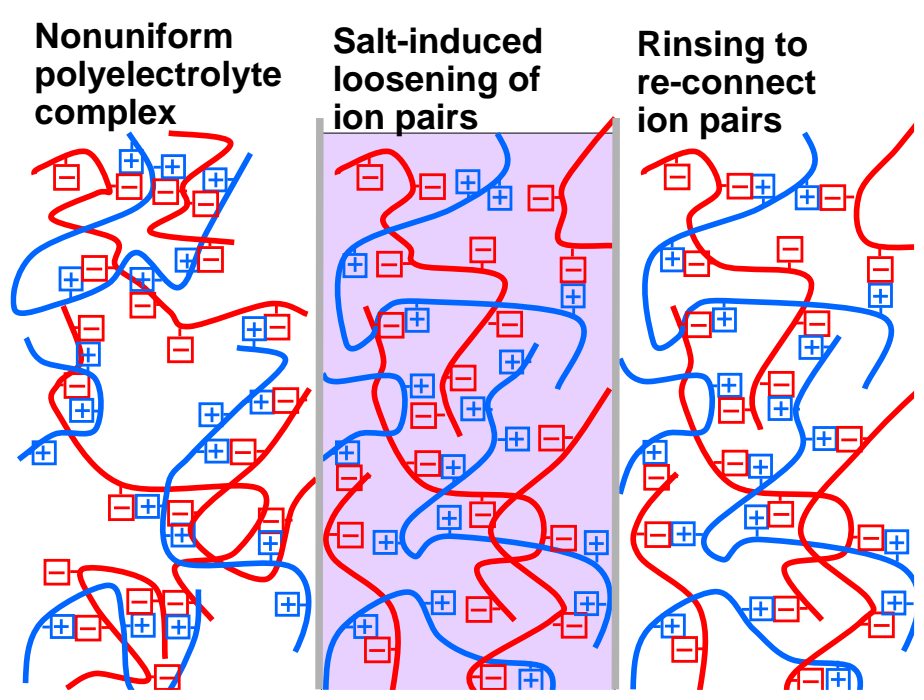

Fig. 20. Concept of a strategy to improve the uniformity of density within an existing PEC film by immersing it in a salt solution to loosen the ion pairs, allowing the polymer segments to diffuse to other positions, then re-establishing the ion pairs in the PEC by rinsing away the salt ions

\section{Hydrogen Bonding Contribution}

When barrier films are prepared by the drying of nanocellulose, it is clear that the resulting barrier properties are highly dependent on a dense pattern of hydrogen bonding between and within the cellulosic phases (Aulin et al. 2013; Hubbe et al. 2017; Lindström and Österberg 2020). A combination of ionic bonding and hydrogen bonding results when such films are treated with divalent metal ions (Li et al. 2019b). The cited authors found that such treatment increased the physical strength of the NFC films; however there were no tests of barrier performance. Feng et al. (2006) proposed that both ionic bonding and hydrogen bonding were working in concert in PEC films comprised of poly(vinylamineco-vinylformamide) and carboxymethyl cellulose (CMC), prepared in an aqueous solution of formic acid. McKee et al. (2014) enhanced the bonding of cellulose nanocrystal (CNC) films by derivatizing the $\mathrm{CNC}$ with 2-ureido- $4[1 \mathrm{H}]$-pyrimidone (UPy) pendant groups. The resulting films were described as being bonded by both ionic bonds and hydrogen bonds. Cho et al. (2015) credited the presence of hydrogen bonding to explain the favorable performance of multi-component films that contained poly(ethylene oxide) (PEO). Since PEO is non-ionic, the authors attributed its contribution to film performance to hydrogen bonding. Though this seems a reasonable assumption, there was no detailed accounting of the hydrogen bonding contribution, nor any spectroscopic evidence presented. The work cited in this paragraph suggests that hydrogen bonds formed during the drying of cellulosic materials or related polymers clearly can be important for achieving barrier performance against oxygen. Such effects can be shown by PEC films that contain such materials.

\section{Contributions of Hydrophobic Effect to PEC Barrier Properties}

The hydrophobic effect was mentioned earlier when discussing self-healing. The idea is that associations among pendant hydrophobic groups may contribute, in a reversible way, to cohesion within a film. Kotov (1999) considered the thermodynamics related to hydrophobic interactions within a PEC. It was noted that such associations may tend to exclude water molecules, which are sometimes a negative factor with respect to achieving a dense film with immobilized polymer segments. Kotov (1999) estimated that the 
hydrophobic effect might contribute to cohesive energy in the range of 7.5 or $60 \mathrm{~kJ} / \mathrm{mol}$ based on a chain of poly-(diallyldimethylammonium chloride). Figure 21 conceptualizes how hydrophobic association within an aqueous system might work within a PEC system where such pendant groups are present. In the figure, the purple lines represent chains of polyelectrolytes, and the green zig-zags represent long-chain alkyl groups or other hydrophobic groups. During the first instants after placing such materials in solution, one can expect formation of micelles in which hydrophobic groups are clustered together, in a reversible process. Though, for simplicity, the figure represents the hydrophobic groups as being absolutely straight, in reality such groups are flexible, and some may contain double bonds, etc., which entail kinks in such chains.

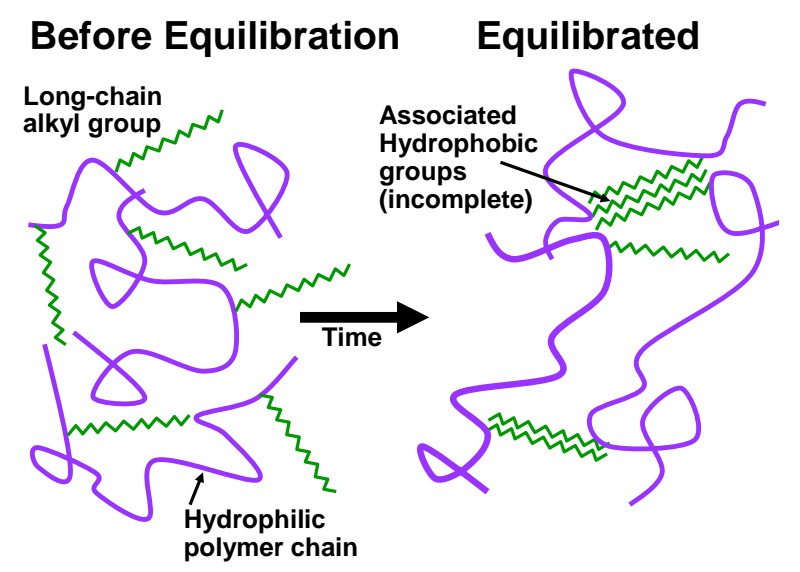

Fig. 21. Illustration of the way in which hydrophobic association among pendant hydrophobic groups might contribute to the structure and properties of PEC films

The best example showing an apparent contribution of hydrophobic associations to barrier performance appears to be that of Stevens et al. (2014). Pyrene side groups were used to modify poly(ethyleneimine), which was used sequentially with poly(acrylic acid) and montmorillonite clay. The resulting PEC barrier films showed excellent resistance to oxygen transmission, in addition to the self-healing effects that were discussed earlier.

\section{Layer Attributes}

The layer-by-layer (LbL) approach to preparing PEC films, as discussed earlier, clearly has the potential to produce a layered film structure. Such a structure can remain detectable even after building up large numbers of layers (Decher et al. 1992, 1994; Caruso et al. 1999; Ladam et al. 2000; Klitzing and Steitz 2002; Ben Dhieb et al. 2019). A question can be asked, however, whether the persistence of distinguishable layers within a PEC film makes a significant difference with respect to barrier properties. The inventor of the LbL approach (Decher 1997) described the layers as being "fuzzy," due to a tendency of polyelectrolytes within successive layers to inter-mingle. Arys et al. (2001) described a process in which each step in an LbL assembly process involves a sequence of adsorption of oppositely charge polyelectrolyte, a blurring step in which that polyelectrolyte diffuses into the previous layer, and a surface-constrained complexation. It is generally believed that the electrostatic effects tend to be short in range, such that any electrical charge on the underlying material will play no further role after application of a couple of layers of polyelectrolyte (Radeva et al. 2001). 
The concept of relative fuzziness of PEC layers in an LbL film is illustrated in Fig. 22. Part A shows a hypothetical example that is drawn with minimum interpenetration, such that layered nature remains obvious in this type of depiction. Part B shows that the inherent layered nature can become obscured when each layer penetrates by about $50 \%$ into the adjacent layers. A structure with substantial overlap, as represented by Part B, is expected to be more likely, since it allows more efficient ion pairing throughout the structure.

If layered structures were very important for purposes of achieving barrier performance, then one ought to expect to find large differences when comparing LbL and direct mixing methods for preparation of PEC barrier films. Ankerfors et al. (2009) made such a comparison for two different chemical combinations, but no barrier properties were evaluated. Rather, the two systems of PECs gave about the same contribution to adhesion, which was the focus of the work. Thus, the present literature search did not find any direct analysis of whether or not there is a relationship between a layered nature of the PEC film and barrier properties.

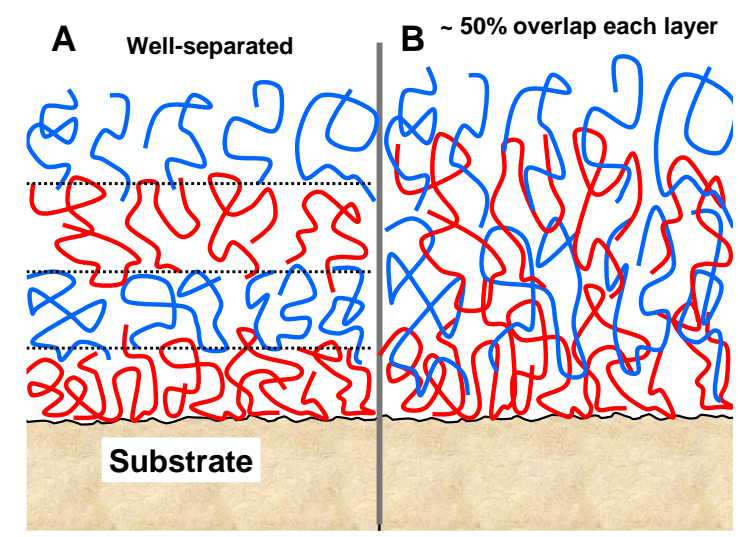

Fig. 22. Different degrees of fuzziness of PEC layers in a multilayer film. A: Well-separated layers with a minimum of inter-diffusion; B: The same polyelectrolyte chains, but each shown with about $50 \%$ of inter-penetration of the adjacent layers

\section{Fillers and Barrier Performance}

Nanocellulose

It is well known that the properties of some film materials can be improved for various applications by formulating them with well-selected particles, i.e. by preparing some kind of composite or nanocomposite. Because nanocellulose films, when dry, can provide superior resistance to the passage of oxygen (Lindström and Österberg 2020), and due to their polar nature, nanocellulose may seem like an ideal choice of filler to enhance the barrier properties of PEC-based films. As discussed in the review article by Klemm et al. (2018), one of the main classes of nanocellulose is cellulose nanocrystals (CNC). The lengths of CNC particles are often about 50 to $300 \mathrm{~nm}$, and the widths are often about 4 to $10 \mathrm{~nm}$. When incorporated into PEC-based films, such nanoparticles have the potential to provide reinforcement. Some researchers have reported improved water vapor barrier properties when CNC particles were incorporated into PEC-type films (Chi and Catchmark 2018a,b). Resistance to water vapor was also reported by Satam et al. (2018), who formed PECs with anionic CNC and cationic chitosan nanofibers. In some other work, only minor effects of CNC on barrier properties of PEC films were observed (Halasz et al. 2015). 
Nanofibrillated cellulose (NFC) is generally at least an order of magnitude longer than CNC and somewhat thicker, and the material also can have a branched or network structure (Klemm et al. 2018). Partly due to its content of non-crystalline regions, and partly due to its great length to width ratio, NFC material can be envisioned as highly flexible in aqueous suspension. High gas barrier performance has been achieved with formulations including NFC and oppositely charged polyelectrolyte (Aulin et al. 2013; Molgaard et al. 2014). Sirviö et al. (2014) achieved a type of PEC with very high grease resistance by first preparing a NFC film with sodium alginate; after drying, the films were crosslinked by exposing them to calcium chloride. In addition to these examples, NFC appears to work very well in combination with highly platy mineral products, which will be discussed next (Qin et al. 2019a). Figure 23 depicts a hypothetical PEC film that has been reinforced with a combination of CNC and NFC. The figure is drawn to suggest the possibility that the reinforcing particles can contribute to holding the film together, especially if the distribution is quite uniform. Note that sometimes, especially in LbL-type films, the nanocellulose may be used in place of an anionic polyelectrolyte layer (Aulin et al. 2013; Li et al. 2013; Halasz et al. 2015; Li et al. 2019b).

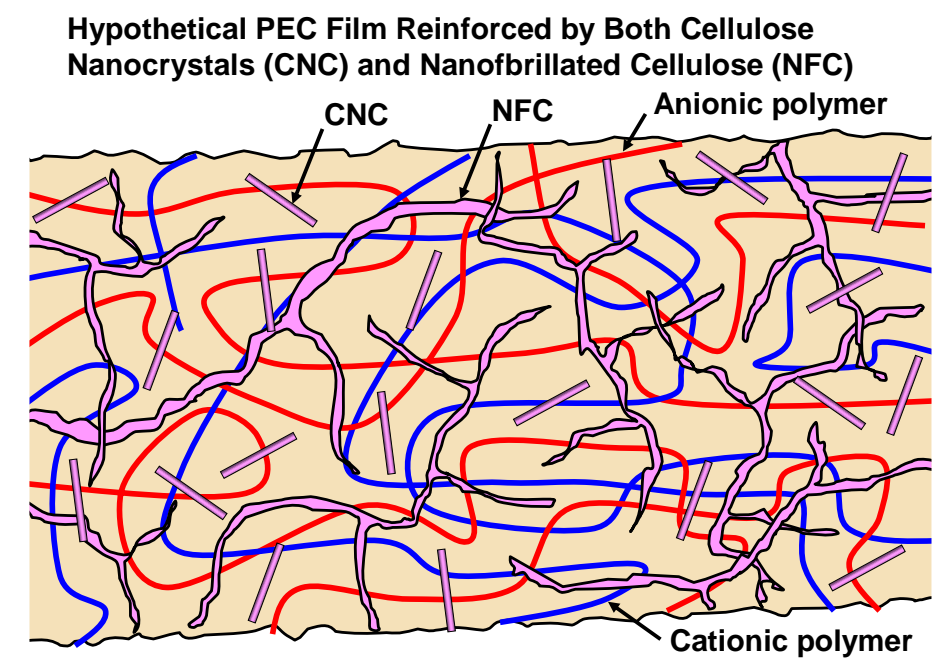

Fig. 23. Illustration of a hypothetical PEC film that has been prepared with both CNC (rodshaped) and NFC (long and irregular) nanocellulose

\section{Platy minerals}

Some of the most promising barrier properties of PEC-based films have involved systems that included highly platy minerals such as sodium montmorillonite (nanoclay). As shown by results listed in Table A, such systems have been reported to have some of the lowest rates of transmission of oxygen and water vapor. Table 1 shows a subset of general findings, limited to PEC-based films that contained sodium montmorillonite. A notable feature of some of these reports is the fact that high resistance to oxygen and other gas transmission was achieved even at high levels of relative humidity (Holder et al. 2012; Song et al. 2016; Wang et al. 2018). In fact, the study by Dou et al. (2014) employed high humidity conditions in a step aimed at improving the barrier performance. Another highly platy material that has been receiving increasing attention for PEC-based barrier layers is graphene. Studies involving such films are listed in Table 2. 
Table 1. Studies of Polyelectrolyte Barrier Films Incorporating Highly Platy Mineral Particles

\begin{tabular}{|c|c|c|c|}
\hline $\begin{array}{l}\text { Mineral } \\
\text { Type }\end{array}$ & Polymers & Effects on barrier properties & Citation \\
\hline Kaolin & PEI \& PAA & OTR reduced. & Chiang et al. 2020 \\
\hline HT & PSS & OTR reduced. & Dou et al. 2014 \\
\hline MMT & PEI or HPMAS & WVTR reduced, especially at high salt. & Findenig et al. 2012 \\
\hline MMT & PAA \& PEI & OTR reduced. & Hagen et al. $2014 \mathrm{a}$ \\
\hline MMT & PEI & OTR reduced. & Hagen et al. $2014 \mathrm{~b}$ \\
\hline MMT & PAA \& PEI & OTR reduced. & Hagen et al. 2016 \\
\hline MMT & PVP & OTR reduced even at high humidity & Holder et al. 2012 \\
\hline MMT & PEl & Durability and scratch resistance & Humood et al. 2016 \\
\hline MMT & cPAM & OTR reduced. & Jang et al. 2008 \\
\hline $\mathrm{NHA}$ & CS \& CMC & WVTR reduced. & Jiang et al. 2009 \\
\hline MMT & CS \& CR & OTR reduced. & Laufer et al. 2013a \\
\hline MMT & CS \& PAA & OTR reduced. & Laufer et al. 2013b \\
\hline MMT & CS \& wax & OTR reduced, WVTR reduced. & Li et al. 2019a \\
\hline MMT & PEI & OTR reduced to very low values. & Priolo et al. 2010a \\
\hline MMT & PEI \& PAA & OTR reduced (with NFC). & Priolo et al. 2010b \\
\hline MMT & PAAm \& PAA & OTR reduced. & Priolo et al. 2013 \\
\hline VMT & Cat. CNF & OTR reduced. & Qin et al. 2019a \\
\hline MMT & PEI & OTR \& $\mathrm{CO}_{2}$ transmission reduced. & Soltani et al. 2017 \\
\hline VMT & PEI \& PAA & OTR reduced even at high humidity. & Song et al. 2016 \\
\hline MMT & PEI \& PAA & OTR reduced. & Tzeng et al. 2014 \\
\hline HT & CMC & $\mathrm{CO}_{2}, \mathrm{~N}_{2}, \mathrm{CH}_{4}$ vapor transmissions reduced. & Wang et al. 2018 \\
\hline
\end{tabular}

Key: Minerals: $\mathrm{HAP}=$ hydroxyapatite; $\mathrm{HT}=$ hydrotalcite; $\mathrm{MMT}=$ montmorillonite; $\mathrm{VMT}=$ vermiculite; Cationic polymers: $\mathrm{CS}=$ chitosan; HPMAS = 2-hydroxy-3-trimethyl-ammonium propyl chloride starch; PAAm = poly(allylamine); $\mathrm{PEI}=$ polyethyleneimine; $\mathrm{PVP}=$ poly(vinylpyrrolidone); Anionic polymers: $\mathrm{CMC}=$ carboxymethyl cellulose; $\mathrm{CR}=$ carrageenan; PAA = poly(acrylic acid); PSS = poly(sodium styrene-4-sulfonate); Barrier properties: OTR = oxygen transmission rate; WVTR = water vapor transmission rate

Table 2. Studies of Polyelectrolyte Barrier Films Incorporating Graphene

\begin{tabular}{|l|l|l|l|}
\hline $\begin{array}{l}\text { Particle } \\
\text { Type }\end{array}$ & Polymers & Effects on barrier properties & Citation \\
\hline GNP & PAA & OTR reduced. & Gokhale et al. 2013 \\
\hline GNP & PVOH & OTR reduced. & Mun et al. 2017 \\
\hline GO & PU+ \& PU- & OTR reduced. & Noh et al. 2018 \\
\hline GO & PEl & OTR \& $\mathrm{CO}_{2}$ transmission reduced. & Yang et al. 2013 \\
\hline GO & PEl & OTR reduced. & Yu et al. 2012 \\
\hline
\end{tabular}

Key: Particles: $G N P=$ graphene nanoplatelets; $G O=$ graphene oxide; Polymers: $P A A=$ poly(acrylic acid); $\mathrm{PEI}=$ poly (ethyleneimine); $\mathrm{PU}+=$ polyurethane with positive charge; $\mathrm{PU}$ - = polyurethane with negative charge $; \mathrm{PVOH}=$ poly (vinyl alcohol)

Figure 24 illustrates a concept presented by Stevens et al. (2014), who employed a system called "nanobrick wall multilayer". The cited authors reported the lowest oxygen permeability when constructing "quad-layers" of the type illustrated in the figure. In the LbL assembly of these films, the negatively charged nanoclay was preceded and followed each time by layers of the highly cationic, branched polymer poly(ethylene imine) (PEI). However, the negatively charged layers alternated between the nanoclay and poly(acrylic acid) (PAA). One can envision such a construction as providing "mortar" to hold the nanoclay "bricks". The nanoclay, due to its shape, orientation, and impermeable nature, is 
an excellent component of a barrier film. However, it appears that PECs can serve as an excellent mortar for such barriers due to the good barrier properties of the PECs themselves.

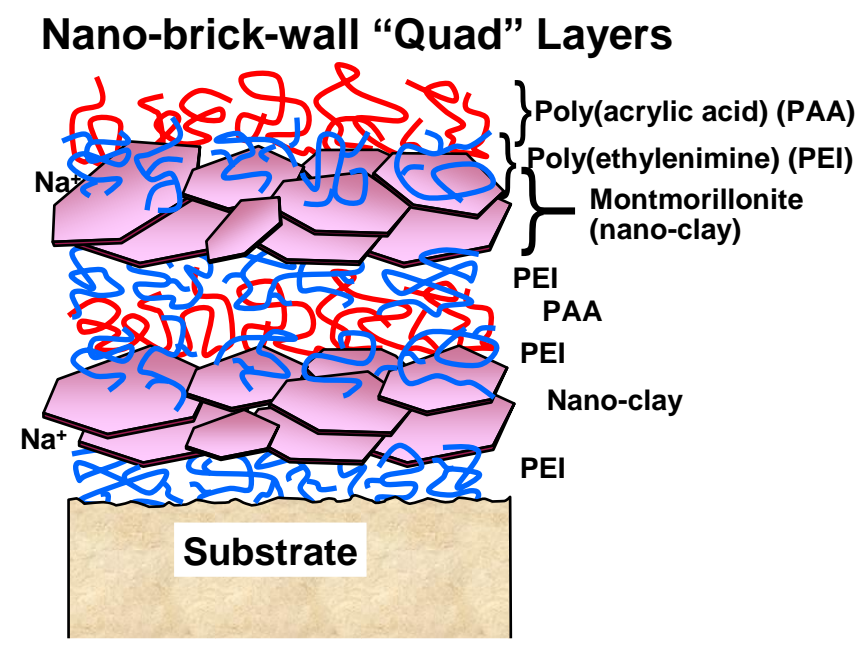

Fig. 24. The "quad"-layer structure benefits from the principle of tortuosity, by which diffusing molecules are forced to take a longer path, thus decreasing the overall rate of diffusion through a material

\section{Tortuosity issues}

To start to explain the strong gas barrier effects that have been achieved with platy minerals or graphene to PEC-based films, one needs to consider the paths that gas molecules need to take when diffusing through a barrier film (Zid et al. 2018). As shown in Fig. 25, if the film contains platy particles, then the required distance of diffusion can be considerably increased, especially if the platy particles have a high aspect ratio and a favorable concentration. In theory, the time required for a molecule to diffuse all the way through a film ought to be proportional to that distance (Belbekhouche et al. 2011; Ghanbarian et al. 2013; Tan and Thomas 2017). Various researchers have mentioned tortuosity as a means to explain superior barrier performance of PEC films that contained platy minerals or graphene, often as layers in a multi-layer structure (Gokhale et al. 2013; Min et al. 2017; Wang et al. 2018).

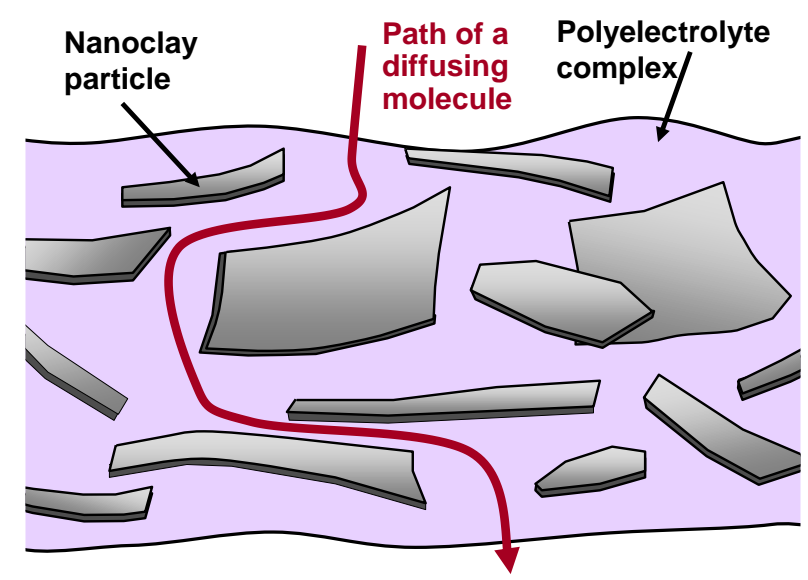

Fig. 25. Schematic for diffusion of a gas molecule through a film with or without the presence of platy impervious particles (figure adapted from a version used earlier by the author) 
In principle, the effectiveness of an impermeable filler material to resist diffusion through a film will be determined by is shape (ideally platy), aspect ratio (e.g. width over thickness of a plate), orientation, and uniformity of distribution within the film (Tan and Thomas 2017). Several groups of researchers have described the nanoclay within their PEC-based barrier layers has being "oriented", thereby providing more efficient blocking of oxygen or water vapor (Priolo et al. 2010a; Holder et al. 2012; Hagen et al. 2014a,b; Tzeng et al. 2014; Wang et al. 2018; Ben Dhieb et al. 2019a). It should be noted, however, that due to the tiny size of the mineral or graphene particles, such reports are very difficult to verify by microscopy. Accordingly, there is a continuing need for new methods and research to better characterize relationships between barrier properties and orientation of particles within a composite film.

\section{Defects}

A key uncertainty, when considering theories related to diffusion and tortuosity, is whether the barrier film being considered is indeed free from significant defects such as cracks and pores. Published articles in which barrier properties were evaluated are generally silent on the issue of whether such defects were present. The issue is challenging because sometimes the best way to detect such defects may be the leakage of oxygen or other substance through the film. Then it becomes really hard to know whether such transport was due to leakage or just due to diffusion through the film in general.

One approach to demonstrating the role of defects with respect to barrier properties is to take steps to plug up the defects. Such an approach was used, for instance, by Spence et al. (2011) to enhance the barrier properties of nanocellulose films. Those authors showed that a layer of beeswax greatly increased resistance to transmission of water vapor through NFC-type films. Because wax by itself is not a particularly good barrier film (Hagenmaier and Shaw 1992; Donhowe and Fennema 1993), the results suggest a plugging mechanism, in which wax is able to plug cracks or pores. Li et al. (2019a) showed reductions in water vapor passage through PEC films comprised of chitosan and montmorillonite following their treatment with carnauba wax.

\section{Other Layers in Combination with PECs}

When problems in the performance of barrier layers are due to defects such as cracks, another reasonable way to approach the problem is to rely upon a support layer, which ideally may prevent cracks from forming. For example, it is known that very high resistance to moisture can be achieved by deposition of thin SiOx films, but such films easily form cracks (Qin et al. 2019b). The cited authors showed that the problem could be solved by pairing the $\mathrm{SiOx}$ film with a PEC multilayer film. The combination of layers overcame the brittleness of the SiOx moisture barrier and also helped protect the PEC multilayer from moisture. PEC-based films also can be combined with bioplastic films, such as poly(lactic acid), which likewise provides moisture protection (Aulin et al. 2013; Laufer et al. 2013a,b; Halasz et al. 2015; Satam et al. 2018). Such a system is illustrated in Fig. 26.

An important question regarding the structure depicted in Fig. 26 is whether there might be problems related to the ability of water vapor to diffuse through the bioplastic film, thus affecting the oxygen-barrier contribution of the PEC-based layer within the sandwich. 


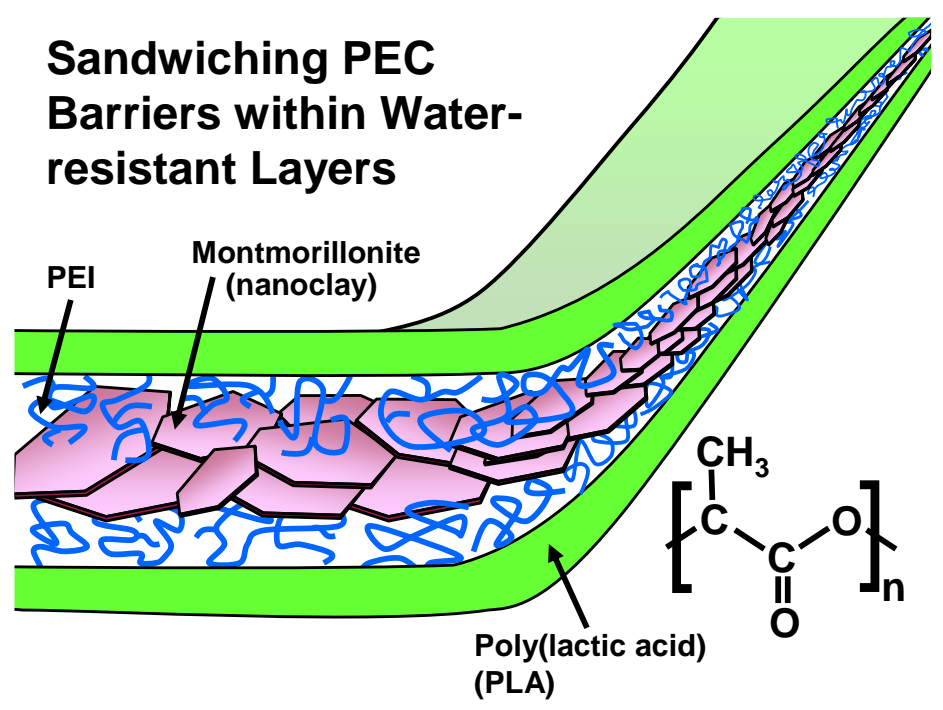

Fig. 26. Sandwich type barrier film in which the PEC film, this time including montmorillonite clay as a component, is protected by upper and lower films of the highly water-resistant bioplastic poly(lactic acid) (PLA)

An effective way to prevent a brittle sheet of paper from developing cracks in the course of folding is to encase that sheet in a close-fitting plastic envelope (Baty et al. 2010). It appears that the layers on each side of the brittle sheet are effective because they increase the minimum radius of bending if the material is creased. A similar approach can be used, in principle, when a brittle barrier layer is supported by other layers. Those layers might, for instance, serve also to protect a brittle layer from moisture.

\section{PATHS FORWARD FOR PEC BARRIER FILMS}

\section{Likely Key Contributions of the PEC Layer}

Based on the published work cited in this article, it is clear that a great deal of progress has been made, at an increasing pace, in understanding and developing effective PEC-based barrier films. It is proposed that important future progress can be achieved by focusing on specific attributes of films that may be desirable in certain applications. For example, there appears to be a demand for research related to the preparation of barrier films under mild conditions, thus allowing direct coating onto perishable objects, such as food. There is an accelerating interest in developing resistance to grease, in response to concerns and regulations about perfluorocarbon grease-proofing agents (Hubbe and Pruszinski 2020). There may be opportunities related to finding ways to achieve better alignment of highly platy mineral particles or graphene flakes within PEC-based barrier layers. In addition, there may be opportunities related to development of more highly stretchable PEC-based films that still retain barrier properties.

\section{PEC Layers Applied Directly to Items}

In several respects, the PEC formation process offers potential advantages for the direct application to fresh foods as a protective layer. To avoid damaging the food, it is possible to carry out the whole process of PEC film deposition, including the drying step, at room temperature. One has the option to employ only food-grade ingredients such as 
chitosan and alginates, etc. (Molgaard et al. 2014). The whole process can be carried out with water as the suspending medium. Meat poses particular challenges due to its propensity to spoil (Kulig et al. 2017). The cited article showed that a PEC film comprising sodium alginate, chitosan, and PEC hydrosols was effective in reducing the rate of spoilage of the meat. Likewise, Younis and Zhao (2019) prepared and evaluated edible PEC films comprised of chitosan and pectin. In such applications, even modest improvements in shelf-life can be beneficial. In principle, a PEC-based film could be applied to a wide variety of sensitive objects of different shapes, with the only requirements being their tolerance to a brief exposure to aqueous solution and a realization that certain hard-to-wet interior pore spaces may remain uncovered.

\section{Pair with Other Layers in Packaging}

Another category of application that seems to hold promise for PEC-type barrier films involves their usage in combination with different layers. Contrasting layers have potential to work together in synergistic ways. Due to the inherent properties of typical PECs, it makes sense to focus on applications where the PEC layer can provide resistance to permeation by greases and oxygen. The PEC-based layer can be paired with other layers having more promise to protect against the effects of water and water vapor (Lagarón et al. 2004). Due to the inherent weakness of typical PEC layers, it also makes sense to pair them with mechanically robust protective layers, which could include nanocellulose-based films.

Some of the most promising PEC-based barrier systems, based on the present review of the literature, are those that involve highly platy mineral products or graphene flakes (Priolo et al. 2010a, 2015; Hagen et al. 2016). Sodium montmorillonite (MMT) particles are generally nontoxic, very highly platy, and endowed with a high density of negative charge, allowing them to serve as the anionic partner in a PEC system. Alternatively, if one wants to pair a negatively charged polyelectrolyte with a positively charged platy material, one can use hydrotalcite (Dou et al. 2014; Lee et al. 2016; Wang et al. 2018). The platy particles in the film structure, especially if they are well aligned and uniformity arranged, can provide a high level of tortuosity, as well as outright blocking of diffusion paths through the film. There appear to be great opportunities to further optimize procedures of PEC film preparation in order to maximize alignment of the impervious mineral or graphene platelets or flakes. The relatively good ability of typical PECs to impede the permeation of oxygen and grease implies that the PEC can serve as an effective "mortar" in the "brick wall" that can be formed with platy mineral particles (Jang et al. 2008; Priolo et al. 2015; Cho et al. 2018; Qin et al. 2019a). In addition, the presence of the minerals has the potential to provide scratch resistance to the PEC films (Humood et al. 2016).

\section{Assessment of the Hypotheses}

Eight hypotheses were proposed at the beginning of this article. The idea was to help focus the discussion and plant the seeds of thinking about important issues. At this point, based on consideration of the published findings, some comments can be made regarding the validity of various hypotheses in the list. These judgments are encapsulated in Table 3. 
Table 3. Judgements about the Hypothesis Statements Based on the Reviewed Literature

\begin{tabular}{|c|c|c|}
\hline Hypothesis Statement & $\begin{array}{l}\text { Judge- } \\
\text { ment }\end{array}$ & Discussion \\
\hline $\begin{array}{l}\text { 1. It is proposed that ionic bonding } \\
\text { within thin films can contribute } \\
\text { substantially to the barrier } \\
\text { performance of thin films prepared } \\
\text { from ionically charged polymers, i.e. } \\
\text { polyelectrolytes and related systems. }\end{array}$ & Yes & $\begin{array}{l}\text { lonic bonds clearly embody sufficient } \\
\text { energy to be able to contribute to effective } \\
\text { resistance to permeation by oxygen and } \\
\text { grease. Thus, PEC-based films can be } \\
\text { regarded as a serious option for preparing } \\
\text { barrier films. }\end{array}$ \\
\hline $\begin{array}{l}\text { 2. It is proposed that it is possible to } \\
\text { achieve a sufficiently contiguous } \\
\text { nanostructure within PECs are } \\
\text { related film structures, as would be } \\
\text { required for very high efficiency of } \\
\text { barrier effects. }\end{array}$ & Yes & $\begin{array}{l}\text { Contiguous, relatively uniform PEC films } \\
\text { can be prepared either by layer-by-layer } \\
\text { (LbL) deposition, by forming the film at very } \\
\text { low pH and then rinsing the film later, or by } \\
\text { exposing a formed PEC film to divalent } \\
\text { metal ions, for instance. }\end{array}$ \\
\hline $\begin{array}{l}\text { 3. It is proposed that the barrier } \\
\text { performance of PEC films can be } \\
\text { improved by incorporation of various } \\
\text { solid fillers or reinforcing particles } \\
\text { during their preparation. }\end{array}$ & Yes & $\begin{array}{l}\text { It is clear from many recent publications that } \\
\text { highly platy particles such as nanoclay can } \\
\text { be very effective to develop resistance to } \\
\text { permeation by oxygen and even by water } \\
\text { vapor. }\end{array}$ \\
\hline $\begin{array}{l}\text { 4. It is proposed that reliance on } \\
\text { ionic bonds is compatible with the } \\
\text { preparation of self-healable barrier } \\
\text { films. }\end{array}$ & Maybe & $\begin{array}{l}\text { Though some self-healing capabilities have } \\
\text { been demonstrated for PEC-based films, } \\
\text { the conditions needed to bring about self- } \\
\text { healing are not the same as the conditions } \\
\text { required to achieve barrier performance. }\end{array}$ \\
\hline $\begin{array}{l}\text { 5. It is proposed that PECs and } \\
\text { related barrier films will tend to be } \\
\text { permeable to various permeants. }\end{array}$ & No & $\begin{array}{l}\text { Although some PECs show permeability, } \\
\text { such characteristics can be avoided by use } \\
\text { of platy particles and layered structures. }\end{array}$ \\
\hline $\begin{array}{l}\text { 6. It is proposed that barrier layer } \\
\text { based on PECs and similar systems } \\
\text { tend to be prone to mechanical } \\
\text { failure. }\end{array}$ & $\begin{array}{l}\text { Yes \& } \\
\text { No }\end{array}$ & $\begin{array}{l}\text { PEC systems that have high cohesive } \\
\text { energy density do tend to be stiff when dry, } \\
\text { so they tend to be prone to cracks. But this } \\
\text { issue will not be a concern for all PECs and } \\
\text { all applications. }\end{array}$ \\
\hline $\begin{array}{l}\text { 7. It is proposed that PECs } \\
\text { essentially become frozen into } \\
\text { structures that are governed by } \\
\text { kinetics, as well as by the flow } \\
\text { conditions during initial mixing and } \\
\text { preparation. }\end{array}$ & Yes & $\begin{array}{l}\text { The irreversible nature of formation of PEC } \\
\text { films, plus the rigid nature of most such } \\
\text { films under dry conditions, implies that non- } \\
\text { uniformity can be expected. }\end{array}$ \\
\hline $\begin{array}{l}\text { 8. It is proposed that PEC-based } \\
\text { films can be described as "fussy". In } \\
\text { other words, it is proposed that } \\
\text { various deviations from ideal } \\
\text { conditions of preparation and } \\
\text { composition will result in unfavorable } \\
\text { barrier performance. }\end{array}$ & $\begin{array}{l}\text { Yes \& } \\
\text { No }\end{array}$ & $\begin{array}{l}\text { Though careful attention to detail is needed } \\
\text { to prepare good PEC-based barrier films, } \\
\text { the technology appears to be quite } \\
\text { forgiving, allowing usage of a wide range of } \\
\text { materials and procedures. }\end{array}$ \\
\hline
\end{tabular}

Some of the most exciting research findings, from the perspective of considering the hypothesis statements, has involved strategies to avoid strong agglomeration of the oppositely charged polyelectrolytes in the course of forming PEC films at high speeds. Though the answer to the second hypothesis listed in Table 3 emphasizes the tried-and-true method of layer-by-layer deposition, such procedures are inherently very slow relative to the needs of typical industrial operations. Thus, it is encouraging to note that progress has 
been made in implementing procedures that are orders of magnitude faster. Such options include high-shear treatment of freshly prepared PEC mixtures, followed by film preparation (Basu et al. 2017), and forming a film with an anionic polymer, then exposing that film to a solution with calcium ions (Sirviö et al. 2014; Shimizu et al. 2016). There also seems to be a lot of potential to apply charge-stabilized PEC colloids onto surfaces (Hubbe 2005), followed by their consolidation using such strategies as treatment with calcium ions or variations in drying procedures (Decher et al. 1994; Gamboa et al. 2010). The simplicity and highly promising results obtained by such methods suggest that additional ways might be found in the coming years to prepare highly effective PEC-based barrier layers at industrial speeds. There will be opportunities to utilize sustainable, biobased polyelectrolytes such as starch derivatives (Chi et al. 2020). In addition, there appear to be many opportunities for researchers to pursue some of the yet-unanswered questions that were noted in the course of this article.

\section{ACKNOWLEDGMENTS}

The work of Martin A. Hubbe is supported by an endowment from the Buckman Foundation for the support of research and teaching related to papermaking technology. The following volunteers provided critical comments and suggested changes based on an earlier draft of this article: Stefano Farris, University of Milan, Department of Food, Environmental, and Nutritional Sciences; Jeffrey M. Catchmark, Penn State University, Department of Agricultural and Biological Engineering (PSU-ABE); Wei-Shu Lin, PSUABE; and Parisa Nazemi, PSU-ABE. Their help is much appreciated.

\section{REFERENCES CITED}

Abdul Khalil, H. P. S.., Saurabh, C. K., Adnan, A. S., Fazita, M. R. N., Syakir, M. I., Davoudpour, Y., Rafatullah, M., Abdullah, C. K., Haafiz, M. K. M., and Dungani, R. (2016). "A review on chitosan-cellulose blends and nanocellulose reinforced chitosan biocomposites: Properties and their applications," Carbohydr. Polym. 150, 216-226. DOI: 10.1016/j.carbpol.2016.05.028

Advincula, R., Aust, E., Meyer, W., and Knoll, W. (1996). "In situ investigation of polymer self-assembly solutions adsorption by surface plasmon spectroscopy," Langmuir 12(15), 3536-3540. DOI: 10.1021/la9601622

Ahmadiannamini, P., Li, X. F., Goyens, W., Meesschaert, B., Vanderlinden, W., De Feyter, S., and Vankelecom, I. F. J. (2012). "Influence of polyanion type and cationic counter ion on the SRNF performance of polyelectrolyte membranes," J. Membrane Sci. 403, 216-226. DOI: 10.1016/j.memsci.2012.02.052

Akkaoui, K., Yang, M., Digby, Z. A., and Schlenoff, J. B. (2020). "Ultraviscosity in entangled polyelectrolyte complexes and coacervates," Macromol. 53(11), 42344246. DOI: 10.1021/acs.macromol.0c00133

Allan, G. G., and Reif, W. M. (1971). "Fiber surface modification. (IX). Stereotopochemistry of ionic bonding in paper," Svensk Papperstidning - Nordisk Cellulosa 54(18), 563-570. 
Allan, G. G., Delgado, E., and Lopez-Dellamary, F. (1993). "New interfiber system for paper involving zwitterions," in Baker, C. F., ed., Products of Papermaking, Trans. $10^{\text {th }}$ Fund. Res. Symp., Pira, Leatherhead, UK, Vol. 2, 1101-1138.

Ankerfors, C., Lingström, R., Wågberg, L., and Ödberg, L. (2009). “A comparison of polyelectrolyte complexes and multilayers: Their adsorption behaviour and use for enhancing tensile strength of paper," Nordic Pulp Paper Res. J. 24(1), 77-86. DOI: 10.3183/npprj-2009-24-01-p077-086

Argüelles-Monal, W., Gárcoga, M., and Peniche-Covas, C. (1990). "Study on the stoichiometric polyelectrolyte complex between chitosan and carboxymethyl cellulose," Polym. Bull. 23(3), 307-313. DOI: 10.1007/BF01032446

Ariga, K., Yamauchi, Y., Mori, T., and Hill, J. P. (2013). "What can be done with the Langmuir-Blodgett method? Recent developments and its critical role in materials science," Advan. Mater. 25(45), 6477-6512. DOI: 10.1002/adma.201302283

Arys, X., Laschewsky, A., and Jonas, A. M. (2001). "Ordered polyelectrolyte 'multilayers'. 1. Mechanisms of growth and structure formation: A comparison with classical fuzzy 'multilayers'," Macromol. 34, 3318-3330. DOI: 10.1021/ma010092s

Askeland, D. R., and Wright, W. J. (2015). The Science of Engineering Materials, $7^{\text {th }}$ Ed., Wright, W. J., CENGATE Learning, Global Engineering, pp. 896.

Aulin, C., Karabulut, E., Tran, A., Wågberg, L., and Lindström, T. (2013). “Transparent nanocellulose multilayer thin films on polylactic acid with tunable gas barrier properties," ACS Appl. Mater. Interfaces 5, 7352-7359. DOI: 10.1021/am401700n

Bajpai, M., Bajpai, S. K., and Jyotishi, P. (2016). "Water absorption and moisture permeation properties of chitosan/poly(acrylamide-co-itaconic acid) IPC films," Int. J. Biol. Macromol. 84, 1-9. DOI: 10.1016/j.ijbiomac.2015.11.088

Basu, S., Plucinski, A., and Catchmark, J. M. (2017). "Sustainable barrier materials based on polysaccharide polyelectrolyte complexes," Green Chem. 19(17), 4080-4092. DOI: $10.1039 / \mathrm{C} 7 \mathrm{GC} 00991 \mathrm{G}$

Baty, J. W., Maitland, C. L., Minter, W., Hubbe, M. A., and Jordan-Mowery, S. K. (2010). "Deacidification for the conservation and preservation of paper-based works: A review," BioResources 5(3), 1955-2023. DOI: 10.15376/biores.5.3.1955-2023

Belbekhouche, S., Bras, J., Siqueira, G., Chappey, C., Lebrun, L., Khelifi, B., Marais, S., and Dufresne, A. (2011). "Water sorption behavior and gas barrier properties of cellulose whiskers and microfibrils films," Carbohyd. Polym. 83, 1740-1748. DOI: 10.1016/j.carbpol.2010.10.036

Ben Dhieb, F., Dil, E. J., Tabatabaei, S. H., Mighri, F., and Ajji, A. (2019a). "Effect of nanoclay orientation on oxygen barrier properties of $\mathrm{LbL}$ nanocomposite coated films," RSC Advan. 9(3), 1632-1641. DOI: 10.1039/c8ra09522a

Ben Dhieb, F., Tabatabaei, S. H., Mighri, F., and Ajji, A. (2019b). "Comparison of crosslinking efficiency in dip and roll-deposited coatings on their oxygen barrier," ACS Omega 4(14), 15772-15779. DOI: 10.1021/acsomega.9b00950

Blasing, M., and Amelung, W. (2018). "Plastics in soil: Analytical methods and possible sources," Sci. Total Environ. 612, 422-435. DOI: 10.1016/j.scitotenv.2017.08.086

Bungenberg de Jong, H. G., and Kruyt, H. R. (1929). "Coacervation (partial miscibility in colloidal systems)," Proceedings Koninklijke Nederlandse Akademie van Wetenschappen 32, 849-856.

Carr, M. E., Hofreiter, B. T., Hamerstrand, G. E., and Russell, C. R. (1974). "Interpolymer from starch xanthate and polyamide-polyamine-epichlorohydrin resin in linerboard and newsprint," TAPPI 57(10), 127-129. 
Caruso, F., Lightenfeld, H., Donath, E., and Mühwald, H. (1999). "Investigation of electrostatic interactions in polyelectrolyte multilayer films: Binding of anionic fluorescent probes in layers assembled onto colloids," Macromol. 32(7), 2317-2328. DOI: $10.1021 / \mathrm{ma} 980674 \mathrm{i}$

Chen, J., Heitmann, J. A., and Hubbe, M. A. (2003). "Dependency of polyelectrolyte complex stoichiometry on the order of addition. 1. Effect of salt concentration during streaming current titrations with strong poly-acid and poly-base," Colloids Surf. A 223(1-3), 215-230. DOI: 10.1016/S0927-7757(03)00222-X

Chen, P., Terenzi, C., Furo, I., Berglund, L. A., and Wohlert, J. (2018). "Hydrationdependent dynamical modes in xyloglucan from molecular dynamics simulation of C13 NMR relaxation times and their distributions," Biomacromol. 19(7), 2567-2579. DOI: 10.1021/acs.biomac.8b00191

Chi, K., and Catchmark, J. M. (2018a). "Sustainable development of polysaccharide polyelectrolyte complexes as eco-friendly barrier materials for packaging applications," in: Green Polym. Chem.: New Prod. Proc. Appl., H. N. Cheng, R. A. Gross, and P. B. Smith (eds.), ACS Symp. Ser. 1310, 109-123. DOI: 10.1021/bk2018-1310.ch008

Chi, K., and Catchmark, J. M. (2018b). "Improved eco-friendly barrier materials based on crystalline nanocellulose/chitosan/carboxymethyl cellulose polyelectrolyte complexes," Food Hydrocolloids 80, 195-205. DOI: 10.1016/j.foodhyd.2018.02.003

Chi, K., Wang, H., and Catchmark, J. M. (2020). "Sustainable starch-based barrier coatings for packaging applications," Food Hydrocol. 103: article no 105696. DOI: 10.1016/j.foodhyd.2020.105696

Chiang, H. C., Kolibaba, T. J., Eberle, B., and Grunlan, J. C. (2020). "Super gas barrier of a polyelectrolyte/clay coacervate thin film," Macromol. Rapid Commun., article no. 2000540. DOI: $10.1002 /$ marc. 202000540

Cho, C. W., Lee, S. M., Paik, U., Yoon, S. M., Choi, J. Y., and Lee, H. S. (2008). "Selfassembled single walled carbon nanotubes on multi-layered polyelectrolyte layer," Colloids Surf. A - Physicochem. Eng. Aspects 313, 419-421. DOI:

10.1016/j.colsurfa.2007.04.180

Cho, C., Song, Y. X., Allen, R., Wallace, K. L., and Grunlan, J. C. (2018). "Stretchable electrically conductive and high gas barrier nanocomposites," J. Mater. Chem. C 6(8), 2095-2104. DOI: 10.1039/c7tc05495e

Cho, C. Y., Xiang, F., Wallace, K. L., and Grunlan, J. C. (2015). "Combined ionic and hydrogen bonding in polymer multi layer thin film for high gas barrier and stretchiness," Macromol. 48(16), 5723-5729. DOI: 10.1021/acs.macromol.5b01279

Chremos, A., and Douglas, J. F. (2016). "Counter-ion distribution around flexible polyelectrolytes having different molecular architecture," Soft Matter 12(11), 29322941. DOI: $10.1039 / \mathrm{c} 5 \mathrm{sm} 02873 \mathrm{f}$

Claesson, P. M., Poptoshev, E., Blomberg, E., and Dedinaite, A. (2005). "Polyelectrolytemediated surface interactions," Advan. Colloid Interface Sci. 114, 173-187. DOI: 10.1016/j.cis.2004.09.008

Cramer, C., and Schonhoff, M. (2014). "Ion conduction in solid polyelectrolyte complex materials," in: Polyelectrolyte Complexes in the Dispersed and Solid State. I: Principles and Theory, M. Muller (ed.), Adv. Polym. Sci. 255, 97-138. DOI: 10.1007/12_2012_203 
da Costa, J. P., Santos, P. S. M., Duarte, A. C., and Rocha-Santos, T. (2016).

"(Nano)plastics in the environment - Sources, fates and effects," Sci. Total Environ. 566, 15-26. DOI: 10.1016/j.scitotenv.2016.05.041

Dai, L., Long, Z., Chen, J., An, X. Y., Cheng, D., Khan, A., and Ni, Y. H. (2017). "Robust guar gum/cellulose nanofibrils multilayer films with good barrier properties," ACS Appl. Mater. Interf. 9(6), 5477-5485. DOI: 10.1021/acsami.6b14471

Das, B. P., and Tsianou, M. (2017). "From polyelectrolyte complexes to polyelectrolyte multilayers: Electrostatic assembly, nanostructure, dynamics, and functional properties," Advan. Colloid Interface Sci. 244, 71-89. DOI: 10.1016/j.cis.2016.12.004

Dautzenberg, H. (1997). "Polyelectrolyte complex formation in highly aggregating systems. 1. Effect of salt: Polyelectrolyte complex formation in the presence of NaCl," Macromol. 30(25), 7810-7815. DOI: 10.1021/ma970803f

Dautzenberg, H., Hartmann, J., Grunewald, S., and Brand, F. (1996). "Stoichiometry and structure of polyelectrolyte complex particles in diluted solutions," Phys. Chem. Chem. Phys. 100(6), 1024-1032. DOI: 10.1002/bbpc.19961000654

De, S., Cramer, C., and Schonhoff, M. (2011). "Humidity dependence of the ionic conductivity of polyelectrolyte complexes," Macromol. 44(22), 8936-8943. DOI: $10.1021 / \mathrm{ma} 201949 \mathrm{~s}$

Debye, P., and Hückel, E. (1923). "The theory of electrolytes. I. The lowering of the freezing point and related occurrences," Phys. Z. 24, 185-206.

Decher, G. (1997). "Fuzzy nanoassemblies toward layered polymeric multicomposites," Science 277(5330), 1232-1237. DOI: 10.1126/science.277.5330.1232

Decher, G., and Hong, J. D. (1991). "Buildup of ultrathin multilayer films by a selfassembly process. I. Consecutive adsorption of anionic and cationic bipolar amphiphiles on charged surfaces," Makromol. Chem. - Macromol. Symp. 46, 321327. DOI: $10.1002 /$ masy.19910460145

Decher, G., Hong, J. D., and Schmitt, J. (1992). "Buildup of ultrathin multilayer films by a self-assembly process. 3. Consecutively alternating adsorption of anionic and cationic polyelectrolytes on charged surfaces," Thin Solid Films 210(1-2), 831-835. DOI: 10.1016/0040-6090(92)90417-A

Decher, G., Lvov, Y., and Schmitt, J. (1994). "Proof of multilayer structural organization in self-assembled polycation-polyanion molecular films," Thin Solid Films 244, 772777. DOI: 10.1016/0040-6090(94)90569-X

De Oliveira, H. C. L., Fonseca, J. L. C., and Pereira, M. R. (2008). “Chitosanpoly(acrylic acid) polyelectrolyte complex membranes: Preparation, characterization and permeability studies," J. Biomater. Sci. - Polym. Ed. 19(2), 143-160. DOI: $10.1163 / 156856208783432471$

Delgado, E., Lopez-Dellamary, F. A., Allan, G. G., and Cresson, T. (1997). "Chemical modification of fibers: Its potential for obtaining wet strength in paper," ISWPC O2$1-4$.

De Lima, M. S. P., Freire, M. S., Fonseca, J. L. C., and Pereira, M. R. (2009). “Chitosan membranes modified by contact with poly(acrylic acid)," Carbohydr. Res. 344(13), 1709-1715. DOI: 10.1016/j.carres.2009.05.024

De Robertis, A., de Stefano, C., Foti, C., Giuffre, O., and Sammartano, S. (2001). "Thermodynamic parameters for the binding of inorganic and organic anions by biogenic polyammonium cations," Talanta, 54(6), 1135-1152. DOI: 10.1016/S00399140(01)00380-0 
Derraik, J. G. B. (2002). "The pollution of the marine environment by plastic debris: A review," Marine Pollut. Bull. 44(9), 842-852. DOI: 10.1016/S0025-326X(02)00220-5

De Stefano, C., Giuffre, O., and Sammartano, S. (1998). "Thermodynamic parameters for the binding of ATP by protonated open-chain polyamines," Faraday Trans. 94(8), 1091-1095. DOI: 10.1039/a709230j

Donhowe, I. G., and Fennema, O. (1993). "Water-vapor and oxygen permeability of wax films," J. Amer. Oil Chemists Soc. 70(9), 867-873. DOI: 10.1007/BF02545345

Doong, S. J., Ho, W. S., and Mastondrea, R. P. (1995). "Prediction of flux and selectivity in pervaporation through a membrane," J. Membrane Sci. 107, 129-146. DOI: 10.1016/0376-7388(95)00109-P

Dou, Y. B., Zhou, A., Pan, T., Han, J. B., Wei, M., Evans, D. G., and Duan, X. (2014). "Humidity-triggered self-healing films with excellent oxygen barrier performance," Chem. Commun. 50(54), 7136-7138. DOI: 10.1039/c4cc01970a

Dubas, S. T., and Schlenoff, J. B. (2001). "Swelling and smoothing of polyelectrolyte multilayers by salt," Langmuir 17(25), 7725-7727. DOI: 10.1021/la0112099

Durandpiana, G., Lafuma, F., and Audebert, R. (1987). "Flocculation and adsorption properties of cationic polyelectrolytes toward Na-montmorillonite dilute suspensions," J. Colloid Interface Sci. 119(2), 474-480. DOI: 10.1016/00219797(87)90293-1

Dury-Brun, C., Chalier, P., Desobry, S., and Voilley, A. (2007). "Multiple mass transfers of small volatile molecules through flexible food packaging," Food Rev. Int. 23(3), 199-255. DOI: 10.1080/87559120701418319

Eriksson, M., Notley, S. M., and Wågberg, L. (2005). “The influence of paper strength properties when building multilayers of weak polyelectrolytes onto wood fibers," $J$. Colloid Interf. Sci. 292(1), 38-45. DOI: 10.1016/j.jcis.2005.05.058

Ermoshkin, A. V., and de la Cruz, M. O. (2003). "Polyelectrolytes in the presence of multivalent ions: Gelation versus segregation," Phys. Rev. Let. 90(12), article no. 125504. Article Number: 125504. DOI: 10.1103/PhysRevLett.90.125504

Fajardo, A. R., Lopes, L. C., Valente, A. J. M., Rubira, A. F., and Muniz, E. C. (2011). "Effect of stoichiometry and $\mathrm{pH}$ on the structure and properties of Chitosan/ Chondroitin sulfate complexes," Colloid Polym. Sci. 289(15-16), 1739-1748. DOI: 10.1007/s00396-011-2497-6

Fang, X. Y., and Vitrac, O. (2017). "Predicting diffusion coefficients of chemicals in and through packaging materials," Crit. Rev. Food Sci. Nutri. 57(2), 275-312. DOI: 10.1080/10408398.2013.849654

Fares, H. M., and Schlenoff, J. B. (2017a). "Equilibrium overcompensation in polyelectrolyte complexes," Macromol. 50(10), 3969-3979. DOI:

10.1021/acs.macromol.7b00665

Fares, H. M., and Schlenoff, J. B. (2017b). "Diffusion of sites versus polymers in polyelectrolyte complexes and multilayers," J. Amer. Chem. Soc. 139(41), 1465614667. DOI: $10.1021 /$ jacs.7b07905

Fares, H. M., Wang, Q. F., Yang, M., and Schlenoff, J. B. (2019). "Swelling and inflation in polyelectrolyte complexes," Macromol. 52(2), 610-619. DOI: 10.1021/acs.macromol.8b01838

Farhat, T., Yassin, G., Dubas, S. T., and Schlenoff, J. B. (1999). "Water and ion pairing in polyelectrolyte multilayers," Langmuir 15(20), 66221-6623. DOI:

10.1021/la990631a 
Fatehi, P., Qian, L. Y., Kititerakun, R., Rirksomboon, T., and Xiao, H. N. (2009). "Complex formation of modified chitosan and carboxymethyl cellulose and its effect on paper properties," TAPPI J. 8(6), 29-35. DOI: 10.32964/TJ8.6.29

Feng, X. H., Pelton, R., and Leduc, M. (2006). "Mechanical properties of polyelectrolyte complex films based on polyvinylamine and carboxymethyl cellulose," Indust. Eng. Chem. Rec. 45(20), 6665-6671. DOI: 10.1021/ie060511f

Feng, X. H., Zhang, D., and Pelton, R. (2009). "Adhesion to wet cellulose - Comparing adhesive layer-by-layer assembly to coating polyelectrolyte complex suspensions," Holzforschung 63(1), 28-32. DOI: 10.1515/HF.2009.003

Findenig, G., Leimgruber, S., Kargl, R., Spirk, S., Stana-Kleinschek, K., and Ribitsch, V. (2012). "Creating water vapor barrier coatings from hydrophilic components," ACS Appl. Mater Interfaces 4(6), 3199-3206. DOI: 10.1021/am300542h

Fu, J. C., Abbett, R. L., Fares, H. M., and Schlenoff, J. B. (2017). "Water and the glass transition temperature in a polyelectrolyte complex," ACS Macro Lett. 6(10). 11141118. DOI: $10.1021 /$ acsmacrolett. 7 b00668

Gamboa, D., Priolo, M. A., Ham, A., and Grunlan, J. C. (2010). "Note: Influence of rinsing and drying routines on growth of multilayer thin films using automated deposition system," Rev. Sci. Instruments 81(3), article no. 036103. DOI: 10.1063/1.3310088

Gärdlund, L., Forsström, J., Andreasson, B., and Wågberg, L. (2005). "Influence of polyelectrolyte complexes on the strength properties of papers from unbleached kraft pulps with different yields," Nordic Pulp Paper Res. J. 20(1), 36-42. DOI: 10.3183/npprj-2005-20-01-p036-042

Gärdlund, L., Wågberg, L., and Gernandt, R. (2003). "Polyelectrolyte complexes for surface modification of wood fibers. 2. Influence of complexes on wet and dry strength of paper," Colloids Surf. A 218(1-3), 137-149. DOI: 10.1016/S09277757(02)00588-5

Ghanbarian, B., Hunt, A., Ewing, R. P., and Sahimi, M. (2013). "Tortuosity in porous media: A critical review," Soil Sci. Soc. Amer. J. 77(5), 1461-1477. DOI: 10.2136/sssaj2012.0435

Ghanbarzadeh, B., Almasi, H., and Entezami, A. A. (2011). "Improving the barrier and mechanical properties of corn starch-based edible films: Effect of citric acid and carboxymethyl cellulose," Indust. Crops Prod. 33(1), 229-235. DOI:

10.1016/j.indcrop.2010.10.016

Ghostine, R. A., Shamoun, R. F., and Schlenoff, J. B. (2013). "Doping and diffusion in an extruded saloplastic polyelectrolyte complex," Macromol. 46(10), 4089-4094. DOI: $10.1021 / \mathrm{ma} 4004083$

Glinel, K., Moussa, A., Jonas, A. M., and Laschewsky, A. (2002). "Influence of polyelectrolyte charge density on the formation of multilayers of strong polyelectrolytes at low ionic strength," Langmuir 18(4), 1408-1412. DOI: 10.1021/la0113670

Gokhale, A. A., Lu, J., Parker, N. J., Izbicki, A. P., Sanyal, O., and Lee, I. (2013). "Conductive oxygen barrier films using supramolecular assembly of graphene embedded polyelectrolyte multilayers," J. Colloid Interf. Sci. 409, 219-226. DOI: 10.1016/j.jcis.2013.07.036

Guo, P. L., Zhang, H. Y., Liu, X. K., and Sun, J. Q. (2018). “Counteranion-mediated intrinsic healing of poly(ionic liquid) copolymers," ACS Appl. Mater. Interf. 10(2), 2105-2113. DOI: 10.1021/acsami.7b16880 
Hagen, D. A., Box, C., Greenlee, S., Xiang, F., Regev, O., and Grunlan, J. C. (2014a). "High gas barrier imparted by similarly charged multilayers in nanobrick wall thin films," RSC Advan. 4(35), 18354-18359. DOI: 10.1039/c4ra01621a

Hagen, D. A., Saucier, L., Grunlan, J. C. (2014b). "Controlling effective aspect ratio and packing of clay with $\mathrm{pH}$ for improved gas barrier in nanobrick wall thin films," ACS Appl. Mater. Interf. 6(24), 22914-22919. DOI: 10.1021/am507603z

Hagen, D. A., Song, Y. X., Saucier, L., Milhorn, A., Stevens, B., and Grunlan, J. C. (2016). "Balancing polyelectrolyte diffusion and clay deposition for high gas barrier," Green Mater. 4(3). DOI: 10.1680/jgrma.16.00012

Hagenmaier, R. D., and Shaw, P. E. (1992). "Gas-permeability of fruit coating waxes," J. Amer. Soc. Horticult. Sci. 117(1), 105-109. DOI: 10.21273/JASHS.117.1.105

Haile, M., Sarwar, O., Henderson, R., Smith, R., and Grunlan, J. C. (2017). "Polyelectrolyte coacervates deposited as high gas barrier thin films," Macromol. Rapid Commun. 38(1), article no. 1600594. DOI: 10.1002/marc.201600594

Halabisky, D. D. (1977). "Wet-end control for the effective use of cationic starch," TAPPI 60(12), 125-127.

Halasz, K., Hosakun, Y., and Csoka, L. (2015). "Reducing water vapor permeability of poly(lactic acid) film and bottle through layer-by-layer deposition of green-processed cellulose nanocrystals and chitosan," Int. J. Polym. Sci. 2015, article no. 954290.

DOI: $10.1155 / 2015 / 954290$

Han, B., Chery, D. R., Yin, J., Lu, X. L., Lee, D., and Han, L. (2016). "Nanomechanics of layer-by-layer polyelectrolyte complexes: A manifestation of ionic cross-links and fixed charges," Soft Matter 12(4), 1158-1169. DOI: 10.1039/c5sm01430a

Hansen, C. M. (2004). "50 Years with solubility parameters - past and future," Prog. Organic Coatings 51(1), 77-84. DOI: 10.1016/j.porgcoat.2004.05.004

Hariri, H. H., and Schlenoff, J. B. (2010). "Saloplastic macroporous polyelectrolyte complexes: Cartilage mimics," Macromol. 43(20), 8656-8663. DOI: $10.1021 / \mathrm{ma1} 012978$

Haronska, P., Kötz, J., and Philipp, B. (1989). "Zur interpretation einer vom Verhältnis 1:1 abweichenden Symplex-Stöchiometrie,” Acta Polymerica 40(2), 110-112. DOI: 10.1002/actp.1989.010400208

Heermann, M. L., Welter, S. R., and Hubbe, M. A. (2006). "Effects of high treatment levels in a dry-strength additive program based on deposition of polyelectrolyte complexes: How much glue is too much?" TAPPI J. 5(6), 9-14.

Holder, K. M., Priolo, M. A., Secrist, K. E., Greenlee, S. M., Nolte, A. J., and Grunlan, J. C. (2012). "Humidity-responsive gas barrier of hydrogen-bonded polymer-clay multilayer thin films," J. Phys. Chem. C 116(37), 19851-19856. DOI: 10.1021/jp306002p

Hubbe, M. A. (1979). "A modified reporting procedure for polyelectrolyte titrations," Tappi 62(8), 120-121.

Hubbe, M. A. (2005). "Dry-strength development by polyelectrolyte complex deposition onto non-bonding glass fibers," J. Pulp Paper Sci. 31(4), 159-166.

Hubbe, M. A., Moore, S. M., and Lee, S. Y. (2005). "Effects of charge ratios and cationic polymer nature on polyelectrolyte complex deposition onto cellulose," Indus. Eng. Chem. Res. 44(9), 3068-3074. DOI: 10.1021/ie048902m

Hubbe, M. A. (2006). "Bonding between cellulosic fibers in the absence and presence of dry-strength agents - A review," BioResources 1(2), 281-318. DOI:

10.15376/biores.1.2.281-318 
Hubbe, M. A. (2007). "Flocculation and redispersion of cellulosic fiber suspensions: A review of effects of hydrodynamic shear and polyelectrolytes," BioResources 2(2), 296-331. DOI: 10.15376/biores.2.2.296-331

Hubbe, M. A., Ayoub, A., Daystar, J. S., Venditti, R. A, and Pawlak, J. J. (2013). "Enhanced absorbent products incorporating cellulose and its derivatives: A review," BioResources 8(4), 6556-6629. DOI: 10.15376/biores.8.4.6556-6629

Hubbe, M. A., Ferrer, A., Tyagi, P., Yin, Y., Salas, C., Pal, L., and Rojas, O. J. (2017). "Nanocellulose in thin films, coatings, and plies for packaging applications: A review," BioResources 12(1), 2143-2233. DOI: 10.15376/biores.12.1.2143-2233

Hubbe, M. A., and Waetzig, D. (2018). "Charge monitoring and control," in: Advances in Papermaking Wet End Chemistry Application Technologies, M. A. Hubbe and S. Rosencrance (eds.), TAPPI Press, Atlanta, Chapter 6, pp. 133-152.

Hubbe, M. A. (2019). "Why, after all, are chitosan films hydrophobic?" BioResources 14(4), 7630-7631.

Hubbe, M. A., McLean, D. S., Stack, K. R., Lu, X. M., Strand, A., and Sundberg, A. (2020). "Self-assembly of alkyl chains of fatty acids in papermaking systems: A review of related pitch issues, hydrophobic sizing, and pH effects," BioResources 15(2), 4591-4635. DOI: 10.15376/biores.15.2.4591-4635

Hubbe, M. A., and Pruszynski, P. (2020). "Greaseproof paper products: A review emphasizing ecofriendly approaches," BioResources 15(1), 1978-2004. DOI: 10.15376/biores.15.1.1978-2004

Humood, M., Chowdhury, S., Song, Y. X., Tzeng, P., Grunlan, J. C., and Polycarpou, A. A. (2016). "Nanomechanical behavior of high gas barrier multilayer thin films," ACS Appl. Mater. Interf. 8(17), 11128-11138. DOI: 10.1021/acsami.5b11478

Ibn Yaich, A., Edlund, U., and Albertsson, A. C. (2015). "Barriers from wood hydrolysate/ quaternized cellulose polyelectrolyte complexes," Cellulose 22(3), 19771991. DOI: $10.1007 / \mathrm{s} 10570-015-0621-3$

Jang, W. S., Rawson, I., and Grunlan, J. C. (2008). "Layer-by-layer assembly of thin film oxygen barrier," Thin Solid Films 516(15), 4819-4825. DOI:

10.1016/j.tsf.2007.08.141

Ji, Y. L., Gu, B. X., An, Q. F., and Gao, C. J. (2017). "Recent advances in the fabrication of membranes containing "ion pairs" for nanofiltration processes," Polym. 9(12), article no. 715. DOI: 10.3390/polym9120715

Jiang, L. Y., Li, Y. B., and Xiong, C. D. (2009). "A novel composite membrane of chitosan-carboxymethyl cellulose polyelectrolyte complex membrane filled with nano-hydroxyapatite I. Preparation and properties," J. Mater. Sci. - Mater. Med. 20(8), 1645-1652. DOI: 10.1007/s10856-009-3720-6

Kekkonen, J., Lattu, H., and Stenius, P. (2002). "Formation, adsorption and interactions of poly-DADMAC/pectic acid complexes," J. Pulp Paper Sci. 28(1), 6-12.

Kiel, M., Mitzscherling, S., Leitenberger, W., Santer, S., Tiersch, B., Sievers, T. K., Mohwald, H., and Bargheer, M. (2010). "Structural characterization of a spin-assisted colloid-polyelectrolyte assembly: Stratified multilayer thin films," Langmuir 26(23), 18499-18502. DOI: 10.1021/la103609f

Klemm, D., Cranston, E. D., Fischer, D., Gama, M., Kedzior, S. A., Kralisch, D., Kramer, F., Kondo, T., Lindstrom, T., Nietzsche, S., Petzold-Welcke, K., and Rauchfuss, F. (2018). "Nanocellulose as a natural source for groundbreaking applications in materials science: Today's state," Mater. Today 21(7), 720-748. DOI: 10.1016/j.mattod.2018.02.001 
Klitzing, R. v., and Steitz, R. (2002). "Internal structure of polyelectrolyte multilayers," in: Handbook of Polyelectrolytes and their Applications, S. K. Tripathy, J. Kumar, and H. S. Nalwa (eds.), Vol. 1, Polyelectrolyte-based Multilayers, Self-assemblies and Nanostructures, Ch. 14, pp. 313-334.

Korhonen, M. H. J., Holappa, S., Stenius, P., and Laine, J. (2013). "Flocculation of fillers with polyelectrolyte complexes," Nordic Pulp Paper Res. J. 28(2), 239-247. DOI: 10.3183/npprj-2013-28-02-p239-247

Kossel, A. (1896). "Über die basischen Stoffe des Zellkernes," Z. Physiol. Chem. 22, 176-187. DOI: $10.1515 / \mathrm{bchm} 2.1897 .22 .2 .176$

Kotov, N. A., Dekany, I., and Fendler, J. H. (1995). "Layer-by-layer self-assembly of polyelectrolyte-semiconductor nanoparticle composite films," J. Phys. Chem. 99(35), 13065-13069. DOI: 10.1021/j100035a005

Kotov, N. A. (1999). "Layer-by-layer self-assembly: The contribution of hydrophobic interactions," Nanostruc. Mater. 12, 789-796. Pt. B. DOI: 10.1016/S09659773(99)00237-8

Kulig, D., Zimoch-Korzycka, A., Krol, Z., Oziemblowski, M., and Jarmoluk, A. (2017). "Effect of film-forming alginate/chitosan polyelectrolyte complex on the storage quality of pork," Molecules 22(1), article no. 98. DOI: 10.3390/molecules22010098

Kurihara, T., and Isogai, A. (2015). "The effect of electric charge density of polyacrylamide (PAM) on properties of PAM/cellulose nanofibril composite films," Cellulose 22(1), 499-506. DOI: 10.1007/s10570-014-0478-x

Ladam, G., Schaad, P., Voegel, J. C., Schaaf, P., Decher, G., and Cuisinier, F. (2000). “In situ determination of the structural properties of internally deposited polyelectrolyte multilayers," Langmuir 16(3), 1249-1255. DOI: 10.1021/la990650k

Lagarón, J. M., Catala, R., and Gavara, R. (2004). "Structural characteristics defining high barrier properties in polymeric materials," Mater Sci. Technol. 20, 1-7. DOI: 10.1179/026708304225010442

Lalwani, S. M., Eneh, C. I., and Lutkenhaus, J. L. (2020). "Emerging trends in the dynamics of polyelectrolyte complexes," Phys. Chem. Chem. Phys. 22(42), 2415724177. DOI: 10.1039/d0cp03696j

Landy, J., McIntosh, D. B., Saleh, O. A., and Pincus, P. (2012). "Ionic excesses and entropies in mean-field screening models," Soft Matter 8(36), 9368-9375. DOI: $10.1039 / \mathrm{c} 2 \mathrm{sm} 25608 \mathrm{~h}$

Lange, J., and Wyser, Y. (2003). "Recent innovations in barrier technologies for plastic packaging - A review," Packag. Technol. Sci. 16(4), 149-158. DOI: 10.1002/pts.621

Laufer, G., Kirkland, C., Cain, A. A., and Grunlan, J. C. (2013a). "Oxygen barrier of multilayer thin films comprised of polysaccharides and clay," Carbohyd. Polym. 95(1), 299-302. DOI: 10.1016/j.carbpol.2013.02.048

Laufer, G., Priolo, M. A., Kirkland, C., and Grunlan, J. C. (2013b). "High oxygen barrier, clay and chitosan-based multilayer thin films: An environmentally friendly foil replacement," Green Mater. 1(1), 4-10. DOI: 10.1680/gmat.12.00002

Lazar, S., Garcia-Valdez, O., Kennedy, E., Champagne, P., Cunningham, M., and Grunlan, J. (2019). "Crosslinkable-chitosan-enabled moisture-resistant multilayer gas barrier thin film," Macromol. Rapid Commun. 40(6), article no. 1800853. DOI: 10.1002/marc. 201800853

Lazutin, A. A., Semenov, A. N., and Vasilevskaya, V. V. (2012). "Polyelectrolyte complexes consisting of macromolecules with varied stiffness: computer simulation," Macromol. Theory Simul. 21(5), 328-339. DOI: 10.1002/mats.201100097 
Lee, J. Y., Gwak, G. H., Kim, H. M., Kim, T. I., Lee, G. J., and Oh, J. M. (2016). "Synthesis of hydrotalcite type layered double hydroxide with various $\mathrm{Mg} / \mathrm{Al}$ ratio and surface charge under controlled reaction condition," Appl. Clay Sci. 134, 44-49. DOI: 10.1016/j.clay.2016.03.029

Li, F., Biagioni, P., Finazzi, M., Tavazzi, S., and Piergiovanni, L. (2013). "Tunable green oxygen barrier through layer-by-layer self-assembly of chitosan and cellulose," Carbohydr. Polym. 92(2), 2128-2134. DOI: 10.1016/j.carbpol.2012.11.091

Li, H., He, Y. Q., Yang, J., Wang, X., Lan, T. Q., and Peng, L. C. (2019a). "Fabrication of food-safe superhydrophobic cellulose paper with improved moisture and air barrier properties," Carbohydr. Polym. 211, 22-30. DOI: 10.1016/j.carbpol.2019.01.107

Li, K., Skolrood, L. N., Aytug, T., Tekinalp, H., and Ozcan, S. (2019b). "Strong and tough cellulose nanofibrils composite films: Mechanism of synergetic effect of hydrogen bonds and ionic interactions," ACS Sustain. Chem. Eng. 7(17), 1434114346. DOI: 10.1021/acssuschemeng.9b03442

Li, Y. F., Jia, H. P., Cheng, Q. L., Pan, F. S., and Jiang, Z. Y. (2011). "Sodium alginategelatin polyelectrolyte complex membranes with both high water vapor permeance and high permselectivity," J. Membrane Sci. 375, 304-312. DOI: 10.1016/j.memsci.2011.03.058

Lin, Z. Y., Renneckar, S., and Hindman, D. P. (2008). "Nanocomposite-based lignocellulosic fibers 1 . Thermal stability of modified fibers with clay-polyelectrolyte multilayers," Cellulose 15(2), 333-346. DOI: 10.1007/s10570-007-9188-y

Lindhoud, S., and Stuart, M. A. C. (2014). "Relaxation phenomena during polyelectrolyte complex formation," in: Polyelectrolyte Complexes in the Dispersed and Solid State. I: Principles and Theory, M. Muller (ed.), Advances in Polymer Science Ser. 255, 139-172. DOI: 10.1007/12_2012_178

Lindström, T., and Österberg, F. (2020). "Evolution of biobased and nanotechnology packaging - A review," Nordic Pulp Paper Res. J. 35(4), 491-515. DOI: 10.1515/npprj-2020-0042

Lofton, M. C., Moore, S. M., Hubbe, M. A., and Lee, S. Y. (2005). "Polyelectrolyte complex deposition as a mechanism of paper dry-strength development," TAPPI J 4(9), 3-7.

Lukas, J., Schwarz, H. H., and Richau, K. (2002). "Polyelectrolyte complex membranes Surface and permeability properties," Macromol. Symp. 188, 155-165. DOI: 10.1002/1521-3900(200211)188:1<155::AID-MASY155>3.0.CO;2-L

Luo, F., Sun, T. L., Nakajima, T., King, D. R., Kurokawa, T., Zhao, Y., Bin Ihsan, A., Li, X. F., Guo, H. L., and Gong, J. P. (2016). "Strong and tough polyion-complex hydrogels from oppositely charged polyelectrolytes: A comparative study with polyampholyte hydrogels," Macromol. 49(7), 2750-2760. DOI:

10.1021/acs.macromol.6b00235

Lv, X. J., Zhang, W. C., Liu, Y. E., Zhao, Y., Zhang, J. S., and Hou, M. X. (2018). "Hygroscopicity modulation of hydrogels based on carboxymethyl chitosan/Alginate polyelectrolyte complexes and its application as $\mathrm{pH}$-sensitive delivery system," Carbohydr. Polym. 198, 86-93. DOI: 10.1016/j.carbpol.2018.06.058

Lvov, Y., Essler, F., and Decher, G. (1993). "Combination of polycation polyanion selfassembly and Langmuir-Blodgett transfer for the construction of superlattice films," J. Phys. Chem. 97(51), 13773-13777. DOI: 10.1021/j100153a055 
Lysaght, M. J. (1976). "Polyelectrolyte complexes," in: Polyelectrolytes, K. C. Frisch (ed.), Technomic Publ., Westport, pp. 34-42.

Lytle, T. K., Chang, L. W., Markiewicz, N., Perry, S. L., and Sing, C. E. (2019). "Designing electrostatic interactions via polyelectrolyte monomer sequence," ACS Central Sci. 5(4), 709-718. DOI: 10.1021/acscentsci.9b00087

Machado, B. R., Facchi, S. P., de Oliveira, A. C., Nunes, C. S., Souza, P. R., Vilsinski, B. H., Popat, K. C., Kipper, M. J., Muniz, E. C., and Martins, A. E. (2020). "Bactericidal pectin/chitosan/glycerol films for food pack coatings: A critical viewpoint," Int. J. Molec. Sci. 21(22), article no. 8663. DOI: 10.3390/ijms21228663

Maximova, N., Laine, J., and Stenius, P. (2005). "Adsorption of lignin-cationic starch complexes on cellulose fibers and their effect on sheet properties," Paperi Puи 87(3), 176-182.

McAloney, R. A., Sinyor, M., Dudnik, V., and Goh, M. C. (2001). “Atomic force microscopy studies of salt effects on polyelectrolyte multilayer film morphology," Langmuir 17(21), 6655-6663. DOI: 10.1021/la010136q

McKee, J. R., Huokuna, J., Martikainen, L., Karesoja, M., Nykanen, A., Kontturi, E., Tenhu, H., Ruokolainen, J., and Ikkala, O. (2014). "Molecular engineering of fracture energy dissipating sacrificial bonds into cellulose nanocrystal nanocomposites," Angew. Chem., Int. Ed. 53(20), 5049-5053. DOI: 10.1002/anie.201401072

Meier-Haack, J., and Muller, M. (2002). "Use of polyelectrolyte multilayer systems for membrane modification," Macromol. Symp. 188, 91-103. DOI: 10.1002/15213900(200211)188:1<91::AID-MASY91>3.0.CO;2-S

Meka, V. S., Singe, M. K. G., Pichika, M. R., Nali, S. R., Kolapaili, V. R. M., and Kesharwani, P. (2017). "A comprehensive review on polyelectrolyte complexes," Drug Discov. Today 22(11), 1697-1706. DOI: 10.1016/j.drudis.2017.06.008

Mende, M., Petzold, G., and Buchhammer, H.-M. (2002). "Polyelectrolyte complex formation between poly(diallyldimethyl-ammonium chloride) and copolymers of acrylamide and sodium acrylate," Colloid Polym. Sci. 280(4), 342-351. DOI: 10.1007/s00396-001-0614-7

Michaels, A. S. (1965). "Polyelectrolyte complexes," Indust. Eng. Chem. 57(10), 32-40. DOI: 10.1021/ie50670a007

Michaels, A. S., Mir, L., and Scheider, N. S. (1965). "A conductometric study of polycation-polyanion reactions in dilute aqueous solution," J. Phys. Chem. 69(5), 1447-1455. DOI: 10.1021/j100889a003

Min, S. J., Lee, S. Y., Lee, J. Y., Lee, S., Choi, K. H., and Shin, G. (2017). "Layer contribution model for layer-by-layer self-assembly oxygen barrier film," Molec. Cryst. Liq. Cryst. 658(1), 127-130. DOI: 10.1080/15421406.2015.1096475

Mocchiutti, P., Schnell, C. N., Rossi, G. D., Peresin, M. S., Zanuttini, M. A., and Galvan, M. V. (2016). "Cationic and anionic polyelectrolyte complexes of xylan and chitosan. Interaction with lignocellulosic surfaces," Carbohydr. Polym. 150, 89-98. DOI: 10.1016/j.carbpol.2016.04.111

Moeller, H. W. (1966). "Cationic starch as a wet-end strength additive," Tappi 49(5), 211214.

Molgaard, S. L., Henriksson, M., Cardenas, M., and Svagan, A. J. (2014). “Cellulosenanofiber/polygalacturonic acid coatings with high oxygen barrier and targeted release properties," Carbohydr. Polym. 114, 179-182. DOI:

10.1016/j.carbpol.2014.08.011 
Mun, S. C., Park, J. J., Park, Y. T., Kim, D. Y., Lee, S. W., Cobos, M., Ye, S. J., Macosko, C. W., and Park, O. O. (2017). "High electrical conductivity and oxygen barrier property of polymer-stabilized graphene thin films," Carbon 125, 492-499. DOI: $10.1016 /$ j.carbon.2017.09.088

Muthukumar, M. (2004). "Theory of counter-ion condensation on flexible polyelectrolytes: Adsorption mechanism," J. Chem. Phys. 120(19), 9343-9350. DOI: 10.1063/1.1701839

Naderi, A., Claesson, P. M., Bergstrom, M., and Dedinaite, A. (2005). “Trapped nonequilibrium states in aqueous solutions of oppositely charged polyelectrolytes and surfactants: Effects of mixing protocol and salt concentration," Colloids Surf. APhysicochem. Eng. Aspects 253, 83-93. DOI: 10.1016/j.colsurfa.2004.10.123

Nagata, T. (1991). "Recent advances of paper strengthening agent: New mechanism of dry-strength development; Concept of anionic and cationic polyacrylamide mixing system," Jpn. TAPPI J. 45(2), 245-249. DOI: 10.2524/jtappij.45.245

Nie, F. M., Cui, J., Zhou, Y. F., Pan, L., Ma, Z., and Li, Y. S. (2019). "Molecular-level tuning toward aggregation dynamics of self-healing materials," Macromol. 52(14), 5289-5297. DOI: 10.1021/acs.macromol.9b00871

Noh, M. J., Oh, M. J., Choi, J. H., Yu, J. C., Kim, W. J., Park, J., Chang, Y. W., and Yoo, P. J. (2018). "Layer-by-layer assembled multilayers of charged polyurethane and graphene oxide platelets for flexible and stretchable gas barrier films," Soft Matter 14(32), 6708-6715. DOI: 10.1039/c8sm00706c

O'Neal, J. T., Dai, E. Y., Zhang, Y. P., Clark, K. B., Wilcox, K. G., George, I. M., Ramasamy, N. E., Enriquez, D., Batys, P., Samrnalkorpi, M., and Lutkenhaus, J. L. (2018). "QCM-D investigation of swelling behavior of layer-by-layer thin films upon exposure to monovalent ions," Langmuir 34(3), 999-1009. DOI: 10.1021/acs.langmuir.7b02836

Ong, Y. K., Shi, G. M., Le, N. L., Tang, Y. P., Zuo, J., Nunes, S. P., and Chung, T. S. (2016). "Recent membrane development for pervaporation processes," Prog. Polymer Sci. 57, 1-31. DOI: 10.1016/j.progpolymsci.2016.02.003

Park, S. Y., Rubner, M. F., and Mayes, A. M. (2002). "Free energy model for layer-bylayer processing of polyelectrolyte multilayer films," Langmuir 18(24), 9600-9604. DOI: $10.1021 / \mathrm{la0261110}$

Peng, Y., Yang, Y., Wu, Q., Wang, S. X., Huang, G. S., and Wu, J. R. (2018). "Strong and tough self-healing elastomers enabled by dual reversible networks formed by ionic interactions and dynamic covalent bonds," Polymer 157, 172-179. DOI: 10.1016/j.polymer.2018.09.038

Pergushov, D. V., Buchhammer, H.-M., and Lunkwitz, K. (1999). "Effect of a lowmolecular-weight salt on colloidal dispersions of interpolyelectrolyte complexes," Colloid Polym. Sci. 277(2-3), 101-107. DOI: 10.1007/PL00013742

Petzold, G., and Schwarz, S. (2014). "Polyelectrolyte complexes in flocculation applications," in: Polyelectrolyte Complexes in the Dispersed and Solid State. II: Application Aspects, M. Muller (ed.), Advan. Polym. Sci. 256, 25-65. DOI: 10.1007/12_2012_205

Philipp, B., Dawydoff, W., and Linow, K.-J. (1982). "Polyelektrolytkomplexe Bildungsweise, Struktur und Anwendungsmöglichkeiten," Z. Chemie 22(1), 1-13. DOI: $10.1002 /$ zfch. 19820220102 
Porcel, C. H., and Schlenoff, J. B. (2009). “Compact polyelectrolyte complexes: 'Saloplastic' candidates for biomaterials,” Biomacromol. 10(11), 2968-2975. DOI: $10.1021 / \mathrm{bm} 900373 \mathrm{c}$

Potaufeux, J. E., Odent, J., Notta-Cuvier, D., Lauro, F., and Raquez, J. M. (2020). “A comprehensive review of the structures and properties of ionic polymeric materials," Polym. Chem. 11(37), 5914-5936. DOI: 10.1039/d0py00770f

Priolo, M. A., Gamboa, D., and Grunlan, J. C. (2010a). "Transparent clay-polymer nano brick wall assemblies with tailorable oxygen barrier," ACS Appl. Mater. Interf. 2(1), 312-320. DOI: 10.1021/am900820k

Priolo, M. A., Gamboa, D., Holder, K. M., and Grunlan, J. C. (2010b). "Super gas barrier of transparent polymer-clay multi layer ultrathin films," Nano Lett. 10(12), 49704974. DOI: $10.1021 / \mathrm{nl} 103047 \mathrm{k}$

Priolo, M. A., Holder, K. M., Greenlee, S. M., Stevens, B. E., and Grunlan, J. C. (2013). "Precisely tuning the clay spacing in nanobrick wall gas barrier thin films," Chem. Mater. 25(9), 1649-1655. DOI: 10.1021/cm4000334

Priolo, M. A., Holder, K. M., Guin, T., and Grunlan, J. C. (2015). "Recent advances in gas barrier thin films via layer-by-layer assembly of polymers and platelets," Macromol. Rapid Commun. 36(10), 866-879. DOI: 10.1002/marc.201500055

Qiao, B. F., Cerda, J. J., and Holm, C. (2010). "Poly(styrenesulfonate)poly(diallyldimethylammonium) mixtures: Toward the understanding of polyelectrolyte complexes and multilayers via atomistic simulations," Macromol. 43(18), 7828-7838. DOI: 10.1021/ma101091k

Qin, S., Pour, M. G., Lazar, S., Koklukaya, O., Gerringer, J., Song, Y. X., Wagberg, L., and Grunlan, J. C. (2019a). "Super gas barrier and fire resistance of nanoplatelet/ nanofibril multilayer thin films," Advan. Mater. Interf. 6(2), article no. 1801424. DOI: 10.1002/admi.201801424

Qin, S., Song, Y., Floto, M. E., and Grunlan, J. C. (2017). “Combined high stretchability and gas barrier in hydrogen-bonded multilayer nanobrick wall thin films," ACS Appl. Mater. Interf. 9(9), 7903-7907. DOI: 10.1021/acsami.7b00844

Qin, S., Xiang, S. S., Eberle, B., Xie, K., and Grunlan, J. C. (2019b). "High moisture barrier with synergistic combination of SiOx and polyelectrolyte nanolayers," $A d v$. Mater. Interfaces 6(16), article no 1900740. DOI: 10.1002/admi.201900740

Radeva, T., Milkova, V., and Petkanchin, I. (2001). "Structure and electrical properties of polyelectrolyte multilayers formed on anisometric colloidal particles," J. Colloid Interface Sci. 244, 24-30. DOI: 10.1006/jcis.2001.7815

Rathee, V. S., Sidky, H., Sikora, B. J., and Whitmer, J. K. (2018). "Role of associative charging in the entropy-energy balance of polyelectrolyte complexes," J. Amer. Chem. Soc. 140(45), 15319-15328. DOI: 10.1021/jacs.8b08649

Reif, W. M. (1972). "The utilization of ionic bonds in the development of paper strength," Proc. TAPPI 1972 Papermakers Conf., TAPPI Press, Atlanta, 47-61.

Ren, Y., Lou, R. Y., Liu, X. C., Gao, M., Zheng, H. Z., Yang, T., Xie, H. G., Yu, W. T., and Ma, X. J. (2016). "A self-healing hydrogel formation strategy via exploiting endothermic interactions between polyelectrolytes," Chem. Commun. 52(37), 62736276. DOI: $10.1039 / \mathrm{c} 6 \mathrm{cc} 02472 \mathrm{f}$

Rhim, J. W., and Lee, J. H. (2004). "Effect of $\mathrm{CaCl}_{2}$ treatment on mechanical and moisture barrier properties of sodium alginate and soy protein-based films," Food Sci. Biotechnol. 13(6), 728-732. 
Riegler, H., and Essler, F. (2002). "Polyelectrolytes. 2. Intrinsic of extrinsic charge compensation. Quantitative charge analysis of PAH/PSS multilayers," Langmuir 18(17), 6694-6698. DOI: 10.1021/la020108n

Rmaile, H. H., and Schlenoff, J. B. (2002). “ 'Internal $\mathrm{p} K_{\mathrm{a}} \mathrm{s}$ ' in polyelectrolyte multilayers: Coupling protons and salt," Langmuir 18(22), 8263-8265. DOI: $10.1021 / \mathrm{la0} 25624 \mathrm{~s}$

Rumyantsev, A. M., Jackson, N. E., Yu, B. Y., Ting, J. M., Chen, W., Tirrell, M. V., and de Pablo, J. J. (2019). "Controlling complex coacervation via random polyelectrolyte sequences," ACS Macro Lett. 8(10), 1296-1302. DOI: 10.1021/acsmacrolett.9b00494

Salas, C., Nypelo, T., Rodriguez-Abreu, C., Carrillo, C., and Rojas, O. J. (2014). "Nanocellulose properties and applications in colloids and interfaces," Current Opin. Colloid Inter. Sci. 19(5), 383-396. DOI: 10.1016/j.cocis.2014.10.003

Sang, Y. Z., Qian, L. Y., He, B. H., and Xiao, H. N. (2010). "The adsorption of cationic PVA on cellulose fibres and its effect with polyelectrolyte complex on paper strength," APPITA J. 63(4), 294-299, 307.

Satam, C. C., Irvin, C. W., Lang, A. W., Jallorina, J. C. R., Shofner, M. L., Reynolds, J. R., and Meredith, J. C. (2018). "Spray-coated multilayer cellulose nanocrystal-chitin nanofiber films for barrier applications," ACS Sustain. Chem. Eng. 6(8), 1063710644. DOI: $10.1021 /$ acssuschemeng.8b01536

Schlenoff, J. B., and Dubas, S. T. (2001). "Mechanism of polyelectrolyte multilayer growth: Charge overcompensation and distribution," Macromol. 34(3), 592-598. DOI: $10.1021 / \mathrm{ma} 0003093$

Schneider, H.-J. (2012). "Ionic interactions in supramolecular complexes," in: Ionic Interactions in Natural and Synthetic Macromolecules, A. Ciferri, and A. Perico, A. (eds.), Wiley, pp. 35-47. DOI:10.1002/9781118165850

Schnell, C. N., Galván, M. V., Peresin, M. S., Inalbon, M. C., Vartiainen, J., Zanuttini, M. A., and Mocchiutti, P. (2017). "Films from xylan/chitosan complexes: Preparation and characterization," Cellulose 24(10), 4393-4403. DOI:10.1007/s10570-017-1411-x

Schnell, C. N., Tarres, Q., Galvan, M. V., Mocchiutti, P., Delgado-Aguilar, M., Zanuttini, M. A., and Mutje, P. (2018). "Polyelectrolyte complexes for assisting the application of lignocellulosic micro/nanofibers in papermaking," Cellulose 25(10), 6083-6092. DOI: $10.1007 / \mathrm{s} 10570-018-1969-\mathrm{y}$

Schoeler, B., Kumaraswamy, G., and Caruso, F. (2002). "Investigation of the influence of polyelectrolyte charge density on the growth of multilayer thin films prepared by the layer-by-layer technique," Macromol. 35(3), 889-897. DOI: 10.1021/ma011349p

Seguela, R. (2005). "Critical review of the molecular topology of semicrystalline polymers: The origin and assessment of intercrystalline tie molecules and chain entanglements," J. Polym. Sci. Part B - Polym Phys. 43(14), 1729-1748. DOI: 10.1002/POLB.20414

Shamoun, R. F., Reisch, A., and Schlenoff, J. B. (2012). "Extruded saloplastic polyelectrolyte complexes," Advan. Func Mater 22(9), 1923-1931. DOI: 10.1002/adfm.201102787

Sherman, J. (1932). "Crystal energies of ionic compounds and thermochemical applications," Chem. Rev. 11(1), 93-170. DOI: 10.1021/cr60038a002

Shimizu, M., Saito, T., and Isogai, A. (2016). "Water-resistant and high oxygen-barrier nanocellulose films with interfibrillar cross-linkages formed through multivalent metal ions," J. Membrane Sci. 500, 1-7. DOI: 10.1016/j.memsci.2015.11.002 
Sirviö, J. A., Kolehmainen, A., Liimatainen, H., Niinimäki, J., and Hormi, O. E. O. (2014). "Biocomposite cellulose-alginate films: Promising packaging materials," Food Chem. 151, 343-351. DOI: 10.1016/j.foodchem.2013.11.037

Smith, R. J., Long, C. T., and Grunlan, J. C. (2018). “Transparent polyelectrolyte complex thin films with ultralow oxygen transmission rate," Langmuir 34(37), 11086-11091. DOI: 10.1021/acs.langmuir.8b02391

Soltani, I., Smith, S. D., and Spontak, R. J. (2017). "Effect of polyelectrolyte on the barrier efficacy of layer-by-layer nanoclay coatings," J. Membrane Sci. 526, 172-180. DOI: 10.1016/j.memsci.2016.12.022

Song, Y. X., Tzeng, P., and Grunlan, J. C. (2016). "Super oxygen and improved water vapor barrier of polypropylene film with polyelectrolyte multilayer nanocoatings," Macromol. Rapid Commun. 37(12), 963-968. DOI: 10.1002/marc.201600140

Song, Y. X., Meyers, K. P., Gerringer, J., Ramakrishnan, R. K., Humood, M., Qin, S., Polycarpou, A. A., Nazarenko, S., and Grunlan, J. C. (2017). "Fast self-healing of polyelectrolyte multilayer nanocoating and restoration of super oxygen barrier," Macromol. Rapid Commun. 38(10), article no 1700064. DOI: 10.1002/marc.201700064

Soni, B., Hassan, E., Schilling, M. W., and Mahmoud, B. (2016). "Transparent bionanocomposite films based on chitosan and TEMPO-oxidized cellulose nanofibers with enhanced mechanical and barrier properties," Carbohydr. Polym. 151, 779-789. DOI: 10.1016/j.carbpol.2016.06.022

South, A. B., and Lyon, L. A. (2010). "Autonomic self-healing of hydrogel thin films," Angew. Chem. - Int. Ed. 49(4), 767-771. DOI: 10.1002/anie.200906040

Spence, K. L., Venditti, R. A., Rojas, O. J., Pawlak, J. J., and Hubbe, M. A. (2011). "Water vapor barrier properties of coated and filled microfibrillated cellulose composite films," BioResources 6(4), 4370-4388. DOI: 10.15376/biores.6.4.43704388

Spruijt, E., van den Berg, S. A., Cohen Stuart, M. A., and van der Gucht, J. (2012). "Direct measurement of the strength of single ionic bonds between hydrated charges," ACS Nano 6(6), 5297-5303. DOI: 10.1021/nn301097y

Stevens, B. E., Odenborg, P. K., Priolo, M. A., and Grunlan, J. C. (2014). "Hydrophobically modified polyelectrolyte for improved oxygen barrier in nanobrick wall multilayer thin films," J. Polym. Sci. Pt. B-Polym. Phys. 52(17), 1153-1156. DOI: $10.1002 /$ polb.23543

Strand, A., Khakalo, A., Kouko, J., Oksanen, A., Ketola, A., Salminen, K., Rojas, O., Retulainen, E., and Sundberg, A. (2017). "The effect of chemical additives on the strength, stiffness and elongation potential of paper," Nordic Pulp Paper Res. J. 32(3), 324-335. DOI: 10.3183/NPPRJ-2017-32-03-p324-335

Sukhishvili, S. A., Kharlampieva, E., and Izumrudov, V. (2006). "Where polyelectrolyte multilayers and polyelectrolyte complexes meet," Macromol. 39(26), 8873-8881. DOI: $10.1021 / \mathrm{ma061617p}$

Tadmor, R., Hernandez-Zapata, E., Chen, N. H., Pincus, P., and Israelachvili, J. N. (2002). "Debye length and double-layer forces in polyelectrolyte solutions," Macromol. 35(6), 2380-2388. DOI: 10.1021/ma011893y

Tan, B. W., and Thomas, N. L. (2017). "Tortuosity model to predict the combined effects of crystallinity and nano-sized clay mineral on the water vapour barrier properties of polylactic acid," Appl. Clay Sci. 141, 46-54. DOI: 10.1016/j.clay.2017.02.014 
Tarabia, M., Hong, H., Davidov, D., Kirstein, S., Steitz, R., Neumann, R., and Avny, Y. (1998). "Neutron and X-ray reflectivity studies of self-assembled heterostructures based on conjugated polymers," J. Appl. Phys. 83(2), 725-732. DOI: $10.1063 / 1.366744$

Terayama, H. (1952). "Method of colloid titration (a new titration between polymer ions)," J. Polym. Sci. 8(2), 243-253. DOI: 10.1002/pol.1952.120080209

Torgnysdøtter, A., and Wågberg, L. (2006). "Tailoring of fiber/fiber joints in order to avoid the negative impacts of drying on paper properties," Nordic Pulp Paper Res. J. 21(3), 411-418. DOI: 10.3183/npprj-2006-21-03-p411-418

Trout, P. E. (1951). "The mechanism of the improvement of the wet strength of paper by polyethylenimine," Tappi 34(12), 539-544.

Tse, S. H. (1979). The Effects of Ionic Spacing and Degree of Polymerization on the Stoichiometry of Polyelectrolyte Interaction in Dilute Aqueous Solutions, Ph.D. Dissertation, The Institute of Paper Chemistry, Appleton, WI, 154 pp.

Tzeng, P., Maupin, C. R., and Grunlan, J. C. (2014). "Influence of polymer interdiffusion and clay concentration on gas barrier of polyelectrolyte/clay nanobrick wall quadlayer assemblies," J. Membrane Sci. 452, 46-53. DOI: 10.1016/j.memsci.2013.10.039

Vainio, A., Paulapuro, H., Koljonen, K., and Laine, J. (2006). "The effect of drying stress and polyelectrolyte complexes on the strength properties of paper," J. Pulp Paper Sci. 32(1), 9-13.

Veis, A. (2011). "A review of the early development of the thermodynamics of the complex coacervation phase separation," Advan. Colloid Interface Sci. 167, 2-11. DOI: 10.1016/j.cis.2011.01.007

Wang, B. C., Liu, P., Qiao, W. L., Yang, L. C., and Shao, P. Y. (2009). "The influencing factors on hydrogel swelling behavior," in: Handbook of Hydrogels: Properties Preparation \& Applications, D. B. Stein (ed.), Book Series: Chemical Engineering Methods and Technology, pp. 619-632.

Wang, J. J., Xu, X. Z., Zhang, J., Chen, M. T., Dong, S. Y., Han, J. B., and Wei, M. (2018). "Moisture-permeable, humidity-enhanced gas barrier films based on organic/inorganic multilayers," ACS Appl. Mater. Interf. 10(33), 28130-28138. DOI: 10.1021/acsami.8b09740

Wang, Q. (2009). "Internal structure and charge compensation of polyelectrolyte multilayers: A numerical study," Soft Matter 5(2), 413-424. DOI: 10.1039/b809095e

Wickramasinhage, R. N., Goswami, S., McAdam, C. J., Hanton, L. R., and Moratti, S. C. (2020). "Tough polymeric hydrogels using ion-pair comonomers," Soft Matter 16(11), 2715-2724. DOI: 10.1039/c9sm02493j

Willstätter, R., and Rhodewald, M. (1934). "Über den Zustand des Glykogens in der Leber, im Muskel und Leukocyten,” Hoppe-Seiler's Z. Physiol. Chem. 225, 103-124. DOI: $10.1515 / \mathrm{bchm} 2.1934 .225 .2-3.103$

Wu, H., Ting, J. M., Werba, O., Meng, S. Q., Tirrell, M. V. (2018). "Non-equilibrium phenomena and kinetic pathways in self-assembled polyelectrolyte complexes," $J$. Chem. Phys. 149(16), article no. 163330. DOI: 10.1063/1.5039621

Yan, X. L., Khor, E., and Lim, L. Y. (2000). "PEC films prepared from chitosan-alginate coacervates," Chem. Pharm. Bull. 48(7), 941-946. DOI: 10.1248/cpb.48.941

Yang, Y. H., Bolling, L., Haile, M., and Grunlan, J. C. (2012). "Improving oxygen barrier and reducing moisture sensitivity of weak polyelectrolyte multilayer thin films with crosslinking," RSC Advan. 2(32), 12355-12363. DOI: 10.1039/c2ra21845c 
Yang, Y. H., Bolling, L., Priolo, M. A., and Grunlan, J. C. (2013). "Super gas barrier and selectivity of graphene oxide-polymer multilayer thin films," Advan. Mater. 25(4), 503-508. DOI: 10.1002/adma.201202951

Yang, Y. H., Haile, M., Park, Y. T., Malek, F. A., and Grunlan, J. C. (2011). "Super gas barrier of all-polymer multilayer thin films," Macromol. 44(6), 1450-1459. DOI: $10.1021 / \mathrm{ma} 1026127$

Yeo, S. J., Kang, H., Kim, Y. H., Han, S., and Yoo, P. J. (2012). “Layer-by-layer assembly of polyelectrolyte multilayers in three-dimensional inverse opal structured templates," ACS Appl. Mater. Interf. 4(4), 2107-2115. DOI: 10.1021/am300072p

Younis, H. G. R., and Zhao, G. H. (2019). "Physicochemical properties of the edible films from the blends of high methoxyl apple pectin and chitosan," Int. J. Biol. Macromol. 131, 1057-1066. DOI: 10.1016/j.ijbiomac.2019.03.096

Yu, L., Lim, Y. S., Han, J. H., Kim, K., Kim, J. Y., Choi, S. Y., and Shin, K. (2012). “A graphene oxide oxygen barrier film deposited via a self-assembly coating method," Synth. Metals 162(7-8), 710-714. DOI: 10.1016/j.synthmet.2012.02.016

Yuan, T., Cui, X. M., Liu, X. K., Qu, X. X., and Sun, J. Q. (2019). "Highly tough, stretchable, self-healing, and recyclable hydrogels reinforced by in situ-formed polyelectrolyte complex nanoparticles," Macromol. 52(8), 3141-3149. DOI: 10.1021/acs.macromol.9b00053

Zhang, H., Wang, C., Zhu, G. Y. J., and Zacharia, N. S. (2016). "Self-healing of bulk polyelectrolyte complex material as a function of $\mathrm{pH}$ and salt," ACS Appl. Mater. Interf. 8(39), 26258-26265. DOI: 10.1021/acsami.6b06776

Zhao, Q., An, Q. F., Liu, T., Chen, J. T., Chen, F., Lee, K. R., and Gao, C. J. (2013). "Bio-inspired polyelectrolyte complex/graphene oxide nanocomposite membranes with enhanced tensile strength and ultra-low gas permeability," Polym. Chem. 4(16), 4298-4302. DOI: 10.1039/c3py00683b

Zhao, Q., Ji, Y. L., Wu, J. K., Shao, L. L., An, Q. F., and Gao, C. J. (2014). "Polyelectrolyte complex nanofiltration membranes: Performance modulation via casting solution $\mathrm{pH}$," RSC Advan. 4(95), 52808-52814. DOI: 10.1039/c4ra09164g

Zheng, Z. G., McDonald, J., Khillan, R., Su, Y., Shutava, T., Grozdits, G., and Lvov, Y. M. (2006). "Layer-by-layer nanocoating of lignocellulose fibers for enhanced paper properties," J. Nanosci. Nanotechnol. 6(3), 624-632. DOI: 10.1166/jnn.2006.081

Zhu, L. Y., Yan, X. Q., Zhang, H. M., Lin, D. Q., Yao, S. J., and Jiang, L. (2014). "Determination of apparent drug permeability coefficients through chitosan-sodium cellulose sulfate polyelectrolyte complex films," Acta Phys.-Chim. Sinica 30(2), 365370. DOI: 10.3866/PKU.WHXB201312091

Zid, S., Zinet, M., and Espuche, E. (2018). "Modeling diffusion mass transport in multiphase polymer systems for gas barrier applications: A review," J. Polym. Sci. Pt. B Polym Phys. 56(8), 621-639. 


\section{APPENDIX}

Table A. Polyelectrolyte Films and Reported Barrier Properties

\begin{tabular}{|c|c|c|c|c|c|c|c|}
\hline $\begin{array}{l}\text { Cationic } \\
\text { polyelec- } \\
\text { trolyte }\end{array}$ & $\begin{array}{l}\text { Anionic } \\
\text { polyelec- } \\
\text { trolyte }\end{array}$ & $\begin{array}{l}\text { Part- } \\
\text { icle } \\
\text { (filler) }\end{array}$ & $\begin{array}{l}\text { Prep- } \\
\text { aration } \\
\text { method }\end{array}$ & General findings & $\begin{array}{l}\text { Perm- } \\
\text { eant }\end{array}$ & $\begin{array}{l}\text { Permeability } \\
\text { (and units) }\end{array}$ & Citation \\
\hline PEI & NFC & (NFC) & LbL 50 & Flexible and transparent & Oxygen & $9 \mathrm{~cm}^{3} /\left(\mathrm{m}^{2} \cdot\right.$ day $\left.\cdot a t m\right)$ & Aulin et al. 2013 \\
\hline PEI & CMC & - & LbL 50 & Tunable props by PE ratios & Oxygen & $11 \mathrm{~cm}^{3} /\left(\mathrm{m}^{2} \cdot\right.$ day $\left.\cdot \mathrm{atm}\right)$ & Aulin et al. 2013 \\
\hline PEI & NFC & (NFC) & LbL 50 & Flexible and transparent & $\mathrm{H}_{2} \mathrm{O}$ vap. & $2.3 \mathrm{~g} /\left(\mathrm{m}^{2} \cdot\right.$ day $\left.\cdot \mathrm{atm}\right)$ & Aulin et al. 2013 \\
\hline PEI & CMC & - & LbL 50 & Tunable props by PE ratios & $\mathrm{H}_{2} \mathrm{O}$ vap. & $2.3 \mathrm{~g} /\left(\mathrm{m}^{2} \cdot \mathrm{day} \cdot \mathrm{atm}\right)$ & Aulin et al. 2013 \\
\hline Chitosan & PAM-Itaconic & - & Mix & Neutral pH best performance & $\mathrm{H}_{2} \mathrm{O}$ vap. & $6300 \mathrm{~g} /\left(\mathrm{m}^{2} \cdot\right.$ day $\cdot$ atm $)$ & Bajpai et al. 2016 \\
\hline Chitosan & CMC & - & Shear & Fiber-like nanostructures & $\mathrm{H}_{2} \mathrm{O}$ vap. & 1000 to $1214 \mathrm{~g} /\left(\right.$ day $\left.\cdot \mathrm{m}^{2}\right)$ & Basu et al. 2017 \\
\hline Chitosan & MMT & (MMT) & LbL 12 & Orientation is important & Oxygen & $1.5 \mathrm{~cm}^{3} /\left(\mathrm{m}^{2} \cdot\right.$ day $\left.\cdot \mathrm{atm}\right)$ & Ben Dhieb et al. 2019a \\
\hline$(\mathrm{PVOH})$ & MMT & (MMT) & LbL 15 & Coating methods & Oxygen & $0.6 \mathrm{~cm}^{3} /\left(\mathrm{m}^{2} \cdot\right.$ day $\left.\cdot a t m\right)$ & Ben Dhieb et al. 2019b \\
\hline Chitosan & CMC & - & Shear & High-shear blending; kit tests & $\mathrm{H}_{2} \mathrm{O}$ vap. & $200 \mathrm{~g} /\left(\mathrm{m}^{2} \cdot\right.$ day $\cdot$ atm $)$ & Chi \& Catchm. 2018a \\
\hline Chitosan & $\mathrm{CMC}$ & - & Shear & High-shear blending, kit tests & $\mathrm{H}_{2} \mathrm{O}$ vap. & $160 \mathrm{~g} /\left(\mathrm{m}^{2} \cdot\right.$ day $\left.\cdot a t m\right)$ & Chi \& Catchm. 2018b \\
\hline PEI & PAA & MMT & Bar coat & Mix, allow to settle, spread & Oxygen & $1 \mathrm{~cm}^{3} /\left(\mathrm{m}^{2} \cdot\right.$ day $\cdot$ atm $)$ & Chiang et al. 2020 \\
\hline$(\mathrm{PVOH})$ & PAA & $\mathrm{GO}$ & LbL 40t & Strain increased transmission & Oxygen & $0.7 \mathrm{~cm}^{3} /\left(\mathrm{m}^{2} \cdot\right.$ day $\left.\cdot a t m\right)$ & Cho et al. 2018 \\
\hline $\mathrm{PEI}$ & PAA (PEO) & - & LbL 20q & Strain increased transmission & Oxygen & $5 \mathrm{~cm}^{3} /\left(\mathrm{m}^{2} \cdot\right.$ day $\left.\cdot \mathrm{atm}\right)$ & Cho et al. 2015 \\
\hline Cat. guar & NFC & (NFC) & LbL 8 & Resists multiple fluid & $\mathrm{O}_{2}, \mathrm{H}_{2} \mathrm{O}$ & Minor effects & Dai et al. 2017 \\
\hline Chitosan & PAA & - & Mix & Formic acid at two levels & A drug & 2 to $10 x$ less permeable & De Oliveira et al. 2008 \\
\hline Chitosan & PAA & - & Wetted & Chitosan film wetted by PAA & $\mathrm{H}_{2} \mathrm{O}$ vap. & Minor effects & De Lima et al. 2009 \\
\hline Hyd-talcite & PSS & $(\mathrm{HT})$ & LbL 20 & Layers \& humidity levels & Oxygen & $10,000 \mathrm{~cm}^{3} /\left(\mathrm{m}^{2} \cdot\right.$ day $\cdot$ atm $)$ & Dou et al. 2014 \\
\hline $\mathrm{PEI}$ & MMT & (MMT) & LbL 20 & Salts enhanced barrier & $\mathrm{H}_{2} \mathrm{O}$ vap. & $150 \mathrm{~g} \mathrm{~m}^{2} /$ day & Findenig et al. 2012 \\
\hline PEI & MMT & (MMT) & LbL 20 & Rinse down, dry up sequence & Oxygen & $0.1 \mathrm{~cm}^{3} /\left(\mathrm{m}^{2} \cdot\right.$ day $\left.\cdot a t \mathrm{~m}\right)$ & Gamboa et al. 2010 \\
\hline PEI & PAA & - & LbL 10 & Adjustment of the $\mathrm{pH} \&$ rinse & Oxygen & $0.4 \mathrm{~cm}^{3} /\left(\mathrm{m}^{2} \cdot\right.$ day $\left.\cdot \mathrm{atm}\right)$ & Gokhale et al. 2013 \\
\hline PEI & PAA & MMT & LbL 20 & Alternating with/without PAA & Oxygen & $0.007 \mathrm{~cm}^{3} /\left(\mathrm{m}^{2} \cdot\right.$ day $\cdot$ atm $)$ & Hagen et al. 2014a \\
\hline PEI & MMT & (MMT) & LbL 15 & Adjustments of $\mathrm{pH}$ & Oxygen & $0.1 \mathrm{~cm}^{3} /\left(\mathrm{m}^{2} \cdot\right.$ day $\cdot$ atm $)$ & Hagen et al. 2014b \\
\hline PEI & PAA & - & Mix & Spread with Mayer rod & Oxygen & $0.08 \mathrm{~cm}^{3} /\left(\mathrm{m}^{2} \cdot\right.$ day $\cdot$ atm $)$ & Haile et al. 2017 \\
\hline Chitosan & CNC & $(\mathrm{CNC})$ & LbL 4 & Ultrasonic dispersion of CNC & $\mathrm{H}_{2} \mathrm{O}$ vap. & Up to $29 \%$ reduction & Halasz et al. 2015 \\
\hline PVP & MMT & (MMT) & LbL 40 & Highly aligned nanobrick wall & Oxygen & $3.5 \mathrm{~cm}^{3} / \mathrm{m}^{2}$ atm day & Holder et al. 2012 \\
\hline $\mathrm{PEI}$ & MMT or GO & (MMT) & LbL 10 & Scratch resistance & Oxygen & $0.15 \mathrm{~cm}^{3} /\left(\mathrm{m}^{2} \cdot\right.$ day $\left.\cdot \mathrm{atm}\right)$ & Humood et al. 2016 \\
\hline Cat. NFC & Xylan & - & LbL 40 & $50 \%$ or $80 \%$ rel. humidity & Oxygen & $100-6000 \mathrm{~g} /\left(\mathrm{m}^{2} \cdot\right.$ day $\left.\cdot a t m\right)$ & Ibn Yaich et al. 2015 \\
\hline cPAM & MMT & (MMT) & LbL 30 & Brick wall construction & Oxygen & $0.015 \mathrm{~cm}^{3} /\left(\mathrm{m}^{2} \cdot\right.$ day $\left.\cdot \mathrm{atm}\right)$ & Jang et al. 2008 \\
\hline Chitosan & Gum & MMT & LbL 10q & Quadlayers & Oxygen & $5 \times 10^{-5} \mathrm{~cm}^{3} /\left(\mathrm{m}^{2} \cdot\right.$ day $\cdot$ atm $)$ & Laufer et al. 2013a \\
\hline Chitosan & PAA & MMT & LbL 10q & Ten quad-layers, $90 \%$ r.h. & Oxygen & $4.6 \mathrm{~cm}^{3} /\left(\mathrm{m}^{2} \cdot\right.$ day $\left.\cdot \mathrm{atm}\right)$ & Laufer et al. $2013 \mathrm{~b}$ \\
\hline Chitosan & PAA & - & LbL 15 & Cross-linking, $90 \%$ r.h. & Oxygen & $0.08 \mathrm{~cm}^{3} /\left(\mathrm{m}^{2} \cdot\right.$ day.atm $)$ & Lazar et al. 2019 \\
\hline
\end{tabular}




\begin{tabular}{|c|c|c|c|c|c|c|c|}
\hline $\begin{array}{l}\text { Cationic } \\
\text { polyelec- } \\
\text { trolyte }\end{array}$ & $\begin{array}{l}\text { Anionic } \\
\text { polyelec- } \\
\text { trolyte }\end{array}$ & $\begin{array}{l}\text { Part- } \\
\text { icle } \\
\text { (filler) }\end{array}$ & $\begin{array}{l}\text { Prep- } \\
\text { aration } \\
\text { method }\end{array}$ & General findings & $\begin{array}{l}\text { Perm- } \\
\text { eant }\end{array}$ & $\begin{array}{l}\text { Permeability } \\
\text { (and units) }\end{array}$ & Citation \\
\hline Chitosan & CNC & $(\mathrm{CNC})$ & LbL 30 & Cellulose nanocrystals & Oxygen & $1.52 \mathrm{~cm}^{3} /\left(\mathrm{m}^{2} \cdot\right.$ day $\cdot$ atm $)$ & Li et al. 2013 \\
\hline Chitosan & Pectin & - & Mix & Glycerol content, washing & Oxygen & $0.7-1.8 \mathrm{~cm}^{3} /\left(\mathrm{m}^{2} \cdot\right.$ day $\cdot$ atm $)$ & Machado et al. 2020 \\
\hline PEl & MMT & (MMT) & LbL 20 & Spraying as an option & Oxygen & $1 \times 10^{-7} \mathrm{~cm}^{3} /\left(\mathrm{m}^{2} \cdot\right.$ day $\cdot$ atm $)$ & Min et al. 2017 \\
\hline Cat. NFC & Pectin & (NFC) & LbL 10 & $20 \%$ relative humidity & Oxygen & $1100 \mathrm{~cm}^{3} /\left(\mathrm{m}^{2} \cdot\right.$ day $\cdot$ atm $)$ & Molgaard et al. 2014 \\
\hline $\mathrm{PVOH}$ & PSS & $\mathrm{GO}$ & LbL 10 & PSS \& GO added together & Oxygen & $<2.5 \mathrm{~cm}^{3} /\left(\mathrm{m}^{2} \cdot\right.$ day $\cdot$ atm $)$ & Mun et al. 2017 \\
\hline Cat. PU & Anionic PU & (GO) & Spin ct. & Spin-coat order; $15 \%$ strain & Oxygen & $20 \mathrm{~cm}^{3} /\left(\mathrm{m}^{2} \cdot\right.$ day $\cdot$ atm $)$ & Noh et al. 2018 \\
\hline PEI & MMT & - & LbL 70 & $\mathrm{pH}$-tailoring & Oxygen & $<0.005 \mathrm{~cm}^{3} /\left(\mathrm{m}^{2} \cdot\right.$ day $\cdot$ atm $)$ & Priolo et al. $2010 \mathrm{a}$ \\
\hline PEI & PAA & MMT & LbL 20 & Quad: PEl/PAA/PEI/MMT & Oxygen & $<0.005 \mathrm{~cm}^{3} /\left(\mathrm{m}^{2} \cdot\right.$ day $\cdot$ atm $)$ & Priolo et al. 2010b \\
\hline PAAm & PAA & MMT & LbL 4 & Different spacing of MMT & Oxygen & $0.02 \mathrm{~cm}^{3} /\left(\mathrm{m}^{2} \cdot\right.$ day $\cdot$ atm $)$ & Priolo et al. 2013 \\
\hline Cat. NFC & VMT & (VMT) & LbL 20 & Strong \& flame-resistant & Oxygen & $0.013 \mathrm{~cm}^{3} /\left(\mathrm{m}^{2} \cdot\right.$ day $\cdot$ atm $)$ & Qin et al. 2019a \\
\hline- & PAA/PEO & MMT & LbL 10 & High stretchability & Oxygen & $1.7 \mathrm{~cm}^{3} /\left(\mathrm{m}^{2} \cdot\right.$ day $\cdot$ atm $)$ & Qin et al. 2017 \\
\hline PEI & PAA & $\mathrm{SiO}_{2}$ & LbL 16 & PEC to protect brittle $\mathrm{SiO}_{2}$ & $\mathrm{H}_{2} \mathrm{O}$ vap. & $0.4 \mathrm{~g} /\left(\mathrm{m}^{2} \cdot\right.$ day $\left.\cdot a t m\right)$ & Qin et al. 2019b \\
\hline $\mathrm{CaCl}_{2}$ & Soy protein & - & Cast & Crosslink by $\mathrm{CaCl}_{2}$ rinse & $\mathrm{H}_{2} \mathrm{O}$ vap. & Minor decrease & Rhim \& Lee 2004 \\
\hline $\mathrm{CaCl}_{2}$ & Alginate & - & Cast & Crosslink by $\mathrm{CaCl}_{2}$ rinse & $\mathrm{H}_{2} \mathrm{O}$ vap. & Minor changes & Rhim \& Lee 2004 \\
\hline Chitin NPs & CNC & Dual & LbL 5 & Cat. \& anionic nanoparticles & Oxygen & $400 \mathrm{~cm}^{3} /\left(\mathrm{m}^{2} \cdot\right.$ day $\cdot$ atm $)$ & Satam et al. 2018 \\
\hline Chitosan & Xylan & - & Mix & Glycerol plasticizer content & Oxygen & $<0.36 \mathrm{~cm}^{3} /\left(\mathrm{m}^{2} \cdot\right.$ day $\cdot$ atm $)$ & Schnell et al. 2017 \\
\hline TO-NFC & Metal ions & (NFC) & Cast & NFC film soaked with cations & Oxygen & $0.1 \mathrm{~cm}^{3} \mu \mathrm{m} / \mathrm{m}^{2} \mathrm{kPa}$ day & Shimizu et al. 2016 \\
\hline $\mathrm{CaCl}_{2}$ & MFC & (NFC) & Cast & MFC decreased permeability & $\mathrm{H}_{2} \mathrm{O}$ vap. & $6200 \mathrm{~g} /\left(\mathrm{m}^{2} \cdot\right.$ day $\cdot$ atm $)$ & Sirviö et al. 2014 \\
\hline pDADMAC & PAA & - & Mix & Mix at $\mathrm{pH} 2$, neutralize film & Oxygen & $0.02 \mathrm{~cm}^{3} /\left(\mathrm{m}^{2} \cdot\right.$ day $\cdot$ atm $)$ & Smith et al. 2018 \\
\hline PEI, PETi & MMT & (MMT) & Expose & PEI, then MMT suspension & $\mathrm{O}_{2}, \mathrm{CO}_{2}$ & $1200 \mathrm{~cm}^{3} /\left(\mathrm{m}^{2} \cdot\right.$ day $\cdot$ atm $)$ & Sontani et al. 2017 \\
\hline PEI & PAA & - & LbL 8 & Self-healing & Oxygen & $<0.005 \mathrm{~cm}^{3} /\left(\mathrm{m}^{2} \cdot\right.$ day $\cdot$ atm $)$ & Song et al. 2017 \\
\hline PEI & PAA & VMT & LbL 30 & Layer thickness, humidity & Oxygen & $15-57 \mathrm{~cm}^{3} /\left(\mathrm{m}^{2} \cdot\right.$ day $\cdot$ atm $)$ & Song et al. 2016 \\
\hline PEI & PAA & VMT & LbL 30 & Layer thickness, humidity & $\mathrm{H}_{2} \mathrm{O}$ vap. & $1.4 \mathrm{~g} /\left(\mathrm{m}^{2} \cdot\right.$ day $\cdot$ atm $)$ & Song et al. 2016 \\
\hline Chitosan & TO-NFC & (NFC) & Cast & Sorbitol plasticizer & Oxygen & $0.3 \mathrm{~cm}^{3} /\left(\mathrm{m}^{2} \cdot\right.$ day $\cdot$ atm $)$ & Soni et al. 2016 \\
\hline Chitosan & TO-NFC & (NFC) & Cast & Sorbitol plasticizer & $\mathrm{H}_{2} \mathrm{O}$ vap. & $4.7 \times 10^{10} \mathrm{~g} /\left(\mathrm{m}^{2} \cdot\right.$ day $\cdot$ atm $)$ & Soni et al. 2016 \\
\hline PEI & PAA & MMT & LbL $4 q$ & Pyrene-labeled PEI, quads & Oxygen & $0.3 \mathrm{~cm}^{3} /\left(\mathrm{m}^{2} \cdot\right.$ day $\cdot$ atm $)$ & Stevens et al. 2014 \\
\hline PVAm,PEI & PAA & MMT & LbL 10q & Various sequences & Oxygen & $4 \times 10^{-8} \mathrm{~cm}^{3} /\left(\mathrm{m}^{2} \cdot\right.$ day $\cdot$ atm $)$ & Tzeng et al. 2014 \\
\hline Hyd-talcite & CMC & $(\mathrm{HT})$ & LbL 30 & Also $\mathrm{CO}_{2}$ and methane & Nitrogen & $0.012 \mathrm{~cm}^{3} /\left(\mathrm{m}^{2} \cdot\right.$ day $\cdot$ atm $)$ & Wang et al. 2018 \\
\hline Chitosan & Alginate & - & LbL 3 & High permeability to water & $\mathrm{H}_{2} \mathrm{O}$ vap. & 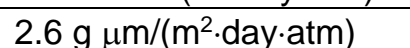 & Yan et al. 2000 \\
\hline PEI & PAA & - & LbL 8 & Glutaraldehyde crosslinking & Oxygen & $0.0077 \mathrm{~cm}^{3} /\left(\mathrm{m}^{2} \cdot\right.$ day $\cdot$ atm $)$ & Yang et al. 2012 \\
\hline PEI & $\mathrm{GO}$ & (GO) & LbL 30 & Also tested $\mathrm{CO}_{2}$ transmission & Oxygen & $0.2 \mathrm{~cm}^{3} /\left(\mathrm{m}^{2} \cdot\right.$ day $\cdot$ atm $)$ & Yang et al. 2013 \\
\hline PEI & PAA & - & LbL 8 & Glutaraldehyde crosslinking & Oxygen & $<0.005 \mathrm{~cm}^{3} /\left(\mathrm{m}^{2} \cdot\right.$ day $\cdot$ atm $)$ & Yang et al. 2011 \\
\hline Chitosan & Pectin & - & Blend & Edible films & $\mathrm{H}_{2} \mathrm{O}$ vap. & Similar to components & Younis \& Zhao 2019 \\
\hline PEI & $\mathrm{GO}$ & (GO) & LbL 5 & Post-treatments & Oxygen & $0.25 \mathrm{~cm}^{3} /\left(\mathrm{m}^{2} \cdot\right.$ day $\cdot$ atm $)$ & Yu et al. 2012 \\
\hline pDADMAC & CMC & $(\mathrm{GO})$ & LbL & CMC \& GO added together & Oxygen & Greatly reduced trans. & Zhao et al. 2013 \\
\hline
\end{tabular}




\section{Notes for Table A}

Labeling: $\mathrm{CNC}=$ cellulose nanocrystals; $\mathrm{cPAM}=$ cationic copolymer of poly(acrylamide); GO = graphene oxide; Hyd-talcite (HT) = double hydroxide, hydrotalcite; $\mathrm{LbL}$ = layer-by-layer; The number following "LbL" indicates the number of repeating sequences, were "t" indicates trilayers and " $\mathrm{q}$ " indicates

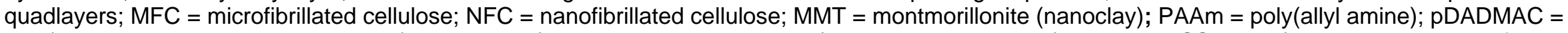

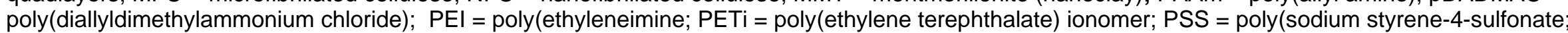
PU = polyurethane; PVP = poly(vinylpyrrolidone; TO-NFC = TEMPO-oxidized nanofibrillated cellulose; VMT = vermiculite; the term "mix" means that the ingredients were combined; the term "shear" means that significant shear stress was applied; and "blend" implies use of a blender device.

Unit conversions: $1 \mathrm{kPa}=0.009869$ atmospheres; $24 \mathrm{~h} /$ day; $1.145 \mathrm{E}-5$ days/s; Certain authors expressed their results based on film thickness. Ben Dhieb et al. 2019a; reported $0.5 \mathrm{~cm}^{3} \cdot \mu \mathrm{m} /\left(\mathrm{m}^{2}\right.$.day $)$; thickness $=0.33 \mu \mathrm{m}$; assume $1 \mathrm{~atm} . \rightarrow 1.5 \mathrm{~cm}^{3} /\left(\mathrm{m}^{2} \cdot \mathrm{day} \cdot \mathrm{atm}\right)$

Ben Dhieb et al. 2019b; reported $0.5 \mathrm{~cm}^{3} \cdot \mu \mathrm{m} /\left(\mathrm{m}^{2} \cdot\right.$ day $)$; thickness $=0.9 \mu \mathrm{m}$; assume $1 \mathrm{~atm} . \rightarrow 0.6 \mathrm{~cm}^{3} /\left(\mathrm{m}^{2} \cdot \mathrm{day} \cdot \mathrm{atm}\right)$

Chi \& Catchm. 2018a; reported $10 \mathrm{~kg} \cdot \mu \mathrm{m} /\left(\mathrm{m}^{2} \cdot\right.$ day $)$; thickness $=50 \mu \mathrm{m}$; assume $1 \mathrm{~atm} . \rightarrow 0.2 \mathrm{~kg} /\left(\mathrm{m}^{2} \cdot \mathrm{day} \cdot \mathrm{atm}\right)=200 \mathrm{~g} /\left(\mathrm{m}^{2} \cdot \mathrm{day} \cdot \mathrm{atm}\right)$

Chi \& Catchm. 2018b; reported $8 \mathrm{~kg} \cdot \mu \mathrm{m} /\left(\mathrm{m}^{2} \cdot\right.$ day $)$; thickness $=50 \mu \mathrm{m}$; assume $1 \mathrm{~atm} . \rightarrow 0.2 \mathrm{~kg} /\left(\mathrm{m}^{2} \cdot \mathrm{day} \cdot \mathrm{atm}\right)=160 \mathrm{~g} /\left(\mathrm{m}^{2} \cdot \mathrm{day} \cdot \mathrm{atm}\right)$

Dou et al. 2014; reported $1 \mathrm{~cm}^{3} / \mathrm{cm}^{2}$ atm day; $\rightarrow 10,000 \mathrm{~cm}^{3} /\left(\mathrm{m}^{2} \cdot\right.$ day.atm)

Humood et al. 2016; reported $10^{-19} \mathrm{~cm}^{3} \mathrm{~cm} /\left(\mathrm{cm}^{2} \mathrm{sPa}\right) ; 1 \mathrm{~s}=1.145 \mathrm{E}-5$ days; thickness $=0.6 \mu \mathrm{m} ; \rightarrow$

$10^{-19} \mathrm{~cm}^{3} \mathrm{~cm} /\left(\mathrm{cm}^{2} \mathrm{sPa}\right) \times\left(10^{4} \mu \mathrm{m} / 0.6 \mu \mathrm{m}\right) /\left[\left(10^{-4} \mathrm{~m}^{2} / \mathrm{cm}^{2}\right) \times(1.145 \mathrm{E}-5\right.$ days $/ \mathrm{s}) \times(0.000009869$ atmospheres $/ \mathrm{Pa})=0.15 \mathrm{~cm}^{3} /\left(\mathrm{m}^{2} \cdot \mathrm{day} \cdot \mathrm{atm}\right)$

Ibn Yaich et al. 2015; reported 0.1-6 $\mathrm{cm}^{3} \mu \mathrm{m} / \mathrm{m}^{2}$ daykPa); Assume a 40-layer film is about $100 \mathrm{~nm}$, based on Molgaard et al. 2014 ; $\rightarrow$

0.1-6 $\mathrm{cm}^{3} \mu \mathrm{m} / \mathrm{m}^{2}$ daykPa $) \times(1 \mu \mathrm{m} / 0.1 \mu \mathrm{m}) \times(\mathrm{kPa} / 0.009869 \mathrm{~atm})=100-6000 \mathrm{~cm}^{3} /\left(\mathrm{m}^{2} \cdot\right.$ day $\cdot$ atm $)$

Laufer et al. $2013 \mathrm{a}$; reported $3 \times 10^{-20} \mathrm{~cm}^{3} \mathrm{~cm} / \mathrm{cm}^{2} \mathrm{~s} \mathrm{~Pa}$; film thickness $=55 \mathrm{~nm}$;

$3 \times 10^{-20} \mathrm{~cm}^{3} \mathrm{~cm} / \mathrm{cm}^{2} \mathrm{~s} \mathrm{~Pa} \times\left[1 /\left(55 \times 10^{-7} \mathrm{~cm}\right)\right] /[(1.145 \mathrm{E}-5$ days $/ \mathrm{s}) \times(0.000009869 \mathrm{~atm} / \mathrm{Pa})]=5 \times 10^{-5} \mathrm{~cm}^{3} /\left(\mathrm{m}^{2} \cdot \mathrm{day} \cdot \mathrm{atm}\right)$

Li et al. 2013; reported $0.015 \mathrm{~cm}^{3} / \mathrm{m}^{2} \mathrm{kPa}$ day $\rightarrow 1.52 \mathrm{~cm}^{3} /\left(\mathrm{m}^{2} \cdot\right.$ day.atm)

Molgaard et al. 2014; reported $0.03 \mathrm{~cm}^{3} \mathrm{~mm} / \mathrm{m}^{2}$ atm day; film thickness $27 \mathrm{~nm} ; \rightarrow$

$0.03 \mathrm{~cm}^{3} \mathrm{~mm} / \mathrm{m}^{2}$ atm day $/ 27 \mathrm{E}-6 \mathrm{~mm}=1100 \mathrm{~cm}^{3} /\left(\mathrm{m}^{2} \cdot\right.$ day $\cdot$ atm $)$

Satam et al. 2018; reported $20 \mathrm{~cm}^{3} \mu \mathrm{m} / \mathrm{m}^{2} \mathrm{kPa}$ day; thickness ca. $5 \mu \mathrm{m} ; \rightarrow$

$20 \mathrm{~cm}^{3} \mu \mathrm{m} /\left(\mathrm{m}^{2} \mathrm{kPa}\right.$ day $) \times(1 / 5 \mu \mathrm{m}) \times(\mathrm{kPa} / 0.009869 \mathrm{~atm})=405 \mathrm{~cm}^{3} /\left(\mathrm{m}^{2} \cdot\right.$ day $\cdot$ atm $)$

Schnell et al. 2017; reported $<0.3 \mathrm{~cm}^{3} \mu \mathrm{m} / \mathrm{m}^{2} \mathrm{kPa}$ day; thickness $=50$ to $120 \mu \mathrm{m}$, take average $=85 \mu \mathrm{m} ; \rightarrow$

$<0.3 \mathrm{~cm}^{3} \mu \mathrm{m} / \mathrm{m}^{2} \mathrm{kPa}$ day $\times(1 / 85 \mu \mathrm{m}) \times(\mathrm{kPa} / 0.009869 \mathrm{~atm})=0.36 \mathrm{~cm}^{3} /\left(\mathrm{m}^{2} \cdot\right.$ day $\cdot$ atm $)$

Shimizu et al. 2016; reported $0.1 \mathrm{~cm}^{3} \mu \mathrm{m} / \mathrm{m}^{2} \mathrm{kPa}$ day; thickness = not stated and no way to estimate thickness.

Sirviö et al. $2014 ; 7 \times 10^{-7} \mathrm{~g} /\left(\right.$ Pa.s. $\left.\mathrm{m}^{2}\right) ; \rightarrow 7 \times 10^{-7} \mathrm{~g} /\left(\right.$ Pa.s. $\left.\mathrm{m}^{2}\right) \times(\mathrm{Pa} / 0.000009869 \mathrm{~atm}) \times(\mathrm{s} / 1.145 \mathrm{E}-5 \mathrm{days})=6200 \mathrm{~g} /\left(\mathrm{m}^{2} \cdot \mathrm{day} \cdot \mathrm{atm}\right)$

Soltani et al. 2017; reported $6 \times 10^{-3} \mathrm{~cm}^{3} \mathrm{~m} / \mathrm{m}^{2}$ atm day; thickness $=500 \mathrm{~nm} ; \rightarrow$

$6 \times 10^{-3} \mathrm{~cm}^{3} \mathrm{~m} / \mathrm{m}^{2}$ atm day $\times(1 / 500 \mathrm{E}-9 \mathrm{~m})=1200 \mathrm{~cm}^{3} /\left(\mathrm{m}^{2} \cdot\right.$ day $\cdot$ atm $)$

Soni et al. 2016; reported $2.6 \mathrm{~g} /(\mathrm{Pa} \mathrm{h} \mathrm{m})$; thickness $=0.1346 \mathrm{~mm} ; \rightarrow$

$2.6 \mathrm{~g} /(\mathrm{Pa} \mathrm{h} \mathrm{m}) \times(\mathrm{Pa} / 0.000009869 \mathrm{~atm}) \times(24 \mathrm{~h} /$ day $) \times(1 / 0.1346 \mathrm{E}-3 \mathrm{~m})=4.7 \mathrm{E} 10 \mathrm{~g} /\left(\mathrm{m}^{2} \cdot \mathrm{day} \cdot \mathrm{atm}\right)$

Tzeng et al. 2014; reported $5 \times 10^{-22} \mathrm{~cm}^{2} \mathrm{~cm} /\left(\mathrm{cm}^{2} \mathrm{Pas}\right) ;$ thickness $=50.9 \mathrm{~nm}$, term not needed $\rightarrow$

$5 \times 10^{-22} \mathrm{~cm}^{2} \mathrm{~cm} /\left(\mathrm{cm}^{2} \mathrm{Pas}\right) \times\left(10000 \mathrm{~cm}^{2} / \mathrm{m}^{2}\right) \times(\mathrm{Pa} / 0.000009869 \mathrm{~atm}) \times(\mathrm{s} / 1.145 \mathrm{E}-5 \mathrm{days})=4.4 \times 10^{-8} 1200 \mathrm{~cm}^{3} /\left(\mathrm{m}^{2} \cdot \mathrm{day} \cdot \mathrm{atm}\right)$

Yan et al. 2000; reported $2 \mathrm{~g} \mathrm{~mm} /\left(\mathrm{m}^{2}\right.$ day $\left.\mathrm{mmHg}\right)$; thickness = not reported and no way to estimate.

$2 \mathrm{~g} \mathrm{~mm} /\left(\mathrm{m}^{2}\right.$ day $\left.\mathrm{mmHg}\right) * 760 \mathrm{mmHg} / \mathrm{atm}=0.0026 \mathrm{~g} \mathrm{~mm} /\left(\mathrm{m}^{2} \cdot\right.$ day $\cdot$ atm $)=2.6 \mathrm{~g} \mathrm{\mu m} /\left(\mathrm{m}^{2} \cdot\right.$ day $\cdot$ atm $)$

Yang et al. 2012; reported $\left.5.9 \times 10^{-21} \mathrm{~cm}^{3} \mathrm{~cm} / \mathrm{cm}^{2} \mathrm{sPa}\right)$; thickness $=551 \mathrm{~nm} ; \rightarrow$

$\left.5.9 \times 10^{-21} \mathrm{~cm}^{3} \mathrm{~cm} / \mathrm{cm}^{2} \mathrm{sPa}\right) \times 1 / 551 \mathrm{E}-7 \mathrm{~cm} \times\left(10000 \mathrm{~cm}^{2} / \mathrm{m}^{2}\right) \times(\mathrm{Pa} / 0.000009869 \mathrm{~atm}) \times(\mathrm{s} / 1.145 \mathrm{E}-5 \mathrm{days})=0.0077 \mathrm{~cm} /\left(\mathrm{m}^{2} \cdot \mathrm{day} \cdot \mathrm{atm}\right)$

Hubbe (2021). "Ionic bonding in PEC barrier films," BioResources 16(2), 4544-4605. 